UNIVERSIDADE DE SÃO PAULO

ESCOLA DE ENFERMAGEM DE RIBEIRÃO PRETO

LUCIANA RODRIGUES BARBOSA

RELAÇÕES ENTRE LIDERANÇA, MOTIVAÇÃO E QUALIDADE NA ASSISTÊNCIA DE ENFERMAGEM: REVISÃO INTEGRATIVA DA LITERATURA

RIBEIRÃO PRETO (SP) 


\section{LUCIANA RODRIGUES BARBOSA}

RELAÇÕES ENTRE LIDERANÇA, MOTIVAÇÃO E QUALIDADE NA ASSISTÊNCIA DE ENFERMAGEM: REVISÃO INTEGRATIVA DA LITERATURA

Dissertação apresentada ao Programa de PósGraduação Enfermagem Fundamental da Escola de Enfermagem de Ribeirão Preto da Universidade de São Paulo, para obtenção do título de mestre em Enfermagem.

Linha de Pesquisa: Dinâmica da organização dos serviços de saúde e de enfermagem.

Orientadora: Profa Dra $^{\mathrm{a}}$ Marcia Regina Antonietto da Costa Melo 


\begin{abstract}
AUTORIZO A REPRODUÇÃO E DIVULGAÇÃO TOTAL OU PARCIAL DESTE TRABALHO, POR QUALQUER MEIO CONVENCIONAL OU ELETRÔNICO, PARA FINS DE ESTUDO E PESQUISA, DESDE QUE CITADA A FONTE.
\end{abstract}

Dados Internacionais de Catalogação na Publicação - CIP (Brasil) Catalogação na Fonte

Barbosa, Luciana Rodrigues
B234r Relação entre liderança, motivação e qualidade da assistência de enfermagem: uma revisão integrativa da literatura. / Luciana Rodrigues Barbosa -- 2007 $138 \mathrm{f}$. il.

Orientadora: Profa. Dra. Marcia R. A. Costa Melo Dissertação (mestrado em Enfermagem) -Escola de Enfermagem de Ribeirão Preto; Universidade de São Paulo, Ribeirão Preto (SP), 2007.

1. Enfermagem. 2. Liderança. 3. Enfermagem - Assistência. 4. Motivação. 5. Qualidade. I. Título. 
FOLHA DE APROVAÇÃO

LUCIANA RODRIGUES BARBOSA

RELAÇÕES ENTRE LIDERANÇA, MOTIVAÇÃO E QUALIDADE NA ASSISTÊNCIA DE ENFERMAGEM: REVISÃO INTEGRATIVA DA LITERATURA

\begin{abstract}
Dissertação apresentada ao Programa de PósGraduação Enfermagem Fundamental da Escola de Enfermagem de Ribeirão Preto da Universidade de São Paulo, para obtenção do título de mestre em Enfermagem.

Linha de Pesquisa: Dinâmica da organização dos serviços de saúde e de enfermagem.
\end{abstract}

Aprovada em:

BANCA EXAMINADORA

Prof $^{\mathrm{a}}$ Dra Marcia Regina Antonietto da Costa Melo

Instituição: Escola de Enfermagem de Ribeirão Preto, Universidade de São Paulo.

Assinatura:

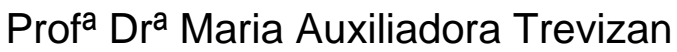

Instituição: Escola de Enfermagem de Ribeirão Preto, Universidade de São Paulo.

Assinatura:

Prof $^{\mathrm{a}}$ Dr $^{\mathrm{a}}$ Káthia de Carvalho Cunha

Instituição: Faculdade Santa Marcelina - FASM, São Paulo - SP.

Assinatura: 
Dedico este trabalho a todos os meus colegas enfermeiros que, mesmo diante das dificuldades da prática diária, buscam dar o melhor de si, valorizam seus 'parceiros' técnicos e auxiliares de enfermagem e se comprometem com a qualidade da assistência prestada ao paciente.

Dedico à Marister Piccoli (in memorian), que me incentivou a compreender o significado das pesquisas em nossa profissão, deixou-me alguns de seus livros e, com o seu jeito doce e amigo, ensinou-me um pouco mais sobre a vida. 


\section{AGRADECIMENTOS}

Dizer somente 'obrigada' não expressa todo o meu sentimento de gratidão àqueles que contribuíram para a realização deste trabalho. Tornaram-se parte da minha história, e não há palavras que traduzam o quanto significam para mim.

O meu crescimento pessoal e profissional é resultado da soma de todas as experiências vividas na graduação, na pós-graduação, nas instituições onde atuei e no convívio com estas pessoas que me proporcionaram este aprendizado.

Olho para trás e me dou conta da presença e fortaleza de Deus em todos os momentos. Sinto-me muito privilegiada por essa oportunidade.

Compartilho minhas conquistas e esta alegria com todos, especialmente minha família, a quem devo tudo que sou, tudo que posso vir a ser; com meus amigos, presentes como fontes de energia e estímulo; e com as docentes componentes da banca examinadora:

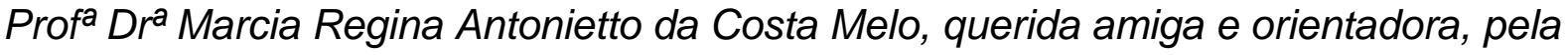
paciência e confiança em meu potencial.

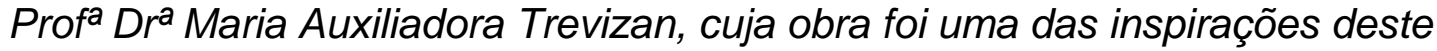
trabalho.

Profa ${ }^{2}{ }^{a}$ Káthia de Carvalho Cunha, pela atenção especial e incentivo, desde a confecção do projeto. 


\section{RESUMO}

BARBOSA, L. R. Relações entre liderança, motivação e qualidade na assistência de enfermagem: revisão integrativa da literatura. 2007. $138 \mathrm{f}$. Dissertação (Mestrado) - Escola de Enfermagem de Ribeirão Preto, Universidade de São Paulo, Ribeirão Preto, 2007.

Apresenta uma revisão integrativa de literatura para avaliar as contribuições das pesquisas produzidas pela Enfermagem brasileira sobre as temáticas liderança, motivação e qualidade da assistência no contexto hospitalar, através da análise de artigos publicados em periódicos nacionais. Pretende destacar as estratégias de liderança, motivação e qualidade que podem ser utilizadas pelo enfermeiro, visando à realização, pela equipe, de ações comprometidas com a assistência de enfermagem. Revisão Integrativa da Literatura é aquela em que conclusões de estudos anteriormente conduzidos são sumarizadas a fim de que se formulem inferências sobre um tópico específico. Mostra a pesquisa feita nas bases de dados LILACS e BDENF da Biblioteca Virtual em Saúde - BVS, utilizando artigos indexados nessas bases, até o ano de 2006. Utiliza para a integração das categorias os descritores: Enfermagem, Assistência de Enfermagem, Liderança, Motivação e Qualidade; estudos de natureza descritiva, relacionados com a 'enfermagem' e/ou 'assistência de enfermagem' em um contexto hospitalar. Composta por 31 estudos, cuja análise foi feita a partir da utilização de um instrumento confeccionado pela própria pesquisadora, submetido a um pré-teste. Categoriza os dados em três grandes conjuntos (liderança, motivação e qualidade) e em subcategorias, as quais foram analisadas sob o enfoque da assistência de enfermagem no contexto hospitalar. Identifica três estudos sobre liderança, três estudos sobre motivação e um estudo sobre qualidade, o que corresponde a cerca de $20 \%$ da amostra. A partir do entendimento das autoras, somente estes estudos apontam estratégias com potencial para promover a assistência de enfermagem. Estas (estratégias), por sua vez, requerem ação e empenho por parte da Enfermagem para que este potencial seja ativado e, assim, provocar as mudanças necessárias à promoção da assistência e, conseqüentemente, à qualidade de todas as ações que caracterizam o exercício da profissão.

Palavras-chave: Enfermagem. Liderança. Motivação. Enfermagem - Assistência. Qualidade. 


\section{ABSTRACT}

BARBOSA, L.R. Relations involving leadership, motivation and quality in the nursing assistance program: integrative review of the literature. 2007. 138 p. Dissertation (Master's degree) - Nursing School of Ribeirão Preto, University of Sao Paulo, Ribeirão Preto, 2007.

This dissertation presents an integrative review of the literature through the analysis of articles published in national journals with the purpose of evaluating the contributions of the research produced by the Brazilian nursing system regarding the leadership, motivation and quality of nursing assistance in a hospital context. It intends to emphasize the leadership, motivation and quality strategies that can be used by the nurse in order to accomplish team actions directed to the nursing assistance. An Integrative Review of Literature is composed by a summary of conclusions from studies previously conducted in order to draw inferences on a specific topic. The research was made using LILACS and BDENF databases and the Health Virtual Library - BVS, with indexed publications up to 2006. The following describers were used for the integration among the categories: Nursing; Nursing Assistance; Leadership; Motivation and Quality; and studies of descriptive nature, related to "nursing" and/or 'nursing assistance' in a hospital context. The dissertation contains 31 studies. The collection of data was made by the use of an instrument produced by the researcher who tested it before application. The data had been grouped into three comprehensive categories (leadership, motivation and quality) and, in subcategories which were analyzed using the nursing assistance approach in a hospital context. The research identified three studies about leadership, three about motivation and one about quality which corresponds to $20 \%$ of the sample. According to the researchers, these studies were the only that indicated strategies with the necessary potential to improve the nursing assistance program. These strategies require action and dedication from the Nursing team in order to activate this potential and, therefore, promote the necessary changes to the nursing assistance program as well as to improve the quality of all activities performed by the nursing professional.

Key-words: Nursing. Leadership. Motivation. Nursing Assistance. Quality. 


\section{RESUMÉN}

BARBOSA, L. R. Relaciones entre lideranza, motivación y calidad en la asistencia de enfermeria: revisión integrativa de la literatura. 2007. $138 \mathrm{~h}$. Disertación (Mestrado) - Escuela de Enfermaria de Ribeirão Preto, Universidad de São Paulo, Ribeirão Preto, 2007.

Presenta una revisión integrativa de literatura para avaliar las contribuiciones de las pesquisas producidas por la Enfermaria Brasileña sobre las temáticas lideranza, motivación, y calidad de la asistencia, en un contexto del hospital, atraves de la analise de articulos publicados em períodicos nacionales. Supone destacar las estratégias de lideranza, motivación y calidad que pueden ser utilizados por el enfermero, visando la realización, por el equipo, de acciones comprometidas con la asistencia de enfermaria. Revisión Integrativa de la Literatura es aquella en que conclusiones de estudios anteriormente conduzidos son sumarizados a fin de que se formulen inferencias sobre un tópico especifico. Muestra la pesquisa hecha en bases de datos LILACS e BDENF y, Biblioteca Virtual en Salud - BVS, utilizando articulos indexados en esas bases, hasta el año de 2006. Utiliza para la integración de las categorias os descritores: Enfermaria, Lideranza, Motivación y calidad; estudios de naturaleza descriptiva, relacionados con la " 'enfermaria' y/u 'asistencia de enfermaria' en un complejo hospitalar. Compuesta por 31 estudios. Se utilizó un instrumento hecho por la própria pesquisadora, submetido a un pré-test. Los datos habían sido agrupados en tres categorías comprensivas (dirección, motivación y calidad) y, en las subcategorías que eran analizadas usando el acercamiento de la ayuda del oficio de enfermera en un contexto del hospital. La investigación identificó tres estudios sobre la lideranza, tres sobre la motivación y uno sobre la calidad que corresponde hasta el $20 \%$ de la muestra. Según los investigadores, estos estudios eran los únicos que indicó estrategias con el potencial necesario de mejorar el programa de la ayuda del oficio de enfermera. Estas estrategias requieren la acción y el esmero del equipo del oficio de enfermera para activar este potencial y, por lo tanto, promover los cambios necesarios al programa de la ayuda del oficio de enfermera tan bien como mejorar la calidad de todas las actividades realizadas por el profesional del oficio de enfermera.

Palabras-Ilave: Enfermaria, Lideranza. Motivación. Enfermaria-Asistencia. Calidad. 


\section{LISTA DE FIGURAS}

Figura 1 O managerial grid (grade gerencial)......................... 23

Figura 2 Liderança Situacional.......................................... 24

Figura 3 A hierarquia das necessidades segundo Maslow.... 30

Figura $4 \quad$ A Teoria $X$ e Teoria $Y$ como diferentes concepções a respeito da natureza humana............................... 32 


\section{LISTA DE QUADROS}

Quadro 1 Resumo das teorias de liderança.............................. 28

Quadro 2 Indicação dos artigos que se repetem nas bases de dados

Quadro $3 \quad$ Categorias e subcategorias dos dados para análise dos resultados................................................... 55

Quadro $4 \quad$ Estudo 1-LID......................................................... 66

Quadro $5 \quad$ Estudo 4........................................................ 67

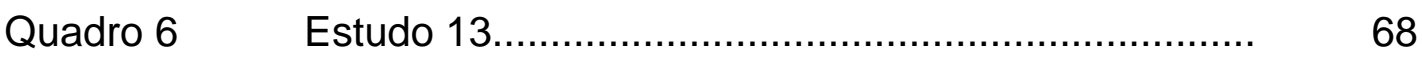

Quadro $7 \quad$ Estudo 17...................................................... 69

Quadro $8 \quad$ Estudo 23.......................................................

Quadro $9 \quad$ Estudo 6.........................................................

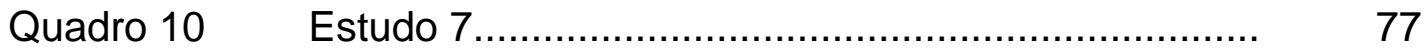

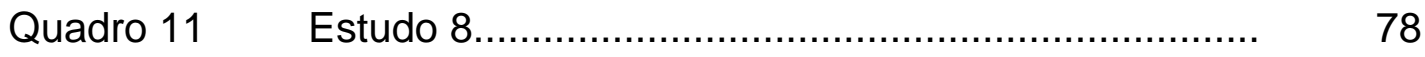

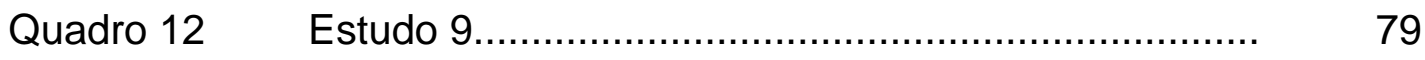

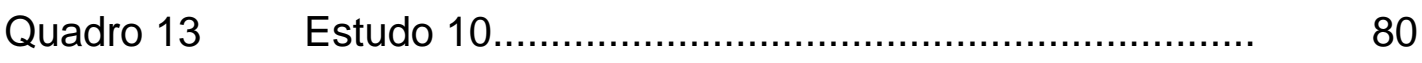

Quadro $14 \quad$ Estudo 11..................................................... 81

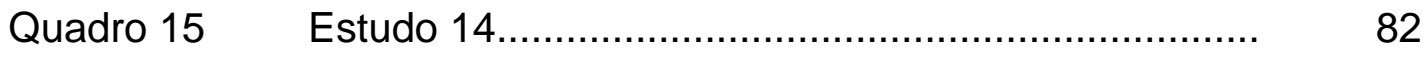

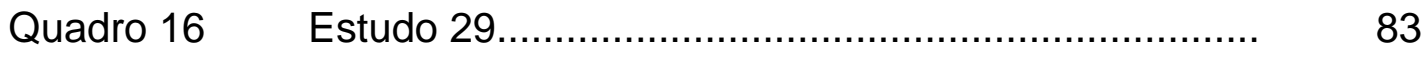

Quadro $17 \quad$ Estudo 30....................................................... 84

Quadro $18 \quad$ Estudo 31.....................................................

Quadro $19 \quad$ Estudo 5............................................................ 93

Quadro $20 \quad$ Estudo 12..................................................... 94

Quadro $21 \quad$ Estudo 15...................................................... 95

Quadro $22 \quad$ Estudo 16-LID.................................................... 96

Quadro $23 \quad$ Estudo 24....................................................... 97

Quadro $24 \quad$ Estudo 25-LID.................................................. 98

Quadro $25 \quad$ Estudo 27...................................................... 99

Quadro $26 \quad$ Estudo 28...................................................... 100

Quadro $27 \quad$ Estudo 2.................................................... 106

Quadro $28 \quad$ Estudo 18....................................................... 107

Quadro $29 \quad$ Estudo 25-MOT ................................................... 108 
Quadro $30 \quad$ Estudo 16-MOT .................................................. 110

Quadro $31 \quad$ Estudo 22....................................................... 111

Quadro $32 \quad$ Estudo 20.................................................... 113

Quadro $33 \quad$ Estudo 21........................................................... 114

Quadro $34 \quad$ Estudo 1-QUA................................................... 116

Quadro $35 \quad$ Estudo 3........................................................ 117

Quadro $36 \quad$ Estudo 19.................................................... 120

Quadro $37 \quad$ Estudo 26......................................................... 123 


\section{LISTA DE TABELAS}

Tabela 1 Freqüência e porcentagem de estudos sobre liderança, motivação e qualidade identificados nos periódicos nacionais indexados nas bases LILACS e BDENF até o ano de 2006, segundo o nome do periódico.

Tabela 2 Freqüência e porcentagem de estudos sobre liderança, motivação e qualidade identificados nos periódicos nacionais indexados nas bases LILACS e BDENF até o ano de 2006, segundo o local de publicação do periódico.

Tabela 3 Freqüência e porcentagem de estudos sobre liderança, motivação e qualidade identificados nos periódicos nacionais indexados nas bases LILACS e BDENF até o ano de 2006, segundo o ano de publicação do periódico

Tabela 4 Freqüência e porcentagem de estudos sobre liderança, motivação e qualidade identificados nos periódicos nacionais indexados nas bases LILACS e BDENF até o ano de 2006, segundo a base de dados em que foi localizado o artigo

Tabela 5 Freqüência e porcentagem de estudos sobre liderança, motivação e qualidade identificados nos periódicos nacionais indexados nas bases LILACS e BDENF até 0 ano de 2006, segundo a titulação/formação acadêmica do primeiro autor dos estudos

Tabela 6 Freqüência e porcentagem de estudos sobre liderança, motivação e qualidade identificados nos periódicos nacionais indexados nas bases LILACS e BDENF até o ano de 2006, segundo a profissão do primeiro autor dos estudos.

Tabela 7 Freqüência e porcentagem de estudos sobre liderança, motivação e qualidade identificados nos periódicos nacionais indexados nas bases LILACS e BDENF até o ano de 2006, segundo o local de atuação do primeiro autor dos estudos

Tabela 8 Freqüência e porcentagem de estudos sobre liderança, motivação e qualidade identificados nos periódicos nacionais indexados nas bases LILACS e BDENF até o ano de 2006, segundo a instituição de ensino onde atuava o primeiro autor dos estudos....... 
Tabela 9 Freqüência e porcentagem de estudos sobre liderança, motivação e qualidade identificados nos periódicos nacionais indexados nas bases LILACS e BDENF até o ano de 2006, segundo o local de pós graduação do primeiro autor dos estudos.

Tabela 10 Freqüência e porcentagem de estudos sobre liderança, motivação e qualidade identificados nos periódicos nacionais indexados nas bases LILACS e BDENF até o ano de 2006, segundo a cidade onde se desenvolveu o estudo

Tabela 11 Freqüência e porcentagem de estudos sobre liderança, motivação e qualidade identificados nos periódicos nacionais indexados nas bases LILACS e BDENF até o ano de 2006, segundo a natureza da instituição local dos estudos

Tabela 12 Freqüência e porcentagem de estudos sobre liderança, motivação e qualidade identificados nos periódicos nacionais indexados nas bases LILACS e BDENF até o ano de 2006, segundo a unidade hospitalar local do estudo

Tabela 13 Freqüência e porcentagem de estudos sobre liderança, motivação e qualidade identificados nos periódicos nacionais indexados nas bases LILACS e BDENF até o ano de 2006, segundo o tipo de pesquisa desenvolvida.

Tabela 14 Freqüência e porcentagem de estudos sobre liderança, motivação e qualidade identificados nos periódicos nacionais indexados nas bases LILACS e BDENF no período de 1985 a 2006, segundo o instrumento de coleta de dados utilizado nos estudos. 
SUMÁRIO

INTRODUÇÃO E JUSTIFICATIVA............................................ 15

REFERENCIAL TEÓRICO..

LIDERANÇA.

MOTIVAÇÃO

QUALIDADE.

OBJETIVOS DO ESTUDO........................................................ 45

Bases de dados utilizadas.

Composição da amostra....................................................... 51 


\section{INTRODUÇÃO E JUSTIFICATIVA}

As organizações funcionam através das pessoas que dela fazem parte, que decidem e agem em seu nome. Podem ser indústrias, comércio, bancos, financeiras, hospitais, universidades, lojas, prestadoras de serviços, etc. Podem ser grandes, médias e pequenas quanto ao seu tamanho. Podem ser públicas ou privadas quanto à sua propriedade. Quase tudo que a sociedade necessita é produzido através de organizações. Vivemos em uma sociedade de organizações, pois nascemos nelas, aprendemos nelas, servimo-nos delas, trabalhamos nelas e passamos a maior parte de nossas vidas dentro delas. (CHIAVENATO, 1999).

Nascemos em organizações, somos educados por organizações, e quase todos nós passamos a trabalhar para organizações. Passamos muitas de nossas horas de lazer a pagar, jogar e a rezar em organizações. Quase todos nós morreremos numa organização, e quando chega o momento do funeral, a maior de todas as organizações - o Estado - precisa dar uma licença especial. (ETZIONI, 1984, p. 1).

O comportamento humano no local de trabalho é o objeto de estudo do Comportamento Organizacional. Investiga-se o impacto que indivíduos, grupos e a estrutura têm sobre o comportamento dentro das organizações. Com o objetivo de melhorar a eficácia organizacional, utiliza-se o conhecimento obtido sobre as pessoas e o efeito da estrutura da organização sobre o seu comportamento. As principais metas do comportamento organizacional são explicar, prever e controlar o comportamento. (ROBBINS, 2005; DUBRIN, 2003).

Para Chiavenato (2005, p. 6), o comportamento organizacional dedica-se ao estudo de indivíduos e grupos que compõem as organizações e está relacionado com as ações das pessoas no ambiente de trabalho. 
[...] é uma área que trata do comportamento individual, isto é, de tópicos como personalidade, atitudes, percepção, aprendizado, motivação [...] e do comportamento grupal, incluindo tópicos como normas, papéis, construção de equipes e conflito e, nesse sentido, baseia-se na contribuição de psicólogos e de psicólogos sociais.

Segundo Drucker (2001, p. 29), os recursos humanos - as pessoas constituem o objeto de estudo da Administração, pois ela "trata dos seres humanos". Administrar, no contexto organizacional, significa:

[...] capacitar as pessoas a funcionar em conjunto, efetivar suas forças e tornar irrelevantes suas fraquezas. É disso que trata uma organização, e esta é a razão pela qual a administração é um fator crítico e determinante. Hoje em dia, praticamente todos nós somos empregados por instituições administradas, grandes ou pequenas, empresariais ou não. Dependemos da administração para nossa sobrevivência. E a nossa capacidade de contribuição à sociedade também depende tanto da administração das organizações em que trabalhamos quanto de nossos próprios talentos, dedicação e esforço.

Dessler (2003) assinalou que a Administração de Recursos Humanos (ARH) refere-se às práticas e às políticas necessárias para conduzir os aspectos relacionados às pessoas no trabalho de gerenciamento, especificamente à contratação, ao treinamento, à avaliação, à remuneração e ao oferecimento de um ambiente bom e seguro aos funcionários da empresa.

A gestão de pessoas pode ser entendida como a versão atual da Administração de Recursos Humanos, constituindo-se em uma das áreas que mais tem sofrido mudanças e transformações nestes últimos anos. Com o intenso movimento pela qualidade e produtividade promovido pela globalização dos negócios, pelo desenvolvimento tecnológico e pelo conseqüente impacto das mudanças, as pessoas passaram a ser consideradas o principal "ativo" das organizações, sendo suas ações e atitudes determinantes para a vantagem competitiva da empresa. Daí a necessidade de tornar as organizações mais conscientes e atentas a seus funcionários. As pessoas podem ampliar ou limitar as 
forças e fraquezas de uma organização, dependendo da maneira como elas são tratadas. (CHIAVENATO, 2005).

Segundo Fisher e Albuquerque (2001), gerenciar pessoas ou a gestão de pessoas é a preocupação de muitas organizações para que seus objetivos sejam atingidos. O gestor - líder - de um grupo eficaz e motivado deverá ser capaz de enfrentar diversos desafios estratégicos, entre eles manter a motivação e desenvolver uma cultura gerencial voltada para a excelência.

Para Vergara (2000, p. 97), entre as capacidades requeridas para o gestor estão o "compartilhar visão, missão, objetivos, metas, estruturas, tecnologias e estratégias", além de ter iniciativa, comprometimento, atitude sinérgica e ousadia.

Desafios estratégicos, compartilhar estratégias, gestão estratégica... Afinal, o que é estratégia?

Para Maximiano (2000, p. 203), "estratégia é a seleção dos meios, de qualquer natureza, empregados para realizar objetivos".

Estratégia é o "curso de ação que o tomador de decisão escolhe para atingir seus objetivos. O curso de ação é o caminho escolhido e depende dos recursos de que ele pode dispor". (CHIAVENATO, 2004, p. 278).

A gestão de pessoas, portanto, baseia-se no fato de que o desempenho de uma organização depende fortemente da contribuição e do esforço das pessoas que a compõem e da forma como elas são estimuladas, capacitadas e mantidas num ambiente de trabalho adequado, o qual deve permitir a satisfação de suas necessidades e as da organização.

A falta de atenção às práticas da gestão de pessoas interfere diretamente no alcance dos objetivos organizacionais, principalmente no que tange à implementação de processos de qualidade. A qualidade resulta de um 
comportamento positivo e concentrado dos colaboradores. Para alcançar a excelência e a conseqüente e desejada competitividade no mercado, as organizações precisam considerar atualmente que gerir pessoas significa estimular o envolvimento e desenvolvimento das mesmas. Desta forma, o comprometimento da administração da instituição e de seus colaboradores, assim como o investimento em melhoria contínua e capacitação destes são imprescindíveis à sobrevivência da organização. (MAXIMIANO, 2005).

Para Dutra (2004), o atual grande desafio da gestão de pessoas é gerar e sustentar o seu comprometimento, o que só é possível se estas perceberem que sua relação com as organizações lhes agrega valor.

A necessidade do comprometimento das pessoas foi ampliando sua importância estratégica para criar e manter diferenciais competitivos por parte das organizações. Ao ganharem voz dentro das organizações, as pessoas tornam-se fonte de pressão, a segunda fonte de pressão sobre a organização, uma pressão proveniente do contexto interno. (DUTRA, 2004, p. 14).

Nos dias de hoje, o que se constata é que as organizações mantêm determinadas políticas de gestão desses Recursos Humanos muito menos por considerar as pessoas como diferenciais competitivos e se preocuparem de fato com elas, e muito mais por terem a convicção de que, mesmo com Recursos Humanos, a satisfação da mão-de-obra é o que garante o andamento adequado dos trabalhos. (BITENCOURT, 2004).

O ser humano e seu desempenho são considerados fatores capazes de transformar a capacidade potencial das organizações em capacidade real. O desempenho de uma organização depende fortemente da contribuição das pessoas, da forma como estão organizadas, estimuladas, capacitadas, lideradas e mantidas no ambiente de trabalho. Elas devem atuar como agentes proativos, empreendedores, inovadores e, assim, prestar serviços de qualidade aos seus 
clientes. E para conduzir as pessoas rumo à concretização dos objetivos organizacionais é preciso conhecer a natureza humana para conceber o desenvolvimento de líderes. (ROBBINS, 2002; MAXIMIANO, 2005; CHIAVENATO, 2005).

Na minha vivência profissional, várias situações colocaram-me à prova, colaborando para a formulação de questões sobre o processo de trabalho da equipe de enfermagem. Como enfermeira de unidade de internação hospitalar, buscava compreender como poderia desenvolver efetivamente o trabalho, sendo uma líder capaz de mobilizar a equipe frente a tantas ações necessárias, coordenando suas atividades para uma assistência de qualidade ao paciente. Aos meus olhos, agiam sem motivação e comprometimento e, assim, almejava ser capaz de estimular envolvimento e entusiasmo daqueles técnicos e auxiliares de enfermagem.

Por várias vezes como enfermeira e, portanto, responsável por tudo o que acontecia na unidade durante meus plantões, sentia o "peso" da responsabilidade por todas as atividades desenvolvidas por profissionais que, aparentemente, não demonstravam o mínimo de empenho e satisfação por ali estarem trabalhando. $\mathrm{Na}$ condição de enfermeira, executava ações dirigidas à manutenção da ordem na unidade e de seus recursos materiais. Por muitas vezes, não foi possível planejar o cuidado de enfermagem, ou mesmo programar atividades de treinamento para a equipe.

A pouca experiência profissional - estava no início da carreira - não me possibilitou agir de acordo com as exigências das situações, motivando-me a refletir sobre a prática profissional do enfermeiro.

Tais questões já me preocupavam na graduação, especificamente ao cursar uma disciplina que tinha como objetivo geral propiciar ao aluno a compreensão de 
aspectos da dinâmica das relações interpessoais em grupo, no desempenho de suas atividades enquanto enfermeiro. Considerando a importância de desenvolver habilidades pessoais e interpessoais para coordenar grupos, acreditava que a prática profissional proporcionar-me-ia condições para estas ações.

No cotidiano, buscava entender o porquê de tais comportamentos, visando conseguir melhorar o trabalho em equipe. Estes aspectos tomaram corpo ao ser contratada para exercer o cargo de chefia de uma unidade de internação hospitalar, o que me estimulou a buscar o ingresso na pós-graduação.

Hoje entendo que a prática profissional é construída a todo instante, em conjunto com toda a equipe de enfermagem, que o agir como líder, o estar e manterse motivado são imprescindíveis à qualidade da assistência.

Diante do exposto, torna-se necessário à promoção da qualidade da assistência de enfermagem analisar como nós, enfermeiros, podemos exercer efetivamente a liderança em nossa prática diária. Como conduzir técnicos e auxiliares de enfermagem para que desenvolvam ações comprometidas com a qualidade da assistência? Quais estratégias podemos utilizar? Que resultados concretos queremos e podemos obter?

Em busca de possíveis respostas a tais questionamentos, o presente trabalho objetiva a realização de uma revisão integrativa da literatura (Ganong, 1987), para uma avaliação das contribuições das pesquisas produzidas pela Enfermagem brasileira acerca das temáticas liderança, motivação e qualidade na assistência, através da análise de artigos publicados em periódicos nacionais. Pretende também focalizar as estratégias relativas à liderança, motivação e qualidade que podem ser utilizadas pelo enfermeiro, visando à realização, pela equipe, de ações comprometidas com a assistência de enfermagem. 


\section{REFERENCIAL TEÓRICO}

\subsection{LIDERANÇA}

"Liderar vem do inglês to lead, que significa conduzir, guiar, comandar, pilotar, levar, dirigir, governar, capitanear, mostrar o caminho, dominar-se." (MINICUCCI, 1982, p. 121).

Liderança pode ser entendida como habilidade imprescindível às transformações das organizações. Visa à estruturação de equipes dinâmicas, ágeis, motivadas, empenhadas em proporcionar o melhor resultado, fundamental ao sucesso de empreendimentos que requerem comando, gerência ou gestão de pessoas. Gerando polêmica por ser fenômeno comportamental compreendido sob diversos enfoques, tem sido discutida com mais freqüência nos últimos anos entre pesquisadores de diversos tipos de organizações, que a percebem imprescindível à qualidade de seus serviços e produtos, bem como ao melhor desenvolvimento de seus processos.

Para Tannenbaum; Weschler e Massarik (1972), liderança é influência interpessoal, exercida em uma situação e dirigida através do processo de comunicação, no sentido do atingimento de um objetivo específico ou objetivos diversos.

Conforme Katz e Kahn (1974, p. 342 - 343),

[...] liderança é um conceito relativo que implica a relação simultânea de pelo menos dois sujeitos: o agente influenciador e as pessoas influenciadas. Sem seguidores não pode haver líder. A essência da liderança organizacional pode ser considerada como o incremento influencial além e acima do cumprimento mecânico das diretivas rotineiras da organização. 
Drake e Smith (1983) definiram liderança como comportamento, entendendo-o em função da personalidade e situação. Para eles, a liderança é estabelecida entre influência e comportamento de pessoas para a execução de tarefas.

$\operatorname{Bass}^{1}$ (1990, apud BERGAMINI, 2006b, p. 51) apontaram que:

[...] o conceito de influência admite o fato de que os indivíduos sejam diferentes uns dos outros, sendo o líder alguém que exerce um tipo particular de relação de poder que resulta da percepção que tem dos membros do grupo. [...] O conceito de influência também reconhece que os líderes possam influenciar os membros do grupo por meio do seu próprio exemplo.

Para Maxwell (1999, p. 37; 34), "liderança é influência - nada mais, nada menos". E ainda diferencia liderança de gerência: "liderança diz respeito à influência exercida sobre as pessoas, enquanto gerência se concentra na manutenção de sistemas e processos".

Tanto as teorias mais simples como as mais complexas procuram formas de avaliar a eficácia da liderança. Buscou-se encontrar parâmetros tais como traços, habilidades, comportamentos, motivações, tipos de fontes de poder e características extrínsecas ao processo de liderança que fossem capazes de explicar qual seria a variável mais importante para se conseguir tornar o líder mais notável em suas atividades de influenciar seus seguidores. (BERGAMINI, 1994).

Percebe-se assim que influência e fenômeno grupal são expressões comuns às pesquisas, presentes nas definições dadas pelos estudiosos do tema liderança.

Segundo Jesuíno² (1987 apud BERGAMINI, 1994), existem quase tantas definições diferentes de liderança como autores que a tentaram definir.

\footnotetext{
${ }^{1}$ BASS, B. M. Bass \& Stogdill's handbook of leadership: survey of theory and research. New York: Free Press, 1990. p. 15 16.

${ }^{2}$ JESUÍNO, J. C. Processos de liderança. Lisboa: Livros Horizonte, 1987.
} 
Durante as décadas de 50 e 60, os estudos da Universidade Estadual de Ohio e da Universidade de Michigan nos Estados Unidos foram os pioneiros. Inspiraram os programas de treinamento e desenvolvimento em liderança oferecidos às empresas, o que repercutiu no mundo todo e, principalmente, dentro das organizações norte-americanas. Em 1964, integrantes do grupo de Ohio, Robert Blake e Jane Mouton, desenvolveram o Grid Gerencial, uma representação gráfica de um programa de treinamento gerencial e desenvolvimento organizacional no qual propuseram a interligação dessas duas dimensões do comportamento de liderança. O grid foi apresentado por uma matriz nove-por-nove, representando 81 estilos diferentes de liderança. Não objetivou mostrar os resultados produzidos, mas sim os fatores dominantes na forma de pensar do líder em relação à obtenção de resultados. (ROBBINS, 2002).

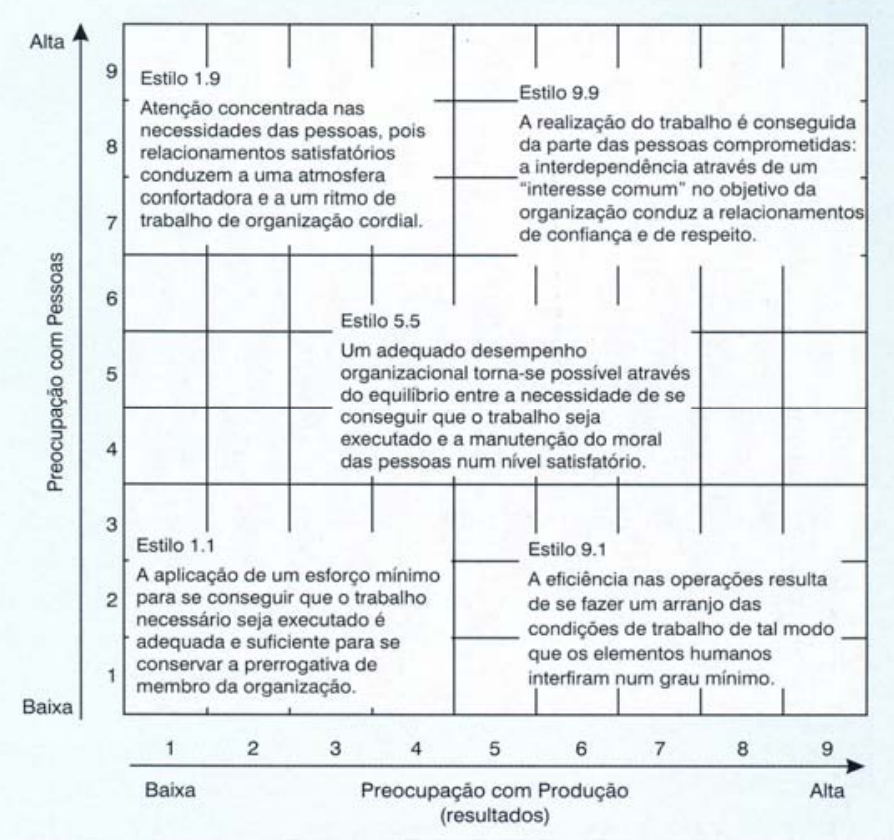

Figura 1. O managerial grid (grade gerencial). Fonte: Chiavenato (2004). 
Entre as teorias contingenciais, destaca-se a Liderança Situacional de Hersey e Blanchard. Esta teoria, publicada pela primeira vez em 1969, reconheceu a importância dos liderados e baseou-se na lógica de que os líderes poderiam interferir nas limitações motivacionais e capacitação de seus seguidores. Eles identificaram quatro comportamentos específicos de líderes - do mais diretivo ao mais laissez-faire. O comportamento mais eficaz depende da capacidade e da motivação dos liderados. De acordo com essa teoria, se os liderados forem incapazes ou estiverem desmotivados a executar uma tarefa, o líder precisará fornecer orientações claras e específicas; se os liderados forem capazes, mas estiverem desmotivados, o líder precisará usar um estilo apoiador e participativo; e, finalmente, se os liderados forem capazes e estiverem motivados, o líder não precisará fazer muita coisa. (ROBBINS, 2002).

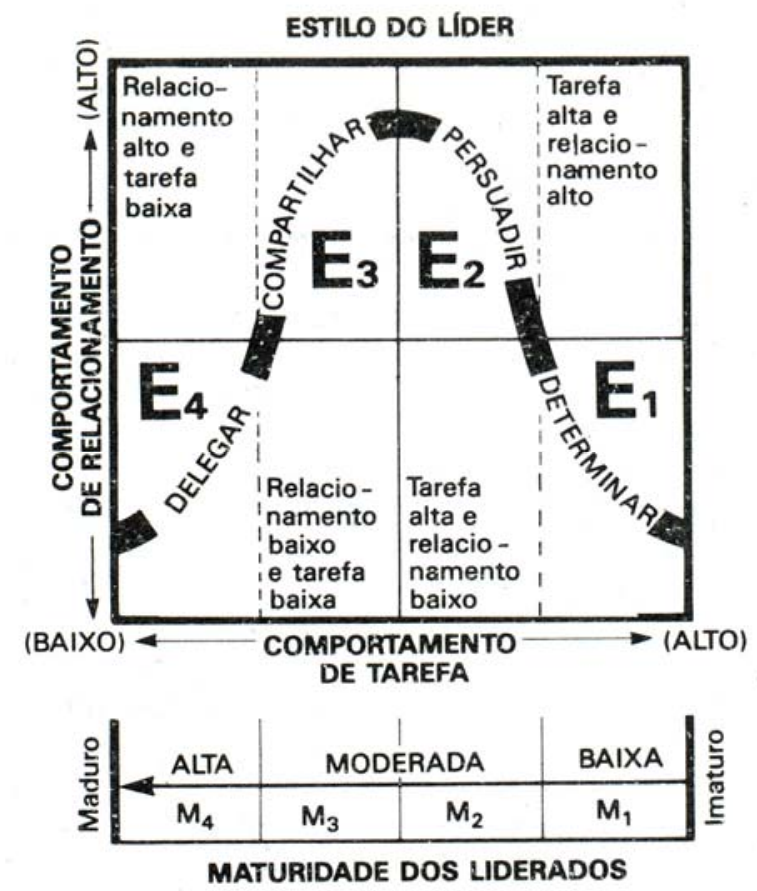

Figura 2. Liderança Situacional. Fonte: Hersey e Blanchard (1986). 
Rensis Likert, pesquisador da Universidade de Michigan, ficou conhecido por suas pesquisas e teorias sobre liderança, teoria organizacional e motivação. No decorrer da década de 1960, desenvolveu uma pesquisa cujo objetivo era estabelecer a natureza da relação entre estilo de gerência e supervisão, de um lado, e desempenho e satisfação do indivíduo, do outro. Likert classificou os sistemas de Administração em relação a quatro variáveis: processo decisorial, sistema de comunicação, relacionamento interpessoal e sistema de recompensas e punições:

- Sistema 1 (autoritário - coercitivo): sistema autocrático e forte, coercitivo e arbitrário, que controla rigidamente tudo o que ocorre dentro da organização.

- Sistema 2 (autoritário - benevolente): centralizado na cúpula administrativa, prevalecendo as comunicações verticais e descendentes.

- Sistema 3 (consultivo): sistema que pende mais para o lado participativo do que para o lado autocrático e impositivo.

- Sistema 4 (participativo): é o sistema administrativo democrático por excelência. É o mais aberto de todos os sistemas. (CHIAVENATO, 2004).

Graças às pesquisas e conseqüente evolução das teorias de liderança, já está incorporada à 'ordem do dia' a concepção de que, nas organizações de serviços, as pessoas devem atuar como agentes proativos, empreendedores, inovadores e, assim, prestar serviços de qualidade aos seus clientes.

Segundo Kotter (2000) um dos motivos da liderança ter se tornado tão importante nos últimos anos é a transformação do mundo dos negócios, cada vez mais competitivo e volátil. Mudanças rápidas são cada vez mais necessárias à sobrevivência do ambiente organizacional. Contudo, mudanças sempre requerem mais liderança. E, neste caso, o papel da liderança é fundamental, uma vez que ela é responsável pela valorização da participação efetiva das pessoas em suas 
relações de trabalho, inspirando-as a trabalharem em conjunto, com visão e objetivo comuns. O mesmo autor resume que "liderar é lidar com a mudança". Ele defende a ação de motivar as pessoas para a mudança, ao invés de controlá-las para meramente solucionar problemas.

\begin{abstract}
Uma vez que a função da liderança é mudar, ser capaz de produzir comportamentos altamente energizados é crucial para lidar com as barreiras inevitáveis à mudança. Assim como o estabelecimento de uma direção indica um caminho adequado para o movimento e um alinhamento eficaz coloca as pessoas nesse caminho, uma motivação bem sucedida assegura que todos terão a energia necessária para superar obstáculos. (KOTTER, 2000, p. 57).
\end{abstract}

Para o efetivo processo de mudança nas organizações é necessário que as pessoas estejam de fato comprometidas com tal transformação, empenhadas com garra e motivação para a conquista das metas, para o alcance dos resultados almejados.

Nannus (2000) referiu que a visão atraente, compensadora, realizável e amplamente compartilhada do futuro é um dos resultados de uma liderança atuante. Para ele, líderes eficazes comunicam suas visões de tal forma que persuadem os outros a assumirem esse compromisso com novas direções e se mostram ávidos por emprestarem seus recursos e energias para torná-las realidade.

Os líderes assumem o controle, fazem com que as coisas aconteçam, sonham e depois traduzem esses sonhos em realidade. A liderança eficaz energiza uma empresa para maximizar a sua contribuição para o bem estar de seus membros e a sociedade mais ampla da qual faz parte. Se os gerentes são conhecidos por suas habilidades para solucionar problemas, os líderes são conhecidos por serem mestres em projetar e construir instituições; eles são os arquitetos do futuro da organização. (NANNUS, 2000, p. 10).

Pesquisa conduzida por Kouzes e Posner (2003) mostrou que a liderança é um conjunto de práticas que se pode observar e aprender. Definiram o que consideram as seis regras da liderança exemplar:

> Desafiar o estabelecido.

, Inspirar uma visão compartilhada. 
> Permitir uma visão compartilhada.

> Permitir que os outros ajam.

, Apontar o caminho.

, Encorajar o coração.

Covey (2005) propôs o conceito de liderança baseada em princípios, defendendo que a designação dos líderes nas empresas de todos os portes não seja feita apenas em função dos cargos que ocupam, mas em decorrência da real capacidade que têm de influenciar as pessoas, colocando princípios no coração e na mente das pessoas, e depois na cultura delas, permeando e afetando todas as outras relações. Covey (2005) afirmou que o líder deve conseguir fazer com que as pessoas se comprometam com um propósito - uma visão ou um conjunto de princípios comuns - e que este, quando já o tiverem dentro de si, o trabalho de liderança terá sido feito. Estabelece ainda a diferença entre liderança e gerência, defendendo que a primeira está voltada para fazer as coisas certas, e a segunda para fazer certo as coisas. Para o autor, liderança garante que as escadas que estamos subindo estão apoiadas na parede certa; gerência assegura que estamos subindo as escadas da maneira mais eficiente possível.

Kotter (1999) já havia alertado sobre a diferença entre gerenciamento e liderança, denominando-os conjuntos de processos.

\footnotetext{
O gerenciamento é um conjunto de processos que podem manter um complicado sistema de pessoas e tecnologias funcionando satisfatoriamente. Os aspectos mais importantes do gerenciamento incluem planejamento, orçamento, organização, recrutamento de pessoal, controle e solução de problemas. A liderança é um conjunto de processos que cria organizações em primeiro lugar ou as adapta para modificar significativamente as circunstâncias. A liderança define como deverá ser 0 futuro, alinha o pessoal a essa visão e as inspira para a ação, apesar dos obstáculos. (KOTTER, 1999, p. 26).
}

Questões conceituais à parte, a discussão sobre o que é liderança permeia os mais variados campos profissionais e é percebida de diferentes formas, tendo em 
vista também os diversos estilos adotados. Liderar equipes é mais que saber

conduzi-las para o alcance de metas. É exercer influência positiva, capaz por sua

vez de despertar comportamentos eficazes e produtivos.

De forma sintética, apresentamos características das teorias de liderança conforme Robbins (2002):

\begin{tabular}{|c|c|}
\hline Teoria dos Traços & $\begin{array}{l}\text { Teorias que buscam traços sociais, físicos, intelectuais ou de } \\
\text { personalidade que diferenciem líderes de não - líderes. }\end{array}$ \\
\hline Teorias Comportamentais & $\begin{array}{l}\text { Teorias que propõem que comportamentos específicos diferenciam os } \\
\text { líderes dos liderados. }\end{array}$ \\
\hline $\begin{array}{l}\text { Estudos da Universidade de } \\
\text { Ohio }\end{array}$ & $\begin{array}{l}\text { Dimensões do comportamento de liderança: } \\
\text { Estrutura de iniciação - extensão em que um líder é capaz de definir e estruturar o seu } \\
\text { próprio papel e o dos seus subordinados na busca de objetivos; } \\
\text { Consideração - extensão em que uma pessoa é capaz de manter relacionamentos de } \\
\text { trabalho caracterizados por confiança mútua, respeito às idéias dos funcionários e cuidado } \\
\text { com os sentimentos deles. }\end{array}$ \\
\hline $\begin{array}{l}\text { Estudos da Universidade de } \\
\text { Michigan }\end{array}$ & $\begin{array}{l}\text { Dimensões do comportamento de liderança: } \\
\text { Líder orientado para o funcionário: aquele que enfatiza as relações interpessoais; } \\
\text { Líder orientado para a produção: aquele que enfatiza os aspectos técnicos e práticos do } \\
\text { trabalho. }\end{array}$ \\
\hline $\begin{array}{l}\text { O Grid Gerencial, Blake e } \\
\text { Mouton (1964) }\end{array}$ & $\begin{array}{l}\text { Representação gráfica de uma visão bidimensional dos estilos de liderança, composta por } \\
\text { uma matriz nove-por-nove, representando } 81 \text { estilos de liderança. Baseado nos estilos } \\
\text { "preocupado com as pessoas" e "preocupado com a produção". }\end{array}$ \\
\hline Estudos Escandinavos & $\begin{array}{l}\text { Pesquisadores da Finlândia e Suécia revisaram dados da pesquisa de Ohio. Propuseram } \\
\text { uma terceira dimensão para o comportamento de liderança: líder orientado para o } \\
\text { desenvolvimento, aquele que valoriza a experimentação, busca novas idéias e gera e } \\
\text { implementa mudanças. }\end{array}$ \\
\hline Teorias das Contingências & Influências da situação são o foco das pesquisas. \\
\hline Modelo de Fiedler (1967) & $\begin{array}{l}\text { A teoria de que os grupos eficazes dependem da adequação entre o estilo do líder em } \\
\text { interagir com os subordinados e quanto de controle e influência a situação proporciona a } \\
\text { ele. Fiedler elaborou o questionário do colega menos querido (LPC - Least Preferred Co - } \\
\text { Worker), instrumento que se propõe a avaliar se uma pessoa é orientada para o } \\
\text { relacionamento ou para a tarefa. Propôs ainda a Teoria do Recurso Cognitivo, conforme a } \\
\text { qual o estresse afeta desfavoravelmente a situação, e que a inteligência e a experiência } \\
\text { do líder podem diminuir essa influência. }\end{array}$ \\
\hline $\begin{array}{l}\text { Teoria Situacional, Hersey e } \\
\text { Blanchard }(1974,1993)\end{array}$ & $\begin{array}{l}\text { Ênfase na prontidão dos liderados, no que se refere à eficácia da liderança, refletindo a } \\
\text { realidade de que são eles que aceitam ou não um líder. Independente do que fizer o líder, } \\
\text { a eficácia dependerá das ações de seus liderados. Definem prontidão como a habilidade e } \\
\text { disposição demonstradas pelas pessoas para a realização de determinada tarefa. }\end{array}$ \\
\hline $\begin{array}{l}\text { Teoria da Troca entre Líder e } \\
\text { Liderados }\end{array}$ & $\begin{array}{l}\text { Os líderes criam grupos "dos de dentro" e "dos de fora", e os liderados dentro do "grupo } \\
\text { de dentro" recebem avaliações de desempenho melhores, apresentam rotatividade menor } \\
\text { e têm maior satisfação com seus superiores. }\end{array}$ \\
\hline Teoria da Meta e do Caminho & $\begin{array}{l}\text { Teoria que sustenta que o comportamento do líder é aceitável para os liderados quanto } \\
\text { estes o percebem como uma fonte de satisfação imediata ou futura. }\end{array}$ \\
\hline $\begin{array}{l}\text { Modelo de Participação e } \\
\text { Liderança, Vroom e Yetton }\end{array}$ & $\begin{array}{l}\text { Teoria que oferece uma seqüência de regras que devem ser seguidas na determinação da } \\
\text { forma e da quantidade de participação no processo decisório, em diferentes situações. }\end{array}$ \\
\hline Teorias Neocarismáticas & $\begin{array}{l}\text { Teorias sobre liderança que enfatizam o simbolismo, o apelo emocional e } \\
\text { o extraordinário compromisso por parte dos liderados. }\end{array}$ \\
\hline Liderança Carismática & $\begin{array}{l}\text { Os liderados fazem atribuições das capacidades heróicas ou extraordinárias de liderança } \\
\text { quando observam determinados comportamentos. }\end{array}$ \\
\hline $\begin{array}{l}\text { Liderança Transacional e } \\
\text { Transformacional }\end{array}$ & $\begin{array}{l}\text { A liderança transformacional é construída em cima da liderança transacional. Líderes } \\
\text { transacionais são aqueles que conduzem ou motivam seus seguidores na direção das } \\
\text { metas estabelecidas por meio do esclarecimento dos papéis e das exigências das tarefas. } \\
\text { Líderes transformacionais são aqueles que oferecem consideração individualizada e } \\
\text { estímulo intelectual a seus liderados, além de possuírem carisma. }\end{array}$ \\
\hline Liderança Visionária & $\begin{array}{l}\text { Capacidade de criar e articular uma visão de futuro realista, atrativa e acreditável para a } \\
\text { organização ou unidade organizacional. Tem como ponto de partida a situação presente e } \\
\text { visa à sua melhoria. }\end{array}$ \\
\hline
\end{tabular}

Quadro 1. Resumo das teorias de liderança. Fonte: Robbins (2002), adaptado pela autora. 


\subsection{MOTIVAÇÃO}

Segundo Chiavenato (2005, p. 273), um dos grandes desafios das organizações é motivar as pessoas. "A motivação significa o desejo de exercer altos níveis de esforço em direção a determinados objetivos organizacionais, condicionados pela capacidade de também satisfazer objetivos individuais". Aponta ainda que a motivação depende basicamente de direção (objetivos), força e intensidade do comportamento (esforço), duração e persistência (necessidade). "Uma necessidade significa uma carência interna da pessoa e cria um estado de tensão no organismo. Daí o processo motivacional".

De acordo com Bergamini (2006b, p. 138 - 139),

[...] o termo motivação é geralmente empregado como sinônimo de forças psicológicas, desejos, impulsos, instintos, necessidades, vontades, intenção, isto é, tudo aquilo que num indivíduo responde pelo seu dinamismo. Todos estes termos têm, em conjunto, a conotação de movimento ou ação. De fato, ao estudar o comportamento humano, descobre-se que uma certa força impele as pessoas a agir, seja no sentido de buscar, ou de fugir de determinadas situações.

As teorias mais conhecidas sobre motivação são relacionadas com as necessidades humanas. Talvez a teoria mais conhecida sobre motivação seja a Teoria da Hierarquia das Necessidades, de Abraham Maslow, segundo o qual as necessidades humanas dispõem-se numa hierarquia, divididas em cinco grupos:

a. Fisiológicas ou básicas: Necessidades de alimento, abrigo, repouso, exercício, sexo e outras necessidades orgânicas.

b. Segurança: Necessidades de proteção contra ameaças, como as de perda do emprego e riscos à integridade física e à sobrevivência. 
c. Sociais: Necessidades de amizade, afeto, interação e aceitação dentro do grupo e da sociedade.

d. Estima: Necessidades de fatores internos de estima, como respeito próprio, realização e autonomia, e fatores externos de estima, como status, reconhecimento e atenção.

e. Auto-realização: Necessidade de utilizar o potencial de aptidões e habilidades. Intenção de tornar-se tudo aquilo que a pessoa é capaz de ser, autodesenvolvimento e alcance do próprio potencial. (MAXIMIANO, 2005; CHIAVENATO, 2004b).

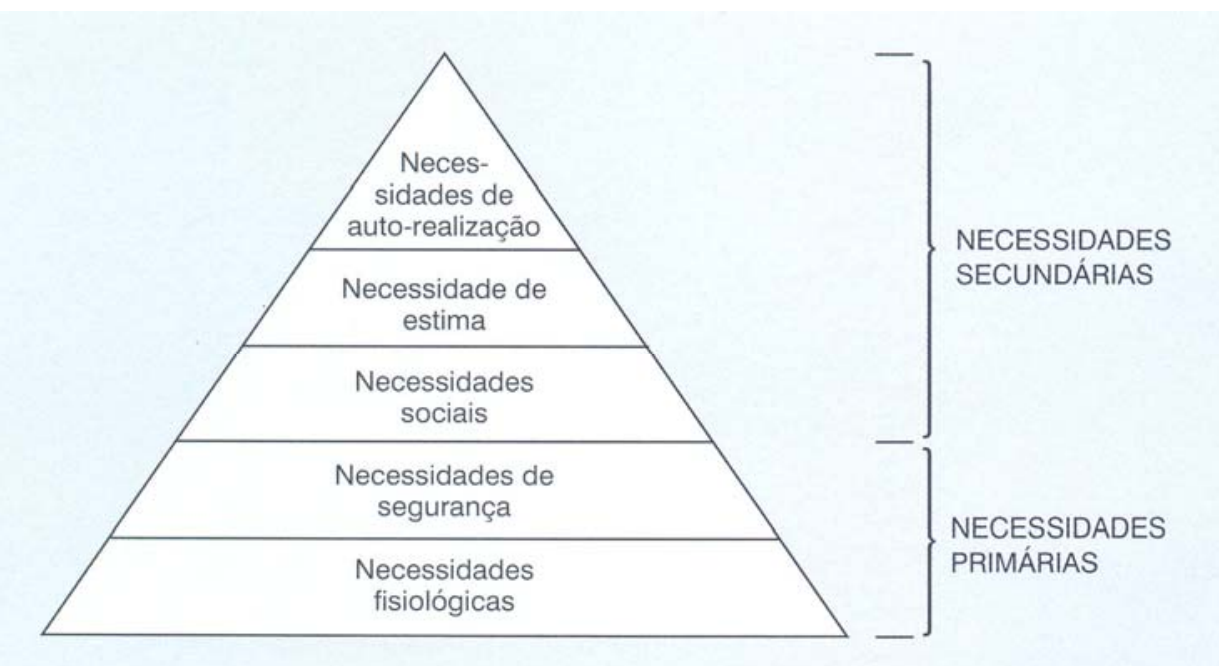

Figura 3. A hierarquia das necessidades segundo Maslow. Fonte: Chiavenato (2004).

Conforme Robbins (2002); Dubrin (2003) e Maximiano (2005), em 1965 David McClelland também propôs sua teoria, baseando-se nas necessidades humanas. Segundo McClelland estas necessidades influenciam o comportamento no trabalho. Quando uma necessidade é suficientemente forte, ela impele uma pessoa a se engajar em atividades de trabalho para satisfazê-la. Essas necessidades específicas são as seguintes: 
- Necessidade de Realização: desejo de conseguir algo difícil por seus próprios méritos. As pessoas com forte necessidade de realização freqüentemente pensam como podem se realizar melhor no cargo. De modo geral, são pessoas que procuram responsabilidades, buscam a excelência e lutam pelo sucesso.

- Necessidade de Poder: desejo de controlar outras pessoas, para influenciar seu comportamento e ser responsável por elas. São aqueles que gostam de controlar todos os recursos, além das pessoas. Preocupam-se em influenciar e controlar os outros e em como ganhar posição de status e autoridade.

- Necessidade de Afiliação: desejo de relacionamentos interpessoais próximos e amigáveis. São pessoas preocupadas em restabelecer relacionamentos rompidos e em amenizar ressentimentos.

Douglas McGregor foi outro pesquisador que se destacou por seus estudos sobre motivação humana em situação de trabalho. Como Maslow, McGregor acreditava que o homem é portador de necessidades e, assim que uma delas tenha sido satisfeita, logo surge outra no lugar. Para ele, este processo estende-se de forma contínua desde o nascimento até a morte. Propôs que cada um, por si mesmo, é capaz de comprometer-se com seu autodesenvolvimento no trabalho, sem que haja coação externa. Se isso não acontecer, muito provavelmente o problema esteja na própria organização, e não no indivíduo.

De acordo com Robbins (2002), McGregor estabeleceu duas visões distintas do ser humano: uma basicamente negativa, chamada de Teoria $X$, e outra basicamente positiva, chamada de Teoria Y. Depois de observar a forma como executivos tratavam seus funcionários, McGregor concluiu que a visão que os executivos têm da natureza dos seres humanos baseia-se em certos agrupamentos de premissas, e que eles tendem a moldar seu próprio comportamento em relação 
aos funcionários de acordo com elas. $\mathrm{Na}$ Teoria $\mathrm{X}$, os funcionários não gostam de trabalhar, são preguiçosos, evitam a responsabilidade e precisam ser coagidos para mostrar desempenho. Já na Teoria $Y$ os funcionários gostam de trabalhar, são criativos, buscam responsabilidades e podem demonstrar auto-orientação.

\begin{tabular}{ll}
\hline PRESSUPOSIÇÕES DA TEORIA X & PRESSUPOSıçōES DA TEORIA Y \\
\hline - As pessoas são preguiçosas e indolentes. & - As pessoas são esforçadas e gostam de ter o que fazer. \\
- As pessoas evitam o trabalho. & - O trabalho é uma atividade tão natural como brincar ou \\
- As pessoas evitam a responsabilidade, a fim de se & descansar. \\
sentirem mais seguras. & - As pessoas procuram e aceitam responsabilidades e desafios. \\
- As pessoas precisam ser controladas e dirigidas. & - As pessoas podem ser automotivadas e autodirigidas. \\
- As pessoas são ingênuas e sem iniciativa. & - As pessoas são criativas e competentes. \\
\hline
\end{tabular}

Figura 4 - A Teoria $X$ e Teoria $Y$ como diferentes concepções a respeito da natureza humana. Fonte: Chiavenato (2004).

Frederick Herzberg propôs a Teoria dos Dois Fatores. Investigou a questão 'o que as pessoas desejam de seu trabalho?', afirmando que a motivação pelo trabalho é diferente da satisfação com o ambiente de trabalho. As condições em torno do trabalho - como o tipo de supervisão recebido, a remuneração, as políticas da empresa, as condições físicas de trabalho, o relacionamento com os outros e a segurança no emprego - foram caracterizadas por Herzberg como fatores higiênicos. A expressão higiene serve para refletir o caráter preventivo e profilático das condições ambientais e mostrar que se destinam a evitar fontes de insatisfação. Quando estes fatores higiênicos são ótimos, simplesmente evitam a insatisfação. Quando são precários, porém, provocam insatisfação. Constituem, assim, o contexto do cargo, atendendo às necessidades que estão na base da pirâmide de Maslow e associados à satisfação. (CHIAVENATO, 2004b; MAXIMIANO, 2005).

Já os fatores motivacionais atendem às necessidades que estão no topo da hierarquia das necessidades. Associados, portanto, à motivação referem-se ao conteúdo do cargo, às tarefas e aos deveres relacionados com o cargo em si. O 
termo motivação envolve sentimentos de realização, de crescimento e de reconhecimento profissional manifestados por meio do exercício das tarefas e atividades que oferecem desafio e significado para o trabalho. Quando os fatores motivacionais são ótimos, eles elevam a satisfação; quando estão precários provocam ausência de satisfação. (MAXIMIANO, 2005; CHIAVENATO, 2004b).

Para Levy-Leboyer ${ }^{3}$ (1994 apud BERGAMINIa, 2006, p. 160-161).

\begin{abstract}
O verbo motivar não pode existir sem complemento. Os responsáveis por empresas cometem o erro de solicitar pessoal 'motivado' dentro do mesmo espírito, como se isso significasse uma qualidade permanente e distribuída de forma homogênea; não existe o pequeno gênio da motivação, que transforma cada um de nós em trabalhador zeloso, ou nos condena a ser o pior dos preguiçosos. Em realidade, a desmotivação não é um defeito de uma geração, nem uma qualidade pessoal, pois ela está ligada a situações específicas. Um indivíduo aqui será diferente em outro lugar.
\end{abstract}

Para Kotter (2000), a motivação e a inspiração energizam as pessoas, não empurrando na direção certa - como fazem os mecanismos de controle -, mas satisfazendo necessidades básicas do ser humano por realização, sendo de propriedade, reconhecimento, auto-estima, sensação de controle sobre sua própria vida e capacidade de viver conforme seus ideais. Ele defende que bons líderes sabem motivar de diversas formas e sempre explicam a visão da empresa de modo a salientar o valor das pessoas às quais se dirigem. Isso torna o trabalho importante para elas. Os líderes também costumam envolvê-las nas decisões quanto ao modo como concretizar a visão da empresa - ou o aspecto dela que for mais significativo para determinado indivíduo. Isso dá às pessoas um senso de controle.

Segundo Katzenbach (2002), equipes de trabalho com alto desempenho são aquelas compostas por funcionários cujo compromisso emocional os capacitem a produzir ou fornecer bens e serviços, representando uma vantagem competitiva

${ }^{3}$ LEVY-LEBOYER. A crise das motivações. São Paulo: Atlas, 1994. 
sustentável para seu empregador. Defende que a energização das pessoas aumentam seu desempenho.

Energizar pessoas visando ao desempenho eleva significativamente o nível de atuação, atingindo o ponto em que muitos funcionários vão além das expectativas dos líderes, da responsabilidade individual, dos resultados financeiros e dos objetivos de curto prazo do mercado. (KATZENBACH, 2002, p. 15).

Ainda conforme Katzenbach (2002, p. 17 - 18), a diferença mais notável entre a equipe de trabalho com maior desempenho e a normal é o nível de energia e compromisso emocional que os funcionários apresentam. "O que gera toda essa energia? É obvio que ela deve vir, em última instância, das próprias pessoas, quando ocorre algo que envolve suas emoções".

Compromisso emocional, energia e desempenho são termos que se relacionam e compõem o conceito de Comprometimento Organizacional sob o ponto de vista de Dessler (2003):

[...] o comprometimento organizacional provém de um elo emocional ou intelectual que une o indivíduo à organização. O comprometimento implica aceitação das metas e da direção da organização, desejo intenso de participar e concordância tácita em rejeitar outras opções de investimento. O comprometimento aparece em várias formas, cada uma das quais com corolários diferentes para o relacionamento entre indivíduos e organização. (DESSLER, 2003, p. 38).

Robbins (2002, p. 79) referiu-se à satisfação com o trabalho como a atitude geral de uma pessoa em relação ao que realiza. O envolvimento com o trabalho exprime o grau de identificação, a partir da sua participação ativa nele, considerando seu desempenho algo valioso. "Funcionários satisfeitos e comprometidos [...] apresentam índices mais baixos de rotatividade e absenteísmo". Muitas pessoas entendem, incorretamente, que a motivação é um traço pessoal, ou seja, alguns têm, outros não. "[...] a motivação é o resultado da interação do indivíduo com a situação. [...] Seu nível varia tanto entre os indivíduos como dentro de cada 
indivíduo, dentro de cada situação". Define motivação como o processo responsável pela intensidade, direção e persistência dos esforços de uma pessoa para o alcance de uma determinada meta.

\begin{abstract}
Os três elementos-chave em nossa definição são intensidade, direção e persistência. Intensidade refere-se a quanto esforço a pessoa despende. Este é o elemento a que mais nos referimos quando falamos de motivação. Contudo, a intensidade não é capaz de levar a resultados favoráveis, a menos que seja conduzida em uma direção que beneficie a organização. [...] Finalmente, a motivação tem uma dimensão de persistência. Esta é uma medida de quanto tempo uma pessoa consegue manter seu esforço. Os indivíduos motivados se mantêm na realização da tarefa até que seus objetivos sejam atendidos. (ROBBINS, 2002, p. 151-152).
\end{abstract}

\title{
2.3 QUALIDADE
}

Muitos significados têm sido atribuídos à palavra 'qualidade'. Uma das abordagens mais comuns refere-se àquela que identifica qualidade com conformidade a especificações e padrões. Dentro deste enfoque, a qualidade seria obtida através da produção sem defeitos. Outra abordagem bastante difundida é aquela que relaciona qualidade ao atendimento das necessidades do cliente. Quando se começou a falar em qualidade, restringia-se sua aplicação às empresas de produção de bens. Além disso, dentro destas empresas, a qualidade estava restrita à área industrial e, mais ainda, ao setor de controle da qualidade existente nesta área. Aos poucos, esta concepção foi mudando, e percebeu-se a importância de relacionar qualidade a todas as organizações e, dentro delas, a todas as áreas e a todas as pessoas.

Assim como liderança e motivação, qualidade é um tema bastante pesquisado e, portanto, polêmico, entendido sob diversos enfoques. 
Qualidade é uma palavra constante do dia-a-dia e desempenha papel importante em todos os aspectos. É o melhor que se pode fazer, padrão mais elevado de desempenho, em qualquer campo de atuação. A idéia de qualidade foi discutida primeiramente pelos filósofos gregos, que pensaram no ideal da excelência, ou aretê. Excelência é a característica que distingue alguma coisa pela superioridade em relação aos semelhantes e depende do contexto. (MAXIMIANO, 2005).

Na administração, o enfoque da qualidade nasceu para resolver, em primeiro lugar, o problema da uniformidade. Para os engenheiros e industriais do século XX, qualidade era sinônimo de uniformidade ou padronização, sendo necessário seu controle estatístico. A administração da qualidade passou por diversos estágios, até chegar à administração da qualidade total. Juran, Deming e Ishikawa são alguns dos principais pesquisadores integrantes da escola da qualidade. (MAXIMIANO, 2005).

Joseph Moses Juran é considerado o pai da qualidade e reconhecido como o autor que a ela acrescentou a dimensão humana, extravasando sua característica meramente estatística através da criação do conceito de Qualidade Total. Propôs que a qualidade fosse gerenciada pelo uso de três processos universais de gerenciamento: planejamento, controle e melhoramento, o que ficou conhecido como a Trilogia de Juran. A Qualidade passou a ser entendida como um esforço global para a contínua adequação da organização aos anseios do cliente externo, do trabalhador e da sociedade como um todo. A Qualidade Total vem sendo tratada sob diversos títulos: Total Quality Management (TQM), Total Quality Control (TQC), Company Wide Quality Control (CWQC), Total Quality Improvement (TQI). Todas essas variantes têm um objetivo em comum: clientes satisfeitos. (CARAVANTES; PANNO; KLOECKNER, 2005). 
W. Edwards Deming desenvolveu 14 pontos que descrevem o que é necessário para uma empresa sobreviver e ser competitiva, o que chamou de programa de melhoria contínua:

1. Criar e publicar os objetivos e propósitos da empresa quanto à melhoria do produto ou serviço. A alta direção deve demonstrar constantemente seu total apoio ao programa.

2. A alta administração e todas as pessoas devem aprender e adotar a nova filosofia.

3. Conhecer os propósitos da qualidade para melhorar os processos e reduzir custos.

4. Suspender a prática de fazer negócios apenas na base do preço.

5. Aperfeiçoar sempre e constantemente o sistema de produção e serviço.

6. Instituir treinamento no trabalho.

7. Ensinar e instituir liderança para conduzir as pessoas na produção.

8. Eliminar o medo de errar. Criar confiança e um clima para a inovação.

9. Incentivar grupos e equipes para alcançar os objetivos e propósitos da empresa.

10. Demolir as barreiras funcionais entre departamentos.

11. Eliminar exortações à produtividade sem que os métodos não tenham sido providenciados.

12. Remover as barreiras que impedem as pessoas de sentir orgulho em relação ao trabalho realizado.

13. Encorajar a educação e o auto-aperfeiçoamento de cada pessoa.

14. Garantir a ação necessária para acompanhar essa transformação. (CHIAVENATO, 2004a; CARAVANTES; PANNO; KLOECKNER, 2005). 
Para Juran, o gerenciamento da qualidade inclui muitos aspectos, tais como:

- Gerenciamento deve prover liderança que assegure que todos na organização sejam guiados pela qualidade e pela melhoria da qualidade;

- Gerenciamento da qualidade significa que a prioridade é dada aos desejos, preferências e necessidades dos clientes e usuários;

- Gerência deve tomar os cuidados necessários para a auto-educação e autodesenvolvimento a fim de capacitá-los a assumir a liderança do programa de melhoria da qualidade através de toda a empresa. (MAXIMIANO, 2005).

Kaoru Ishikawa teve participação essencial no desenvolvimento da qualidade no Japão. Foi um dos criadores dos chamados CCQs - Círculos de Controle da Qualidade. Propôs o diagrama "Espinha-de-Peixe" como uma ferramenta gráfica a ser utilizada pela Administração para o Gerenciamento e o Controle da Qualidade (CQ) em processos diversos. (CARAVANTES; PANNO; KLOECKNER, 2005).

Para Mezomo (2001, p. 73), qualidade é "um conjunto de propriedades de um serviço (produto) que o tornam adequado à missão de uma organização (empresa) concebida como resposta às necessidades e legítimas expectativas de seus clientes".

Relacionados à qualidade em sua dimensão prática, os conceitos de eficiência e eficácia são utilizados para avaliação de resultados no contexto das organizações. Todas as pessoas que administram organizações, de qualquer dimensão, são responsáveis pela realização de objetivos e pela forma como os recursos são utilizados. Eficiência e eficácia são os principais critérios para medir e avaliar o desempenho das organizações e também de seus administradores.

Eficiência é um princípio de administração de recursos, mais que uma simples medida de desempenho. O princípio geral da eficiência é o da relação entre 
esforço e resultado: quanto menor o esforço necessário para produzir um resultado, mais eficiente é o processo. A antítese da eficiência é o desperdício. Já eficácia é o conceito de desempenho que se relaciona com os objetivos e resultados. Eficácia significa: grau de coincidência dos resultados em relação aos objetivos; capacidade de um sistema, processo, produto ou serviço na resolução de problemas; fazer as coisas certas; sobrevivência. (MAXIMIANO, 2000).

\subsection{GESTÃO DE PESSOAS NA ENFERMAGEM}

No Brasil, o setor saúde vem buscando propostas inovadoras para seus modelos de assistência e de gestão. Embora avanços quanto à descentralização e constituição do Sistema Único de Saúde são percebidos, os serviços de saúde vêm enfrentando uma crise de governabilidade, de eficiência e resolutividade. Os dirigentes vêm apontando o desafio de gerar compromisso, participação e "adesão" dos seus funcionários a um projeto que aumente a responsabilidade institucional

para com seus resultados e produza mudanças na organização e na assistência. (AZEVEDO, 2002).

A característica que diferencia o hospital do contexto das empresas de serviço é a natureza do seu trabalho. O trabalho dirigido a aliviar o sofrimento e a preservar a saúde e a vida é difícil de ser contextualizado como área de negócio ou indústria para os cidadãos, políticos e profissionais do setor saúde. No entanto, a necessidade de profissionalizar a gestão dos hospitais tem dado origem a modelos e disciplinas que fazem desequilibrar a concepção da organização hospitalar. O 
hospital é uma empresa social [atende às necessidades e às expectativas da sociedade], porquanto suas ações se orientam para o cumprimento de objetivos fixados nas políticas públicas de saúde de um país, na medida em que produz serviços que respondam com efetividade às necessidades e às demandas sociais. É uma empresa de produção de serviços a indivíduos e comunidades. (OPAS, 2004).

O trabalho em saúde implica uma relação direta entre o recurso humano e a população. Nesta relação, o conhecimento científico e técnico que possui o profissional deveria permitir-lhe atuar como intérprete das necessidades de saúde da comunidade. Este caráter de intérprete exige ao recurso humano uma adequada preparação para desempenhar uma complexa intermediação que, se é cumprida adequadamente, projeta seu desejo na formulação de qualquer proposta de ação e mudança que se apresente. Já não é possível pensar em saúde ou em formas modernas de gerência hospitalar que não considerem a necessária participação e ação de seus recursos humanos. (OPAS, 2004, p. 249).

Para Marx e Morita (2003), o principal aspecto que difere uma organização hospitalar de outros segmentos empresariais é o seu capital humano, constituído de "pessoas preocupadas em cuidar de outras pessoas", pautando sua razão em existir a serviços destas pessoas.

Nesse contexto, cabe aos profissionais de Enfermagem contribuir, através de assistência sistematizada e segura, para reconduzir o paciente/cliente à recuperação de sua saúde e reintegração à sociedade, em condições de retomar na medida do possível, as funções que desempenhava anteriormente. (MARX; MORITA, 2003, p. 2).

Conforme Daniel (1987, p. 17), a Enfermagem pode ser considerada, primeiramente, "um serviço de assistência, que visa o indivíduo no seu conjunto bio psico - sócio - espiritual, no sentido de manutenção da saúde, tratamento e reabilitação da doença".

Segundo Waldow (2001), a finalidade do cuidar na enfermagem é prioritariamente aliviar o sofrimento humano, manter a dignidade e facilitar os meios para manejar com as crises e com as experiências do viver e do morrer. 
Em relação ao termo cuidados de Enfermagem, acredita-se como mais adequada a expressão cuidados de pacientes. Se o primeiro centra-se na Enfermagem, o outro refere o cuidar do paciente (o cliente). Esse cuidar do remete à idéia (concretizada na prática) de controle, exercício sobre algo (paciente, coisa). Pensa-se que o cuidar é para o paciente. Cuida-se $O$ paciente, com o paciente, quando possível. (WALDOW, 2001, p. 128-129).

"Que sentido tem a equipe de saúde quando UM (Enfermeiro) dos membros procura fazer tudo por todos (da equipe) e TODOS não se propõem a fazer alguma coisa por UM?"; são questões propostas por Santos e Figueiredo (2004, p. 101) visando a um repensar das práticas de enfermagem.

[...] com tanto sofrimento, quem deseja fazer enfermagem? Há que se resgatar a dignidade de um trabalho digno, sobretudo porque é destinado ao cuidar do ser humano. [...] Há que se instituir uma enfermagem dialógica, interativa, transacional e, portanto, solidária, na qual seus profissionais utilizam seus órgãos dos sentidos, sua intelectualidade, emoções e intuição [...]. Para fazer esta enfermagem exige-se ao menos o cuidado de si em termos de sua saúde integral visando não só ao poder profissional, social e econômico, mas a qualidade do atendimento do cliente, lembrando que esta só será alcançada se houver satisfação para cliente e profissional. (SANTOS; FIGUEIREDO, 2004, p. 102).

Trevizan (1993, p. 44) já expressava que o grande desafio é proporcionar a integração dos membros da equipe de enfermagem "aos serviços necessários aos pacientes, de forma que o envolvimento, a participação e o comprometimento estejam presentes nas atitudes e nas ações de todos". Para a autora, este desafio também expressa o sentido da expectativa de comportamento do enfermeiro-líder.

Significa uma busca constante do enfermeiro para que todos estejam dispostos a se envolver e se comprometer com propósitos relacionados à excelência do trabalho - o esforço comum para alcançar o melhor em termos de assistência de enfermagem é resultante da participação pessoal estimulada pelo enfermeiro, provocando em todos o interesse pelo sucesso do serviço. Estou falando em acepção ideal, mas acredito que é necessário pensar e tentar buscar o melhor para, em seguida, fundamentar planos, ações etc. sobre uma conciliação do ideal imaginado com o real adequado e possível. (TREVIZAN, 1993, p. 44).

No que concerne à Enfermagem, a perspectiva é que liderança se refere a um processo por meio do qual uma pessoa, que é o enfermeiro, influencia as ações do processo de trabalho de toda a equipe de enfermagem, da qual ele é o líder e 
membro ativo. É ele quem coordena e gerencia todo o processo de assistência a ser desenvolvido em relação ao paciente e tudo o que o envolve no contexto da instituição hospitalar. O paciente e suas especificidades, suas necessidades, sua alta ou recuperação, constituem a principal razão da assistência de enfermagem. Esta deve ser realizada eficientemente, com comprometimento de quem a desenvolve, garantindo qualidade do cuidado prestado e, principalmente, a satisfação do paciente e seus familiares.

São muitos os fatores que influenciam o exercício de liderança pelo enfermeiro. Entre eles, destaca-se o desafio de encorajar, estimular a equipe de enfermagem a ver a necessidade de motivar-se a prestar o cuidado de forma eficaz e com qualidade. O enfermeiro, líder por essência, deve ser o entusiasmador de ações que visam ao envolvimento de toda a equipe, para a realização do conjunto de ações de enfermagem.

"Cabe ao enfermeiro a responsabilidade de liderar o grupo com vistas ao alcance dos objetivos assistenciais e promover a boa integração da equipe de enfermagem com os demais elementos da equipe de saúde". (CARNEIRO, 1986, p. $67)$.

A importância de se desenvolver enfermeiros líderes é cada vez mais evidente, considerando os campos e formas de atuação destes profissionais. Liderar a equipe de enfermagem é função essencial ao desenvolvimento pleno de suas ações, assistenciais ou administrativas.

Repensar a liderança diante de um pensamento crítico - criativo contextualizado é emergente em nossa práxis atual. Assim, buscar estratégias conciliando os objetivos organizacionais com os do grupo de enfermagem na busca da melhoria da qualidade da assistência de enfermagem é um caminho. (PROCHNOW et al., 2003, p. 322). 
Com as mudanças na prestação de serviços e no padrão de comportamento da sociedade, o cidadão comum passa a exigir qualidade ao consumir serviços e produtos, deixando de agir de forma passiva e condescendente. Ao profissional de enfermagem é solicitada uma atitude de reflexão acerca do seu comportamento diante dos desafios que a prática diária impõe, o que tende a promover uma mudança de seus paradigmas e, possivelmente, evolução da profissão.

Estratégias que estimulam o despertar da motivação nos membros da equipe de enfermagem devem ser estudadas e implementadas de modo a gerar um círculo virtuoso, que se ajusta à satisfação / recuperação do paciente. O empenho de todos os membros da equipe pode desencadear todo um processo determinante da qualidade da assistência. (DONNER; WHEELER, 2004).

Entre papéis de liderança para a criação de um clima de trabalho motivador, Marquis e Huston (2002) listaram: reconhecer cada funcionário como um indivíduo único, motivado por diferentes fatores; encorajar os funcionários a 'dar o máximo de si' num esforço para promover o autocrescimento e a auto-realização; elaborar uma filosofia na unidade de trabalho que reconheça o valor único de cada funcionário.

Teixeira et al. (2006) entendeu que os profissionais de enfermagem devem desenvolver ações de saúde com conhecimento, habilidade e competência, objetivando atender às expectativas dos clientes e alcançar a almejada qualidade assistencial.

Segundo Kurcgant (2005), os objetos de trabalho do enfermeiro no processo de trabalho gerencial são os recursos humanos de enfermagem e a organização do trabalho. Para a execução deste processo, cabe ao enfermeiro utilizar um conjunto de instrumentos técnicos próprios da gerência, ou seja, o planejamento, o dimensionamento de pessoal de enfermagem, o recrutamento e seleção de pessoal, a educação continuada e/ou permanente, a supervisão, a avaliação de desempenho 
e outros. Também são utilizados outros meios ou instrumentos como a força de trabalho, os materiais, equipamentos e instalações, além dos diferentes saberes administrativos.

Adami (2000) destacou os instrumentos que um serviço de Enfermagem dispõe para gestão da qualidade, subdividindo-os em internos e externos. Entre os internos aponta as seguintes comissões: avaliação interna da qualidade, constituída de elementos da equipe multidisciplinar; auditoria de enfermagem; prevenção e controle de infecções hospitalares; ética em pesquisa; gerenciamento de riscos; prevenção interna de acidentes; serviços de educação continuada; atendimento ao cliente. Cita a acreditação hospitalar como um instrumento externo, preconizada por órgãos governamentais, considerando-a uma prática relevante para a gestão da qualidade que vem sendo gradativamente empregada nas instituições de saúde.

Conforme Cadah (2000), os trabalhos realizados em termos de avaliação da assistência têm privilegiado a ótica do enfermeiro e, na realidade brasileira, pouco tem se publicado sobre a percepção do paciente em relação a esta avaliação. Defende que, embora os pacientes sejam a razão da existência do serviço de saúde, raras vezes lhes é favorecida a oportunidade de opinar em relação ao mesmo. A administração para a qualidade necessita buscar o perfil da clientela e a identificação de suas expectativas e necessidades. 


\section{OBJETIVOS DO ESTUDO}

\subsection{OBJETIVO GERAL}

Avaliar as contribuições das pesquisas produzidas pela enfermagem brasileira acerca das temáticas liderança, motivação e qualidade na assistência de Enfermagem em instituições hospitalares, tomando por base artigos publicados em periódicos nacionais.

\subsection{OBJETIVOS ESPECÍFICOS}

1 - Caracterizar as pesquisas produzidas pelos enfermeiros brasileiros sobre liderança, motivação e qualidade na assistência de enfermagem quanto aos dados dos estudos, de seus autores e suas publicações.

2 - Identificar estratégias relativas à liderança, motivação e qualidade que podem ser utilizadas pelo enfermeiro, visando à realização, pela equipe, de ações comprometidas com a assistência de enfermagem. 


\section{PROCEDIMENTO METODOLÓGICO}

Os estudos publicados que compõem a amostra foram analisados conforme os pressupostos de Ganong (1987), que, por sua vez, baseou - se nas proposições de Jackson (1980) e Cooper (1982).

A Revisão Integrativa da Literatura é definida como um instrumento de obtenção, identificação, análise e síntese da literatura direcionada a um tema específico, por meio do qual conclusões de estudos anteriormente conduzidos são sumarizadas, a fim de que se formulem inferências sobre um tópico específico. A sua realização consiste na possibilidade do oferecimento de subsídios para a implementação de modificações que promovam a qualidade das condutas assistenciais de enfermagem por meio de modelos de pesquisa. Permite construir a análise ampla da literatura, abordando, inclusive, discussões sobre os métodos e resultados das publicações. (GANONG, 1987).

Jackson (1980) esclarece que o método de "revisões integrativas da literatura" envolve seis passos, quais sejam:

1. Estabelecimento do problema da revisão

2. Seleção da amostra

3. Categorização dos estudos

4. Análise dos resultados

5. Apresentação e discussão dos resultados

6. Apresentação da revisão 


\subsection{ESTABELECIMENTO DO PROBLEMA DA REVISÃO}

Nesta etapa são formuladas as hipóteses ou questões para a revisão. Segundo Ganong (1987), o problema deve ser estabelecido com a mesma clareza e especificidade que a hipótese de uma pesquisa primária. A construção da questão de pesquisa deve estar relacionada a um raciocínio teórico e deve basear-se em definições já apreendidas pelo pesquisador.

A presente revisão pretende responder à seguinte questão:

- Dentre as contribuições das pesquisas produzidas pela enfermagem brasileira divulgadas em periódicos nacionais, tendo em vista o contexto hospitalar, são apontadas estratégias relativas à liderança, motivação e qualidade que promovam a assistência de enfermagem?

\subsection{SELEÇÃO DA AMOSTRA}

Nesta etapa, os critérios de inclusão/exclusão de artigos são estabelecidos e são selecionadas as pesquisas que serão revisadas.

Conforme Ganong (1987), a amostra é um indicador crítico de como conclusões amplas podem ser generalizadas e que tipo de confiança ela produz. A omissão de procedimentos pode ser a principal ameaça para a validade da revisão.

Para tanto, a utilização de "index", listas de referências, bibliotecas - padrão, como também índices de citação, é recomendada para orientar a seleção das 
pesquisas que irão compor a amostra. Os critérios de amostragem devem ser claros e necessitam garantir a representatividade da amostra sob pena de interferir na validade do estudo. Ganong (1987) indica que a melhor amostragem seria a inclusão de todos os estudos encontrados, ou a seleção randomizada dos mesmos, ou caso as duas possibilidades não sejam possíveis, os critérios de inclusão / exclusão dos artigos devem ser claramente expostos e discutidos. Estes mesmos critérios poderão sofrer reorganização durante o processo de busca dos artigos, tendo em vista que na medida em que avança o procedimento metodológico pode-se fazer necessária uma redefinição destes critérios e até mesmo do problema, face aos artigos encontrados na literatura.

A avaliação da adequação de metodologia não deve ser utilizada como um critério de inclusão, pois esta exigência seria um problema se o pesquisador excluísse quase todos os estudos encontrados com metodologia inadequada. (JACKSON, 1980).

Para identificar os trabalhos publicados sobre liderança, motivação e qualidade na assistência de enfermagem foi realizada uma busca nas bases de dados LILACS e BDENF do sítio da Biblioteca Virtual em Saúde (BVS) disponibilizada através da BIREME - Centro Latino Americano e do Caribe de Informação em Ciências da Saúde (centro especializado da Organização Pan Americana de Saúde - OPAS). Como biblioteca, a BVS é uma coleção descentralizada e dinâmica de fontes de informação que tem como objetivo o acesso eqüitativo ao conhecimento científico em saúde. Distingue-se do conjunto de fontes de informação disponíveis na Internet por obedecer a critérios de seleção e controle de qualidade. Constitui-se em um espaço comum entre usuários, intermediários e produtores de informação. 


\subsubsection{Bases de dados utilizadas}

A Literatura Latino-Americana e do Caribe em Ciências da Saúde (LILACS) é uma base de dados cooperativa da Rede BVS que compreende a literatura relativa às ciências da saúde, publicada nos países da América Latina e Caribe, a partir de 1982.

A Base de Dados de Enfermagem (BDENF) é área especializada, fonte de informação composta por referências bibliográficas da literatura técnico-científica brasileira em Enfermagem. Sua operação, manutenção e atualização são coordenadas pela Escola de Enfermagem da UFMG e Centros Cooperantes REDE BVS ENFERMAGEM.

Por serem as bases de dados mais conhecidas na América Latina e por reunirem os trabalhos de pesquisa em enfermagem dos países que a englobam, foram utilizadas tendo em vista o objetivo de caracterizar a produção científica brasileira sobre as temáticas liderança, motivação e qualidade da assistência.

Foram utilizados os seguintes campos de busca na interface gráfica das bases de dados:

a) Descritores de assunto: 'enfermagem' e/ou 'assistência de enfermagem', acrescidos dos termos 'liderança', 'motivação' e 'qualidade', através de suas categorias (Decs).

b) Tipo de literatura: somente publicações em periódicos.

c) País, ano de publicação: Brasil. 


\subsubsection{Período de tempo}

Foram considerados trabalhos publicados em periódicos nacionais, indexados nas bases de dados LILACS e BDENF até o ano de 2006. A busca por período não foi delimitada, considerando o objetivo da revisão em apresentar o que já foi produzido sobre as categorias temáticas do modo mais completo possível.

\subsubsection{Localização de publicações e aquisição dos artigos}

A busca dos periódicos e a aquisição dos artigos foram realizadas nas seguintes unidades / instituições:

- Biblioteca "Wanda de Aguiar Horta", da Escola de Enfermagem da Universidade de São Paulo.

- Biblioteca da Universidade Federal de São Paulo, Escola Paulista de Medicina.

- BVS - Biblioteca Virtual em Saúde / BIREME - Centro Latino-Americano e do Caribe de Informação em Ciências da Saúde.

- Núcleo de Apoio Bibliográfico da Escola de Enfermagem de Ribeirão Preto da Universidade de São Paulo. 


\subsubsection{População}

Foram encontrados na base de dados LILACS 42 artigos sobre liderança, 12 sobre motivação e sete sobre qualidade. $\mathrm{Na}$ base de dados BDENF foram encontrados 68 artigos sobre liderança, 25 sobre motivação e 14 sobre qualidade.

Como alguns trabalhos repetiram-se em ambas as bases, a população do estudo ficou constituída por 61 artigos sobre Liderança, 22 artigos sobre Motivação e 13 artigos sobre Qualidade, ao todo 96 artigos.

Somente um artigo citado pela base de dados não foi fisicamente localizado, uma vez que houve uma falha em seu processo de indexação, ou seja, dados insuficientes para a busca das informações.

A partir de então foi realizada a leitura do conjunto de artigos que constituiu a população do estudo, permitindo assim a identificação de seus objetivos/objetos e, em seguida, o estabelecimento dos critérios de exclusão e inclusão para composição da amostra.

\subsubsection{Composição da amostra}

Para responder às questões da presente revisão integrativa se fez necessária a delimitação da situação/ambiente dos fenômenos estudados: a assistência de enfermagem prestada aos pacientes atendidos em instituições hospitalares. 
Foram excluídos da amostra os artigos que apresentaram pesquisas cujos objetivos ou objetos estudados, assim como população/amostras estudadas, não se relacionavam, essencialmente, com a temática 'enfermagem' e/ou 'assistência de enfermagem' em um contexto hospitalar.

Além destes, os estudos de natureza teórica, tais como artigos de revisão de literatura (revisões bibliográficas), reflexões, ensaios e editoriais foram também excluídos por não apresentarem uma investigação. Por conta do caráter conceitual e, por vezes, subjetivo de seus conteúdos, a identificação e análise da contribuição direta de tais estudos tornam-se complexas.

Tais estudos são de suma importância para a consolidação do conhecimento em suas bases fundamentais. Entretanto, considerando o objetivo dessa revisão integrativa, a tarefa de captar em um artigo científico o que o autor de uma revisão bibliográfica, por exemplo, infere ou conclui a respeito de uma determinada temática, constitui algo complexo e particular, podendo tal ação ser traduzida como um possível viés e, portanto, indesejável.

Desta forma, entre os estudos/artigos que foram identificados como relacionados às categorias temáticas - liderança (LID), motivação (MOT) e qualidade (QUA) - foram destacados somente aqueles que apresentaram pesquisas de natureza descritiva - exploratória para compor a amostra da revisão integrativa. Seus autores propuseram-se a estudar e descrever determinado fenômeno, atribuindo um caráter objetivo às suas pesquisas permitindo, assim, caracterizá-las de forma a identificar o conhecimento produzido a partir das mesmas, tornando possível o alcance dos objetivos desta pesquisa.

A amostra foi então composta por 31 estudos, subdivididos nas categorias temáticas supracitadas. Para facilitar o processo de organização e leitura dos 
trabalhos e para coleta de dados, os artigos foram listados por ordem alfabética a partir do sobrenome do primeiro autor, conforme foram citados pelas bases de dados (Apêndice A).

Dentre estes, três artigos foram encontrados em mais de uma categoria temática por terem sido indexados com a utilização conjunta dos termos 'liderança e motivação' ou 'liderança e qualidade' como descritores de assunto (Decs). Mesmo assim, foram mantidos na amostra e analisados sob o aspecto individual de cada categoria, buscando-se a informação desejada conforme os objetivos já referidos. Para facilitar a análise, tais artigos receberam a seguinte identificação:

\begin{tabular}{|l|c|}
\hline \multicolumn{1}{|c|}{ ARTIGo } & ESTUDOS \\
\hline $\begin{array}{l}\text { 1. ANTUNES, A. V. Liderança para a qualidade na enfermagem. Nursing, Säo } \\
\text { Paulo, v. 2, n. 15, p. 22-26, ago. 1999. }\end{array}$ & 1 - LID \\
\hline $\begin{array}{l}\text { 16. LUIZ, M. V. A enfermagem e o conhecimento dos conceitos de liderança, } \\
\text { motivação, comunicação e mudança. Acta Paul. Enfermagem, v. 2, n. 4, p. 111- } \\
\text { 22, dez. 1989. }\end{array}$ & 16 - LID \\
\hline $\begin{array}{l}\text { 25. SANTOS, S. R.; RODRIGUES FILHO, J. Enfermagem: fatores de satisfação. } \\
\text { Rev. Bras. Enfermagem, v. 48, n. 3, p. 242-50, jul./set. 1995. }\end{array}$ & 25 - LID \\
\hline
\end{tabular}

Quadro 2. Indicação dos artigos que se repetem nas bases de dados. Fonte: Elaborado pela autora (2007).

Sendo assim, de forma sintética, foram critérios de composição da amostra:

- Artigos indexados nas bases de dados LILACS e BDENF, até o ano de 2006, a partir da integração das categorias de descritores Enfermagem, Assistência de Enfermagem, liderança, motivação e qualidade.

- Estudos que apresentam uma pesquisa de natureza descritiva, diretamente relacionada com a temática 'enfermagem' e/ou 'assistência de enfermagem' em um contexto hospitalar. 


\subsection{CATEGORIZAÇÃO DOS ESTUDOS}

Nesta etapa são representadas as características dos estudos e seus achados, a partir da definição das informações a serem extraídas dos artigos selecionados. Segundo Ganong (1987), a essência da revisão integrativa é a categorização dos estudos. Esta etapa consiste na tarefa de definir quais serão as características ou informações que serão coletadas dos estudos.

Para extrair os dados dos artigos selecionados faz-se necessário um instrumento que permita avaliar separadamente cada artigo, para possibilitar a síntese dos artigos.

Segundo Ganong (1987), a representação das características da pesquisa pode ser feita através de construção de tabelas, que permitem apresentar uma quantidade expressiva de dados, facilitando a avaliação sistemática, discussão de achados importantes e conclusões.

A coleta de dados do presente estudo foi feita através de um instrumento confeccionado pela própria pesquisadora (Apêndice 2), submetendo-o, primeiramente, a um pré-teste a fim de adequá-lo aos propósitos da pesquisa, utilizando para esse fim 15 artigos (50\% da amostra). Após o pré-teste, o roteiro foi revisto e adaptado às alterações necessárias, visando à coleta dos dados mais pertinentes ao estudo.

Os dados extraídos dos estudos foram categorizados em três grandes conjuntos (liderança, motivação e qualidade) e, posteriormente, em subcategorias conforme objeto/objetivo estudado, o que permitiu uma melhor compreensão dos achados e o alcance dos objetivos do presente estudo. 


\begin{tabular}{|c|c|c|c|}
\hline $\begin{array}{l}\text { CATEGORIAS } \\
\text { TEMÁTICAS }\end{array}$ & \multicolumn{2}{|c|}{ SUBCATEGORIAS } & ARTIGOS \\
\hline \multirow{4}{*}{ LIDERANÇA } & \multicolumn{2}{|c|}{ GERÊNCIA E LIDERANÇA } & 1-LID, 4, 13, 17, 23 \\
\hline & \multirow{2}{*}{$\begin{array}{c}\text { ESTILOS / MODELOS DE } \\
\text { LIDERANÇA }\end{array}$} & GRID GERENCIAL & $10,11,29$ \\
\hline & & LIDERANÇA SITUACIONAL & $6,7,8,9,14,30,31$ \\
\hline & \multicolumn{2}{|c|}{ SIGNIFICADOS E PERCEPÇÕES DE LIDERANÇA } & $\begin{array}{c}5,12,15,16-\text { LID, } 24, \\
25-\text { LID }, 27,28\end{array}$ \\
\hline \multirow{3}{*}{ MOTIVAÇÃO } & \multicolumn{2}{|c|}{ SATISFAÇÃO E MOTIVAÇÃO } & $2,18,25-\mathrm{MOT}$ \\
\hline & \multicolumn{2}{|c|}{ SIGNIFICADOS E PERCEPÇÕES DE MOTIVAÇÃO } & 16-MOT, 22 \\
\hline & \multicolumn{2}{|c|}{ FATORES E PERFIS MOTIVACIONAIS } & 20,21 \\
\hline \multirow{3}{*}{ QUALIDADE } & \multicolumn{2}{|c|}{ GERENCIAMENTO DA QUALIDADE } & 1-QUA, 3 \\
\hline & \multicolumn{2}{|c|}{ SATISFAÇÃO NO TRABALHO } & 19 \\
\hline & \multicolumn{2}{|c|}{ QUALIDADE SOB A ÓTICA DOS PACIENTES } & 26 \\
\hline
\end{tabular}

Quadro 3: Categorias e subcategorias dos dados para análise dos resultados. Fonte: Elaborado pela autora (2007).

\subsection{ANÁLISE DOS RESULTADOS}

Nesta etapa os achados são analisados a partir dos critérios de inclusão, os estudos são lidos e os formulários são utilizados para coletar os dados.

Conforme Ganong (1987), o pesquisador deve informar claramente a maneira como os estudos serão avaliados, e pode fazê-lo listando variáveis, escolhendo estudos válidos e descartando os outros, analisando estatisticamente os resultados dos estudos ou pela determinação de médias. Qualquer que seja a abordagem escolhida, a critério do pesquisador, este deve garantir que a análise sistemática dos artigos ocorra, buscando explicações para as variáveis ou características apresentadas pelos artigos incluídos na revisão.

Ganong (1987) ainda ressaltou que o critério para a revisão integrativa deve seguir padrões rigorosos de análise, que incluem: usar métodos para assegurar o alcance dos objetivos; realizar análises minuciosas; examinar a teoria adotada; estabelecer relações com os resultados, métodos, sujeitos e variáveis do estudo, a 
fim de proporcionar ao leitor informações sobre os estudos revisados, sem focalizar apenas os resultados, apresentando o máximo de informações possíveis.

O processo de análise dos estudos deu-se a partir da confecção de quadros, seguindo a sugestão de Ganong (1987), que foram integrados à discussão do presente trabalho.

\subsection{APRESENTAÇÃO E DISCUSSÃO DOS RESULTADOS}

Nesta etapa, os resultados são interpretados, e deve-se discuti-los estabelecendo relações com outras teorias, dando sugestões para futuras pesquisas. Os dados obtidos dos artigos são discutidos e sintetizados de forma explícita sob regras claras. Para tópicos amplamente estudados, é possível aprofundar a discussão ou, ao levantar as lacunas de conhecimento existentes, sugerir caminhos para futuros estudos.

No presente trabalho, a síntese dos dados extraídos dos artigos foi apresentada de forma descritiva, reunida ao conhecimento produzido sobre os temas investigados. Os resultados subdividiram-se em:

- Dados referentes às publicações;

- Dados referentes aos pesquisadores;

- Dados referentes às pesquisas;

- Contribuições das pesquisas. 


\subsection{APRESENTAÇÃO DA REVISÃO}

Nesta fase deve-se comunicar e publicar a revisão, tornando acessíveis os procedimentos adotados, possibilitando a indicação de ameaças que comprometam a validade dos achados.

O rigor no detalhamento das etapas, critérios e procedimentos permitirão ao leitor um exame crítico dos achados, uma avaliação da fidedignidade e confiabilidade da revisão integrativa relativa ao tópico estudado.

Segundo Ganong (1987), o propósito da revisão integrativa não é atingido com revisões baseadas em metodologias questionáveis ou não claras, uma vez que propõe sintetizar as evidências das pesquisas primárias contribuindo para a identificação de lacunas e pontos fracos. 
5 APRESENTAÇÃO E DISCUSSÃO DOS RESULTADOS

\subsection{DADOS REFERENTES ÀS PUBLICAÇÕES}

São apresentadas abaixo as informações acerca dos periódicos que integraram a amostra através de seus estudos - nome do periódico, cidade e ano em que o estudo foi publicado.

Tabela 1 - Freqüência e porcentagem de estudos sobre liderança, motivação e qualidade identificados nos periódicos nacionais indexados na LILACS e BDENF até o ano de 2006, segundo o nome do periódico, Ribeirão Preto, 2007.

\begin{tabular}{lccc}
\hline NOME DO PERIÓDICO & $\mathbf{f}$ & \% \\
\hline Revista Latino - Americana de Enfermagem & 10 & $33 \%$ \\
Revista Brasileira de Enfermagem & 5 & $17 \%$ \\
Acta Paulista de Enfermagem & 3 & $11 \%$ \\
Revista da Escola de Enfermagem da USP & 2 & $6 \%$ \\
Revista Paulista de Enfermagem & 2 & $6 \%$ \\
Nursing & 1 & $3 \%$ \\
O Mundo da Saúde & 2 & $6 \%$ \\
Revista de Enfermagem da UERJ & 2 & $6 \%$ \\
Revista Gaúcha de Enfermagem & 2 & $6 \%$ \\
Online Brazilian Journal of Nursing & 1 & $3 \%$ \\
Ciência, Cuidado e Saúde & 1 & $3 \%$ \\
TOTAL & $\mathbf{3 1}$ & $\mathbf{1 0 0 \%}$ \\
\hline
\end{tabular}

Fonte: Dados coletados pela autora (2007).

A Tabela 1 demonstra que os artigos que compõem a amostra foram publicados em 11 periódicos, sendo que o mais se destacou foi a Revista Latino Americana de Enfermagem, da Escola de Enfermagem de Ribeirão Preto da Universidade de São Paulo. 
Tabela 2 - Freqüência e porcentagem de estudos sobre liderança, motivação e qualidade identificados nos periódicos nacionais indexados na LILACS e BDENF até o ano de 2006, segundo o local de publicação do periódico, Ribeirão Preto, 2007.

\begin{tabular}{lccc}
\hline CIDADE & $\mathbf{f}$ & \% \\
\hline São Paulo - SP & 10 & $33 \%$ \\
Ribeirão Preto - SP & 10 & $33 \%$ \\
Brasília - DF & 5 & $16 \%$ \\
Rio de Janeiro - RJ & 2 & $6 \%$ \\
Porto Alegre - RS & 2 & $6 \%$ \\
Goiânia - GO & 1 & $3 \%$ \\
Maringá - PR & 1 & $3 \%$ \\
TOTAL & $\mathbf{3 1}$ & $\mathbf{1 0 0 \%}$ \\
\hline
\end{tabular}

Fonte: Dados coletados pela autora (2007).

A Tabela 2 mostra a distribuição dos periódicos conforme a cidade em que foram publicados. Destaca-se a cidade de São Paulo-SP, uma vez que dos 11 periódicos, cinco (45\%) são nela publicados.

Tabela 3 - Freqüência e porcentagem de estudos sobre liderança, motivação e qualidade identificados nos periódicos nacionais indexados na LILACS e BDENF até o ano de 2006, segundo o ano de publicação do periódico, Ribeirão Preto, 2007.

\begin{tabular}{|c|c|c|}
\hline ANO & $f$ & $\%$ \\
\hline 1985 & 1 & $3 \%$ \\
\hline 1989 & 1 & $3 \%$ \\
\hline 1991 & 2 & $6 \%$ \\
\hline 1993 & 1 & $3 \%$ \\
\hline 1995 & 2 & $6 \%$ \\
\hline 1996 & 2 & $6 \%$ \\
\hline 1997 & 4 & $14 \%$ \\
\hline 1998 & 1 & $3 \%$ \\
\hline 1999 & 2 & $6 \%$ \\
\hline 2000 & 4 & $14 \%$ \\
\hline 2001 & 3 & $11 \%$ \\
\hline 2002 & 1 & $3 \%$ \\
\hline 2003 & 3 & $10 \%$ \\
\hline 2004 & 2 & $6 \%$ \\
\hline 2005 & 2 & $6 \%$ \\
\hline TOTAL & 31 & $100 \%$ \\
\hline
\end{tabular}

Fonte: Dados coletados pela autora (2007). 
Em relação ao ano em que foram publicados, não houve discrepância significativa entre os períodos, o que não permitiu relacioná-los a algum possível evento ou mudança na área àquela época.

Tabela 4 - Freqüência e porcentagem de estudos sobre liderança, motivação e qualidade identificados nos periódicos nacionais indexados na LILACS e BDENF até o ano de 2006, segundo a base de dados em que foi localizado o artigo, Ribeirão Preto, 2007.

\begin{tabular}{lcc}
\hline BASES DE DADOS & f & \% \\
\hline SOMENTE BDENF & 7 & $23 \%$ \\
SOMENTE LILACS & 3 & $10 \%$ \\
BDENF E LILACS & 21 & $67 \%$ \\
TOTAL & $\mathbf{3 1}$ & $\mathbf{1 0 0 \%}$ \\
\hline
\end{tabular}

Fonte: Dados coletados pela autora (2007).

A indexação dos artigos em ambas as bases (67\%) demonstra uma preocupação da BVS em disponibilizar os artigos de forma a viabilizar o acesso à literatura da América Latina e do Caribe e da área de Enfermagem.

\subsection{DADOS REFERENTES AOS PESQUISADORES}

Apresentamos dados referentes ao primeiro autor dos artigos da amostra.

Tabela 5 - Freqüência e porcentagem de estudos sobre liderança, motivação e qualidade identificados nos periódicos nacionais indexados na LILACS e BDENF até o ano de 2006, segundo a titulação/formação acadêmica do primeiro autor dos estudos, Ribeirão Preto, 2007.

\begin{tabular}{|c|c|c|}
\hline TITULAÇÃO/FORMAÇÃO ACADÊMICA (1 ${ }^{\circ}$ autor) & $\mathbf{f}$ & $\%$ \\
\hline Discente & 1 & $3 \%$ \\
\hline Doutor & 8 & $26 \%$ \\
\hline Doutoranda & 4 & $13 \%$ \\
\hline Mestranda & 3 & $10 \%$ \\
\hline Mestre & 5 & $16 \%$ \\
\hline Mestre e Doutor & 1 & $3 \%$ \\
\hline Mestre e Livre Docente & 1 & $3 \%$ \\
\hline Não especificado & 8 & $26 \%$ \\
\hline TOTAL & 31 & $100 \%$ \\
\hline
\end{tabular}

Fonte: Dados coletados pela autora (2007). 
Quase 30\% dos autores não indicaram sua titulação. Entre os que identificaram, a maioria (26\%) eram doutores à época de realização do estudo, embora não indicaram se também já eram mestres, sendo que apenas um assim o fez.

Tabela 6 - Freqüência e porcentagem de estudos sobre liderança, motivação e qualidade identificados nos periódicos nacionais indexados na LILACS e BDENF até o ano de 2006, segundo a profissão do primeiro autor dos estudos, Ribeirão Preto, 2007.

\begin{tabular}{lccc}
\hline PROFISSÃO (1 $\mathbf{1}^{\circ}$ autor) & $\mathbf{f}$ & \multicolumn{1}{c}{$\%$} \\
\hline Enfermeiro & 8 & $26 \%$ \\
Docente & 7 & $23 \%$ \\
Enfermeiro e docente & 10 & $32 \%$ \\
Não especificado & 6 & $19 \%$ \\
TOTAL & 31 & $\mathbf{1 0 0 \%}$ \\
\hline
\end{tabular}

Fonte: Dados coletados pela autora (2007).

Alguns autores identificaram-se apenas como enfermeiros (26\%), o que não permite inferir se também são docentes, embora aqueles que lecionam o conteúdo relativo à área são enfermeiros. Dos que informaram acerca de seu exercício profissional, 32\% identificaram-se como enfermeiros e docentes.

Tabela 7 - Freqüência e porcentagem de estudos sobre liderança, motivação e qualidade identificados nos periódicos nacionais indexados na LILACS e BDENF até o ano de 2006, segundo o local de atuação do primeiro autor dos estudos, Ribeirão Preto, 2007.

\begin{tabular}{lccc}
\hline LOCAL DE ATUAÇÃO (10 autor) & $\mathbf{f}$ & $\mathbf{\%}$ \\
\hline Instituição de ensino & 16 & $52 \%$ \\
Instituição de saúde & 6 & $19 \%$ \\
Ambas & 5 & $16 \%$ \\
Não especificado & 4 & $13 \%$ \\
TOTAL & $\mathbf{3 1}$ & $\mathbf{1 0 0 \%}$ \\
\hline
\end{tabular}

Fonte: Dados coletados pela autora (2007).

Os enfermeiros atuantes à época da realização do estudo informaram estar vinculados a instituições de ensino (52\%) e, na sua maioria, universidades, como mostra a tabela a seguir: 
Tabela 8 - Freqüência e porcentagem de estudos sobre liderança, motivação e qualidade identificados nos periódicos nacionais indexados na LILACS e BDENF até o ano de 2006, segundo a instituição de ensino onde atuava o primeiro autor dos estudos, Ribeirão Preto, 2007.

\begin{tabular}{llcc}
\hline INSTITUIÇÃO DE ENSINO (1º autor) & f & $\%$ \\
\hline Escola de Enfermagem da Universidade de São Paulo, São Paulo - SP & & 1 & $5 \%$ \\
Escola de Enfermagem de Ribeirão Preto da Universidade de São Paulo, & 7 & $32 \%$ \\
Ribeirão Preto - SP & & \\
Faculdade Adventista de Enfermagem, São Paulo - SP & 1 & $5 \%$ \\
Universidade Estadual de Maringá, Maringá - PR & 1 & $5 \%$ \\
Universidade Estadual do Ceará, Fortaleza - CE & 2 & $9 \%$ \\
Universidade Estadual do Rio de Janeiro, Rio de Janeiro - RJ & 1 & $5 \%$ \\
Universidade Federal da Paraíba, João Pessoa - PB & 1 & $5 \%$ \\
Universidade Federal de São Paulo, São Paulo & 1 & $5 \%$ \\
Universidade Federal de Uberlândia, Uberlândia - MG & 2 & $9 \%$ \\
Universidade Federal do Rio Grande do Sul, Porto Alegre - RS & 1 & $5 \%$ \\
Universidade Federal do Triângulo Mineiro, Uberaba - MG & 2 & $\mathbf{1 0 \%}$ \\
SENAC Marília - SP & 1 & $\mathbf{5 \%}$ \\
TOTAL & $\mathbf{2 1}$ & $\mathbf{1 0 0 \%}$ \\
\hline
\end{tabular}

Fonte: Dados coletados pela autora (2007).

Tabela 9. Freqüência e porcentagem de estudos sobre liderança, motivação e qualidade identificados nos periódicos nacionais indexados na LILACS e BDENF até o ano de 2006, segundo o local de pós - graduação do primeiro autor dos estudos, Ribeirão Preto, 2007.

\begin{tabular}{lccc}
\hline LOCAL DA PÓS - GRADUAÇÃO (1º autor) & f & \% \\
\hline Faculdade de Ciências da Saúde São Camilo, São Paulo - SP & 1 & $3 \%$ \\
Escola de Enfermagem de Ribeirão Preto da Universidade de São Paulo, & 11 & $35 \%$ \\
Ribeirão Preto - SP & 19 & $62 \%$ \\
Não especificado & $\mathbf{3 1}$ & $\mathbf{1 0 0 \%}$ \\
TOTAL & &
\end{tabular}

Fonte: Dados coletados pela autora (2007).

Dentre os autores vinculados a instituições de ensino, sete (32\%) atuavam na Escola de Enfermagem de Ribeirão Preto da Universidade de São Paulo à época da realização do estudo, local onde também cursaram pós - graduação, como mostram as Tabelas 8 e 9, acima apresentadas. 


\subsection{DADOS REFERENTES ÀS PESQUISAS}

Os estudos apresentados através dos artigos foram analisados quanto à cidade em que se localizava a instituição hospitalar pesquisada, quanto à sua natureza e suas respectivas unidades. Posteriormente, foram analisados quanto ao tipo de pesquisa realizada e quanto ao instrumento de coleta de dados utilizado.

Tabela 10 - Freqüência e porcentagem de estudos sobre liderança, motivação e qualidade identificados nos periódicos nacionais indexados na LILACS e BDENF até o ano de 2006, segundo a cidade onde se desenvolveu o estudo, Ribeirão Preto, 2007.

\begin{tabular}{lccc}
\hline CIDADE LOCAL DO ESTUDO & $\mathbf{f}$ & & \% \\
\hline Fortaleza - CE & 2 & $6 \%$ \\
João Pessoa - PB & 2 & $6 \%$ \\
Porto Alegre - RS & 1 & $3 \%$ \\
Ribeirão Preto - SP & 8 & $28 \%$ \\
Rio de Janeiro - RJ & 2 & $6 \%$ \\
São José do Rio Preto - SP & 2 & $6 \%$ \\
São Paulo - SP & 1 & $3 \%$ \\
Uberlândia - MG & 2 & $6 \%$ \\
Não especificado & 11 & $36 \%$ \\
TOTAL & 31 & $\mathbf{1 0 0 \%}$ \\
\hline
\end{tabular}

Fonte: Dados coletados pela autora (2007).

Entre os estudos que especificaram a cidade em que foram desenvolvidos, oito (28\%) localizaram-se em Ribeirão Preto - SP. O Estado de São Paulo destacase como aquele que mais sediou os estudos desta amostra, se considerarmos a cidade de São José do Rio Preto e a capital, São Paulo.

Tabela 11 - Freqüência e porcentagem de estudos sobre liderança, motivação e qualidade identificados nos periódicos nacionais indexados na LILACS e BDENF até o ano de 2006, segundo a natureza da instituição local dos estudos, Ribeirão Preto, 2007.

\begin{tabular}{lccc}
\hline NATUREZA INSTITUIÇÃO & $\mathbf{f}$ & \% \\
\hline Públicos & 15 & $48 \%$ \\
Privados & 4 & $13 \%$ \\
Públicos e privados & 7 & $23 \%$ \\
Não especificado & 5 & $16 \%$ \\
TOTAL & $\mathbf{3 1}$ & $\mathbf{1 0 0 \%}$ \\
\hline
\end{tabular}

Fonte: Dados coletados pela autora (2007). 
As instituições hospitalares de caráter público foram as mais utilizadas como campo de estudo (48\%). Sete estudos (23\%) desenvolveram-se tanto em instituições públicas como privadas.

Tabela 12 - Freqüência e porcentagem de estudos sobre liderança, motivação e qualidade identificados nos periódicos nacionais indexados na LILACS e BDENF até o ano de 2006, segundo a unidade hospitalar local do estudo, Ribeirão Preto, 2007.

\begin{tabular}{lcc}
\hline UNIDADE HOSPITALAR LOCAL DO ESTUDO & $\mathbf{f}$ & $\%$ \\
\hline Centro Cirúrgico & 1 & $3 \%$ \\
Sala de Trauma de Unidade de Emergência & 1 & $3 \%$ \\
Unidade de Emergência & 2 & $6 \%$ \\
Unidade de Internação de Clínica Médico - Cirúrgica & 7 & $23 \%$ \\
Ambulatório & 1 & $3 \%$ \\
Unidade de Terapia Intensiva & 3 & $10 \%$ \\
Não especificado & 16 & $52 \%$ \\
TOTAL & 31 & $\mathbf{1 0 0 \%}$ \\
\hline
\end{tabular}

Fonte: Dados coletados pela autora (2007).

A unidade de internação de clínica médico-cirúrgica destacou-se como o local da instituição onde o maior número de estudos foi realizado (23\%). Tal dado pode sugerir que é neste tipo de unidade onde as questões que envolvem aspectos relativos à liderança e à qualidade da assistência foram mais vivenciadas pelo grupo de pesquisadores.

Tabela 13 - Freqüência e porcentagem de estudos sobre liderança, motivação e qualidade identificados nos periódicos nacionais indexados na LILACS e BDENF até o ano de 2006, segundo o tipo de pesquisa desenvolvida, Ribeirão Preto, 2007.

\begin{tabular}{lcc}
\hline TIPO DE PESQUISA & $\mathbf{f}$ & $\mathbf{\%}$ \\
\hline Quantitativa & 3 & $7 \%$ \\
Qualitativa & 1 & $3 \%$ \\
Quanti - qualitativa & 1 & $3 \%$ \\
Experimental & 1 & $3 \%$ \\
Não - experimental & 1 & $3 \%$ \\
Quase - experimental & 1 & $3 \%$ \\
Descritivo & 2 & $5 \%$ \\
Exploratório & 3 & $7 \%$ \\
Descritivo - exploratório & $3 \%$ \\
Não especificado & 3 & $7 \%$ \\
TOTAL & 24 & $59 \%$ \\
\hline
\end{tabular}

Fonte: Dados coletados pela autora (2007). 
Quanto ao tipo de pesquisa, é importante destacar que quase $60 \%$ dos artigos não apresentavam a informação acerca do tipo de pesquisa realizada, o que pode ser devido à não-exigência pelo corpo editorial do periódico, à época do estudo. Entre aqueles que especificaram, destacam-se as de natureza descritiva e exploratória. Foram totalizados 40 estudos porque seis destes especificaram mais de uma característica, como por exemplo, natureza descritiva e abordagem qualitativa.

Tabela 14 - Freqüência e porcentagem de estudos sobre liderança, motivação e qualidade identificados nos periódicos nacionais indexados na LILACS e BDENF no período de 1985 a 2006, segundo o instrumento de coleta de dados utilizado nos estudos, Ribeirão Preto, 2007.

\begin{tabular}{lccc}
\hline INSTRUMENTO DE COLETA DE DADOS & f & & \% \\
\cline { 2 - 3 } Duas escalas tipo Likert (Inventário MOSE e ACTRA) e um questionário & 1 & $3 \%$ \\
Entrevista & 10 & $33 \%$ \\
Formulário e observação & 1 & $3 \%$ \\
Instrumento - Grid \& Liderança em Enfermagem: comportamento ideal, de Trevizan & 1 & $3 \%$ \\
(1993) & 2 & $7 \%$ \\
Instrumento - Integração de Maturidade e Estilo, Hersey \& Blanchard (1986) & 1 & $3 \%$ \\
Instrumento - LEAD (Descrição da Eficácia e de Adaptabilidade do Líder), Hersey \& & 1 & \\
Blanchard (1986) & 1 & $3 \%$ \\
Instrumento (Questionário) & 1 & $3 \%$ \\
Instrumento Grid \& Liderança em Enfermagem, Trevizan (1989) & 2 & $6 \%$ \\
Instrumento Integração de Maturidade e Estilo, Hersey, Blanchard e Keilty (Galvão, \\
1995) & 1 & $3 \%$ \\
Questionário e entrevista & 10 & $33 \%$ \\
Questionário & $\mathbf{3 1}$ & $\mathbf{1 0 0 \%}$ \\
TOTAL & &
\end{tabular}

Fonte: Dados coletados pela autora (2007).

Os questionários e entrevistas destacaram-se entre os instrumentos de coleta de dados mais utilizados, o que pode ser justificado pela natureza da maioria dos estudos realizados, descritivo-exploratória. 


\subsection{CONTRIBUIÇÕES DAS PESQUISAS}

\subsubsection{Categoria temática liderança}

\subsubsection{Subcategoria Gerência e Liderança}

\begin{tabular}{|c|c|}
\hline TÍTULO & Liderança para a Qualidade na Enfermagem. \\
\hline AUTOR (ES) & Arthur Velloso Antunes. \\
\hline PERIÓDICO & Nursing. São Paulo. \\
\hline ANO PUBLICAÇÃO & 1999. \\
\hline OBJETIVOS & $\begin{array}{l}\text { Analisar o gerenciamento da qualidade em um serviço de } \\
\text { enfermagem de uma instituição hospitalar. }\end{array}$ \\
\hline POPULAÇÃO ESTUDADA & $\begin{array}{l}70 \text { enfermeiros - } 01 \text { gerente de divisão, } 05 \text { chefes de setores, } 22 \\
\text { supervisores, e } 42 \text { assistenciais. }\end{array}$ \\
\hline AMOSTRA & 57 enfermeiros (81\%). \\
\hline $\begin{array}{l}\text { INSTRUMENTO COLETA DE } \\
\text { DADOS }\end{array}$ & Questionário. \\
\hline RESULTADOS/CONCLUSÕES & $\begin{array}{l}\text { Analisado gerenciamento sob a aplicação do Princípio } 7 \text { de } \\
\text { Deming (1990) - adotar e instituir liderança: } \\
\text { Princípio não utilizado adequadamente; supervisão ainda é } \\
\text { importante; funcionários expressam medo; há clima de cooperação } \\
\text { e participação; chefes são apoiadores e facilitadores com certa } \\
\text { freqüência; há a adoção do trabalho em equipe. } \\
\text { "A liderança é fundamental ao bom gerenciamento do serviço de } \\
\text { enfermagem e, consequentemente, à qualidade da assistência } \\
\text { prestada ao paciente". }\end{array}$ \\
\hline $\begin{array}{l}\text { RECOMENDAÇÕES PARA A } \\
\text { ENFERMAGEM }\end{array}$ & $\begin{array}{l}\text { “[...] é indispensável que o enfermeiro que atua como líder no } \\
\text { desempenho de suas atividades esteja capacitado para atuar } \\
\text { como um 'líder competente' nas diferentes situações profissionais". } \\
\text { Para o desenvolvimento e melhoria da qualidade da assistência } \\
\text { que presta ao paciente, Liderança deve ser tema presente nos } \\
\text { cursos de graduação e pós - graduação em Enfermagem, bem } \\
\text { como nos programas de capacitação das instituições de saúde. }\end{array}$ \\
\hline REFEREM-SE À MOTIVAÇÃO? & Não. Citam estímulo ao envolvimento, ao comprometimento. \\
\hline REFEREM-SE À QUALIDADE? & $\begin{array}{l}\text { Por todo o texto. Liderança como fundamento para o } \\
\text { gerenciamento da qualidade na Enfermagem. } \\
\text { Que o enfermeiro seja líder da qualidade da assistência de } \\
\text { enfermagem. }\end{array}$ \\
\hline
\end{tabular}

Quadro 4. Estudo 1-LID. Fonte: Dados analisados pela autora (2007). 


\begin{tabular}{|c|c|}
\hline TÍTULO & Atuação dos enfermeiros nos diferentes níveis gerenciais. \\
\hline AUTOR (ES) & Nalva Pereira Caldas, Iraci dos Santos. \\
\hline PERIÓDICO & Revista de Enfermagem da UERJ. Rio de Janeiro - RJ. \\
\hline ANO PUBLICAÇÃO & 1993 \\
\hline OBJETIVOS & $\begin{array}{l}\text { Geral: } \\
\text { Contribuir para o aperfeiçoamento do desempenho gerencial do } \\
\text { enfermeiro e dos programas de ensino da Administração Aplicada à } \\
\text { Enfermagem. } \\
\text { Específicos: } \\
1 \text { - Identificar o perfil do grupo de enfermeiros que no momento } \\
\text { desenvolve atividades gerenciais; } \\
2 \text { - Levantar a freqüência com que atividades são desenvolvidas pelo } \\
\text { grupo que está gerenciando a assistência de enfermagem; } \\
3 \text { - Verificar que agências educacionais estão preparando os } \\
\text { enfermeiros para suas funções; } \\
4 \text { - Diagnosticar o estilo gerencial adotado pelos enfermeiros em } \\
\text { confronto com as Teorias Comportamentais X e Y de McGregor; } \\
5 \text { - Colher subsídios para avaliação de programas de ensino de } \\
\text { Administração Aplicada à Enfermagem. }\end{array}$ \\
\hline POPULAÇÃO ESTUDADA & $\begin{array}{l}170 \text { enfermeiros que exercem funções administrativas em três } \\
\text { hospitais governamentais diferentes }(A, B \text { e } C) \text {. }\end{array}$ \\
\hline AMOSTRA & $\begin{array}{l}\text { "... amostra casual (?), constituída daqueles que atenderam a } \\
\text { solicitação para responderem o questionário". }\end{array}$ \\
\hline $\begin{array}{l}\text { INSTRUMENTO COLETA DE } \\
\text { DADOS }\end{array}$ & Questionário. \\
\hline RESULTADOS / CONCLUSÕES & $\begin{array}{l}1 \text { - Perfil do grupo: a maioria é constituída de chefes de unidade com } \\
\text { tempo de exercício de chefia de } 1 \text { a } 5 \text { anos, possuindo cursos de } \\
\text { especialização; o tempo de exercício profissional é mais de dez anos; } \\
\text { predomina o sexo feminino e a faixa etária está entre } 25 \text { e } 36 \text { anos. } \\
2 \text { - Freqüência das atividades: coordenação, controle, avaliação, } \\
\text { planejamento e de educação são as de maior freqüência. } \\
3 \text { - Agências e ocasiões de aprendizagem: curso de graduação. } \\
\text { Contribuição da pós - graduação é inexpressiva. } \\
4 \text { - Estilos gerenciais, baseados em McGregor: tendência para o estilo } \\
\text { gerencial Y, porém a ligação ao estilo gerencial X ainda se faz } \\
\text { presente. }\end{array}$ \\
\hline $\begin{array}{l}\text { RECOMENDAÇÕES PARA A } \\
\text { ENFERMAGEM }\end{array}$ & Não. \\
\hline REFEREM-SE À MOTIVAÇÃO? & $\begin{array}{l}\text { "... as pessoas podem ser automotivadas e autodirigidas.", da Teoria } Y \\
\text { de McGregor. }\end{array}$ \\
\hline REFEREM-SE À QUALIDADE? & $\begin{array}{l}\text { "A permanente escassez de pessoal de enfermagem coloca em } \\
\text { evidência a necessidade cada vez maior da atuação do enfermeiro } \\
\text { como agente multiplicador. Essa condição é alcançada através do } \\
\text { treinamento e da supervisão, garantindo assim a boa QUALIDADE da } \\
\text { assistência". }\end{array}$ \\
\hline
\end{tabular}

Quadro 5. Estudo 4. Fonte: Dados analisados pela autora (2007). 


\begin{tabular}{|c|c|}
\hline TítULO & $\begin{array}{l}\text { Clima organizacional: novos rumos no perfil do enfermeiro e } \\
\text { desafios a assistência de enfermagem. }\end{array}$ \\
\hline $\operatorname{AUTOR}(E S)$ & Ilse Maria Tigre de Arruda Leitão, Raquel Barreto de Arruda. \\
\hline PERIÓDICO & O Mundo da Saúde. São Paulo - SP. \\
\hline ANO PUBLICAÇÃO & 2004. \\
\hline OBJETIVOS & $\begin{array}{l}\text { Conhecer os sistemas de gerência do enfermeiro com relação aos } \\
\text { perfis organizacionais junto a seus processos de trabalho em um UTI } \\
\text { com base nos perfis organizacionais de Likert. } \\
\text { Enfocar a liderança do enfermeiro e o perfil organizacional baseado } \\
\text { na teoria de Likert, que defende a motivação e a participação como } \\
\text { principais ferramentas na administração. }\end{array}$ \\
\hline POPULAÇÃO ESTUDADA & $\begin{array}{l}\text { Enfermeiros de uma unidade de terapia intensiva coronariana de um } \\
\text { hospital de nível terciário do município de Fortaleza - CE. }\end{array}$ \\
\hline AMOSTRA & $\begin{array}{l}08 \text { enfermeiros assistenciais e } 01 \text { enfermeira chefe do serviço de } \\
\text { enfermagem da instituição. }\end{array}$ \\
\hline $\begin{array}{l}\text { INSTRUMENTO COLETA DE } \\
\text { DADOS }\end{array}$ & $\begin{array}{l}\text { Formulário baseado nos perfis organizacionais de Likert e } \\
\text { observação. }\end{array}$ \\
\hline RESULTADOS / CONCLUSÕES & 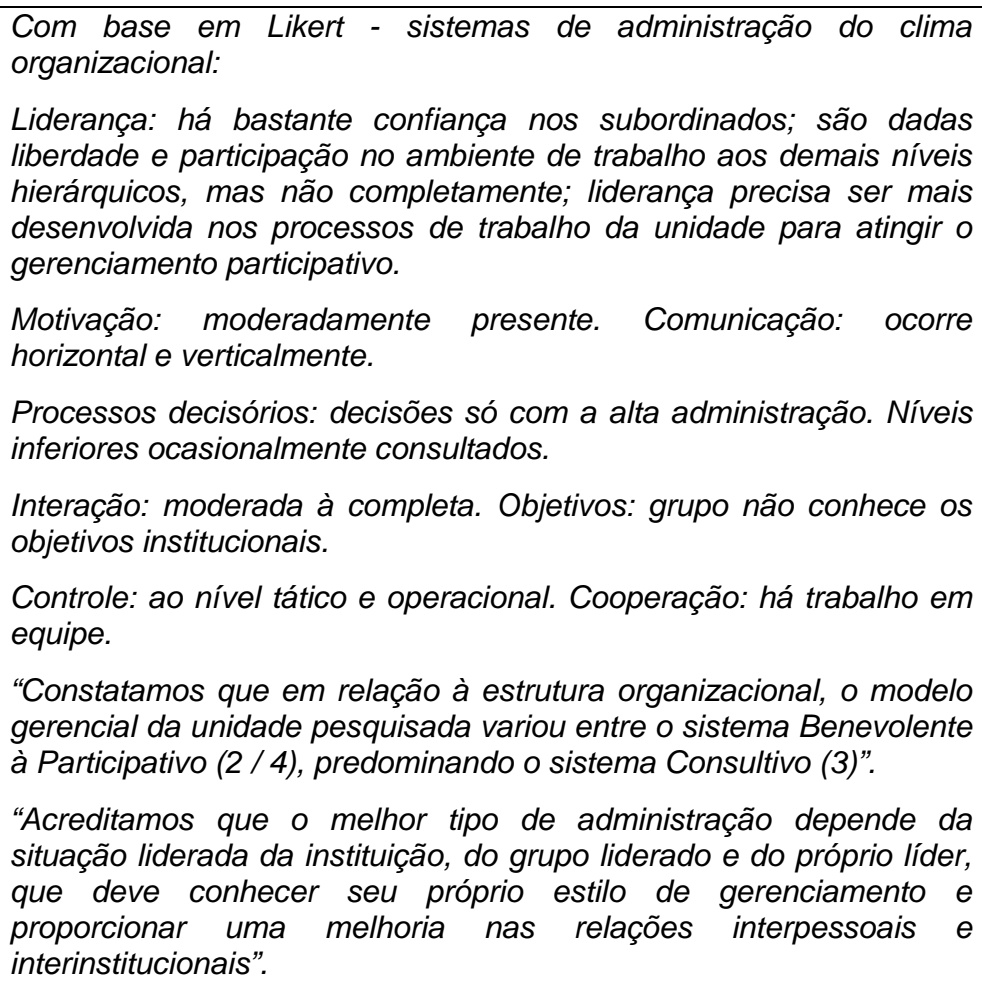 \\
\hline $\begin{array}{l}\text { RECOMENDAÇÕES PARA A } \\
\text { ENFERMAGEM }\end{array}$ & $\begin{array}{l}\text { "Percebemos o crescimento ascendente do gerente enfermeiro, } \\
\text { sabendo que o estudo e a vivência desta área ampliarão o } \\
\text { crescimento da profissão". }\end{array}$ \\
\hline REFEREM-SE À MOTIVAÇÃO? & $\begin{array}{l}\text { Como um dos sistemas de administração do clima organizacional, } \\
\text { com base em Likert. } \\
\text { Citando Bergamini (1994), “... o líder não pode dar motivação...”. }\end{array}$ \\
\hline REFEREM-SE À QUALIDADE? & $\begin{array}{l}\text { Citando Padilha (2001), “... falhas que podem comprometer a } \\
\text { qualidade e segurança desejada”. }\end{array}$ \\
\hline
\end{tabular}

Quadro 6. Estudo 13. Fonte: Dados analisados pela autora (2007). 


\begin{tabular}{|c|c|}
\hline TÍTULO & $\begin{array}{l}\text { O trabalho em equipe: instrumento básico e um desafio para a } \\
\text { enfermagem. }\end{array}$ \\
\hline$\overline{A U T O R}(E S)$ & Maria Clara Cassuli Matheus. \\
\hline PERIÓDICO & Revista da Escola de Enfermagem da USP. São Paulo - SP. \\
\hline ANO PUBLICAÇÃO & 1995. \\
\hline OBJETIVOS & $\begin{array}{l}\text { Conhecer como as enfermeiras caracterizam o trabalho em equipe. } \\
\text { Identificar como as enfermeiras vivenciam o trabalho em equipe. }\end{array}$ \\
\hline POPULAÇÃO ESTUDADA & $\begin{array}{l}16 \text { enfermeiras de unidade de internação de clínica médica ou } \\
\text { cirúrgica, de um hospital governamental na cidade de São Paulo - } \\
\text { SP. }\end{array}$ \\
\hline AMOSTRA & 10 enfermeiras. \\
\hline $\begin{array}{l}\text { INSTRUMENTO COLETA DE } \\
\text { DADOS }\end{array}$ & Questionário. \\
\hline RESULTADOS / CONCLUSÕES & $\begin{array}{l}\text { Quanto à caracterização: } \\
\text { "A maioria descreveu que, para haver trabalho em equipe, é } \\
\text { necessário que seus membros tenham objetivos comuns e que as } \\
\text { tarefas sejam divididas". } \\
\text { "[...] metade das enfermeiras que fizeram parte deste estudo leva em } \\
\text { consideração para caracterizar o trabalho em equipe aqueles } \\
\text { comportamentos dirigidos às relações pessoais". } \\
\text { Quanto à vivência: } \\
\text { "... dificuldades para o desenvolvimento do trabalho em equipe } \\
\text { quando se depende da equipe médica...". } \\
\text { "... equipe é unida". } \\
\text { “.. objetivo comum da equipe é o bem estar do paciente". } \\
\text { "... dificuldade do fluxo de informações entre os elementos da equipe } \\
\text { "... há divisão de tarefas". } \\
\text { o1 enfermeira disse "não se ver trabalhando em equipe". } \\
\text { Concluem que “... o conceito e características do trabalho em equipe } \\
\text { modificaram-se com o decorrer do tempo. [...] vivenciá-lo na prática, } \\
\text { como instrumento básico para o desenvolvimento das atividades de } \\
\text { enfermagem da forma como propõe Amaru (1986), ainda parece ser } \\
\text { um desafio". }\end{array}$ \\
\hline $\begin{array}{l}\text { RECOMENDAÇÕES PARA A } \\
\text { ENFERMAGEM }\end{array}$ & $\begin{array}{l}\text { "... buscar novos dados que possibilitem uma maior compreensão } \\
\text { das dificuldades de desenvolver o trabalho em equipe, } \\
\text { principalmente, aquelas relacionadas às relações interpessoais". }\end{array}$ \\
\hline REFEREM-SE À MOTIVAÇÃO? & $\begin{array}{l}\text { Citando Amaru (1986), “... uma equipe é definida quando a } \\
\text { organização, interação, MOTIVAÇÃO e percepção estão } \\
\text { simultaneamente presentes...”. Citando Megginson et al (1992), “... } \\
\text { dizem que a motivação é essencial...”. “... ambiente pode influenciar } \\
\text { [...] na motivação da equipe”. }\end{array}$ \\
\hline REFEREM-SE À QUALIDADE? & $\begin{array}{l}\text { "[...] Quando acontece este tipo de liderança - autocrática - a } \\
\text { QUALIDADE é menor...". } \\
\text { “... tarefa realizada pelo grupo conduzido por um líder democrático } \\
\text { pode ser menor, mas de QUALIDADE superior...”. }\end{array}$ \\
\hline
\end{tabular}

Quadro 7. Estudo 17. Fonte: Dados analisados pela autora (2007). 


\begin{tabular}{|c|c|}
\hline TÍTULO & $\begin{array}{l}\text { Estilos gerenciais dos enfermeiros na área de recuperação da } \\
\text { saúde. }\end{array}$ \\
\hline AUTOR (ES) & Iraci dos Santos. \\
\hline PERIÓDICO & Revista Brasileira de Enfermagem. Brasília - DF. \\
\hline ANO PUBLICAÇÃO & 1991. \\
\hline OBJETIVOS & $\begin{array}{l}\text { Identificar o estilo gerencial predominante adotado pelos enfermeiros } \\
\text { em auto - avaliação antes e após o ensino de Liderança, considerando } \\
\text { os aspectos do trabalho supervisor. } \\
\text { Analisar a evolução gerencial dos enfermeiros segundo sua percepção } \\
\text { anterior e posterior ao estudo da Liderança relativa aos estilos Grid. }\end{array}$ \\
\hline POPULAÇÃO ESTUDADA & Enfermeiros de dois hospitais universitários. \\
\hline AMOSTRA & $\begin{array}{l}38 \text { enfermeiros do Hospital A, como campo de pesquisa utilizado para } \\
\text { a testagem do instrumento de coleta de dados, e } 20 \text { enfermeiros do } \\
\text { Hospital } B \text {, como campo da aplicação da escala definitiva e do } \\
\text { Programa de Ensino. }\end{array}$ \\
\hline $\begin{array}{l}\text { INSTRUMENTO COLETA DE } \\
\text { DADOS }\end{array}$ & Questionário. \\
\hline RESULTADOS / CONCLUSÕES & $\begin{array}{l}\text { Foram avaliados quanto aos seguintes aspectos do trabalho: ação, } \\
\text { constatação de erros, abordagem do problema, e emoções. } \\
\text { O estilo gerencial } 9.9 \text { (participativo) foi predominantemente percebido } \\
\text { pelos enfermeiros na fase anterior à aplicação do programa de ensino } \\
\text { sobre Liderança, como seu estilo de adoção. } \\
\text { Após trabalhos de dinâmicas de grupo e grupos de discussão, } \\
\text { observou-se uma indefinição de estilos gerenciais correspondentes aos } \\
\text { aspectos do trabalho supervisor quais sejam: ação, constatação de } \\
\text { erros, abordagem do problema, e emoções. } \\
\text { "Concluiu-se que o ensino de Liderança proporcionou ao grupo } \\
\text { amostral, conhecimentos e experiências sobre a utilização dos vários } \\
\text { estilos gerenciais, levando-o a refletir sobre seu desempenho, } \\
\text { enquanto líder, mediante o estudo de situações relativas aos aspectos } \\
\text { do trabalho supervisor". }\end{array}$ \\
\hline $\begin{array}{l}\text { RECOMENDAÇÕES PARA A } \\
\text { ENFERMAGEM }\end{array}$ & $\begin{array}{l}\text { "Considerando a importância do estudo de liderança para a função } \\
\text { gerencial da enfermagem, sugere-se aos enfermeiros que incentivem a } \\
\text { abordagem deste assunto nos cursos de graduação e pós - graduação. } \\
\text { Haja vista a indefinição de estilos gerenciais constatada } \\
\text { posteriormente, sugere-se aos administradores de enfermagem que } \\
\text { averiguem as causas deste comportamento dos enfermeiros". }\end{array}$ \\
\hline REFEREM-SE À MOTIVAÇÃO? & Não. \\
\hline REFEREM-SE À QUALIDADE? & $\begin{array}{l}\text { “... para atingir o objetivo da supervisão, a melhoria da qualidade da } \\
\text { assistência de enfermagem, o supervisor, ao constatar erros no } \\
\text { trabalho da equipe de enfermagem, deverá tomar decisões relativas à } \\
\text { correção destes". }\end{array}$ \\
\hline
\end{tabular}

Quadro 8. Estudo 23. Fonte: Dados analisados pela autora (2007). 
Foram aqui reunidos os artigos que apresentaram esses temas como objeto de estudo comum a suas pesquisas. São os estudos 1-LID, 4, 13, 17 e 23.

No estudo 1-LID, Antunes (1999) apontou a liderança como recurso para atribuir qualidade à assistência de enfermagem, sugerindo que o enfermeiro pode liderar sua equipe com vistas a alcançar a excelência de sua prática. Enfocando os princípios de Deming (1990), defendeu que o enfermeiro deve ser líder da qualidade, ou seja, que ele deve exercer sua liderança para gerenciar a qualidade. Recomendou a capacitação do enfermeiro para ser líder, e líder competente, sugerindo que o tema liderança deve ser abordado nos cursos universitários e nos programas de capacitação das instituições de saúde. Entretanto, não foram apontadas maneiras possíveis de se promover tal capacitação, ou ainda da forma como liderança deveria ser abordada nos cursos de formação.

Caldas e Santos (1993) - estudo 4 - focalizaram as funções administrativas do enfermeiro gerente. Caracterizaram um grupo de enfermeiros, identificando a atuação destes nos variados níveis gerenciais. Entre os problemas discutidos estão a escassez de pessoal na enfermagem e a ocupação prematura pelo enfermeiro na função administrativa - isto é, sem experiência ou conhecimento anterior. As autoras recomendaram que o enfermeiro deveria atuar como agente multiplicador de conhecimento através de treinamento e supervisão de sua equipe com vistas a garantir a boa qualidade da assistência. Não se discutiu, contudo, como agir de forma a 'multiplicar' este conhecimento, como proporcionar e desenvolver treinamento ao enfermeiro para que ele seja agente desta ação.

No estudo 13, Leitão e Arruda (2004) buscaram conhecer os sistemas de gerência do enfermeiro com relação aos perfis organizacionais sob o enfoque de Likert (1995) e seus pressupostos. Justificaram seu trabalho afirmando que o 
enfermeiro gerente poderá desenvolver melhor sua liderança se conhecer seu próprio estilo e orientação, estudando e vivenciando o gerenciamento. Desta forma, recomendaram que o enfermeiro deve estudar e vivenciar gerenciamento e promover assim o crescimento da profissão, embora não sugerissem como tal estudo ou vivência poderia se desenvolver para alcançar tal objetivo.

No estudo 17, abordando a modalidade de trabalho em equipe como sendo um dos instrumentos básicos à gerência da assistência de enfermagem, Matheus (1995) defendeu que cabe à enfermeira a responsabilidade de adquirir conhecimentos e habilidades sobre o trabalho em equipe, principalmente com o objetivo de desenvolver - se e estimular os membros da equipe a também se desenvolverem, uma vez que é ela a responsável por planejar, coordenar e avaliar os cuidados prestados por estes profissionais. A autora ainda sugeriu a busca de dados para a compreensão das dificuldades referentes às relações interpessoais, não indicando, porém, como deveria ser realizada tal busca, ou ainda como aplicar as informações obtidas a partir de tais dados.

Santos (1991), no estudo 23, propôs-se a identificar o estilo gerencial adotado por enfermeiros antes e após uma intervenção de ensino sobre liderança. Justificou seu estudo afirmando que "a gerência do enfermeiro é função das mais complexas, considerando-se o fato de que ele deve fazer funcionar as pessoas que cuidam de outras pessoas em situações delicadas de vida e de morte".

De modo geral, os estudos que envolveram a temática gerência e liderança versaram sobre o desenvolvimento de enfermeiros gerentes e líderes para garantir a boa qualidade da assistência. Dentre as recomendações propostas por estes autores estavam a aplicação dos princípios de qualidade, treinamento e desenvolvimento da equipe de enfermagem, responsabilização do enfermeiro pelo 
seu desenvolvimento enquanto líder e profissional, buscando aquisição de conhecimento para seu aperfeiçoamento. Identifica-se, então, que para estes autores há uma relação determinante entre liderança e qualidade da assistência de enfermagem.

No que concerne à Enfermagem, a perspectiva é que liderança se refere a um processo por meio do qual uma pessoa, que é o enfermeiro, influencia as ações do processo de trabalho de toda a equipe de enfermagem, da qual ele é líder e membro ativo. É ele quem coordena e gerencia todo o processo de assistência a ser desenvolvido em relação ao paciente e tudo o que o envolve no contexto da instituição hospitalar. O paciente e suas especificidades, suas necessidades, sua alta ou recuperação, constituem a principal razão da assistência de enfermagem dentro deste contexto e, portanto, deve ser realizada eficientemente, com comprometimento de quem a desenvolve, garantindo qualidade da assistência prestada e, principalmente, a satisfação e atendimento das expectativas do paciente/cliente.

Se liderança é essencial ao desempenho do enfermeiro enquanto gerente da assistência, ele deve saber exercê-la de forma competente, considerando ser essa a sua maior responsabilidade.

Para Boog (1991, p. 15 - 16), competência é a qualidade de quem é capaz de apreciar e resolver certo assunto, fazer determinada coisa; significa capacidade, habilidade, aptidão e idoneidade. Já a competência gerencial refere-se ao conjunto de qualidades e características que os gerentes desenvolvem para atingir continuamente os resultados de uma empresa.

Mas, o que se deve esperar de um enfermeiro - líder - competente? Não seria redundante a expressão enfermeiro - líder? Não se trata de um substantivo composto, nem de um tipo ou classe de enfermeiro para que a hifenização seja 
necessária. É necessário desmistificar a liderança, como propõe Rozendo (2000, p. 75), quando apontou que liderança é um tema tratado "quase como um dogma, assumindo um caráter mistificado e retificado, o que contribui mais para a manutenção do status quo do que para o seu contrário".

A preocupação deve ser com o como aplicar princípios de qualidade à assistência de enfermagem, além de investigar a possibilidade em aplicá-los. É preciso pesquisar novas formas de gerenciar a assistência, liderando a equipe de enfermagem visando oferecer assistência de boa qualidade.

De que forma se desenvolveria uma capacitação para liderança? Como capacitar o enfermeiro para a liderança? Ao compreendermos que ser enfermeiro é ser gerente da assistência de enfermagem, liderança - enquanto comportamento parece tornar-se uma conseqüência natural dessa gerência. Talvez o desafio maior não seja liderar, e sim gerenciar. Ao gerenciar, o enfermeiro deve 'tomar as rédeas' que guiam a assistência, ou seja, planejá - la traçando estratégias que norteiam o alcance de sua finalidade. E este 'tomar as rédeas' da assistência resultará em um exercício natural de liderança. É necessário um olhar revisor e crítico sobre o que nós, enfermeiros, de fato estamos fazendo, para, em seguida, pensarmos sobre como podemos fazer melhor.

Conforme Rozendo (2000, p. 78) "as enfermeiras atuam, primordialmente, nas atividades administrativas e pouco se envolvem com a assistência direta".

Entendo que estas atividades administrativas dizem respeito a tudo aquilo que "faz funcionar" o serviço. Este "fazer funcionar" o serviço tem uma relação mais direta com as atividades próprias da gerência. Ou seja, parece-me que o que convencionamos chamar de liderança na realidade trata-se de gerência. $E$ isso faz alguma diferença? Faz sim, porque liderança e gerência são coisas distintas, embora sejam confundidas e estejam fortemente imbricadas no mundo do trabalho. [...] A liderança diz respeito mais a uma habilidade para influenciar e motivar pessoas a trabalharem em torno de convicções comuns. [...]. 
Rozendo (2000, p. 78) entendeu gerência como "um conjunto de técnicas e estratégias que levam ao funcionamento esperado de uma organização". Estratégias! Não seria o momento de revermos como estamos operacionalizando as possíveis soluções aos problemas que identificamos em nossa prática diária? Não deveríamos nos dedicar a pesquisar quais os melhores meios de realizarmos nossos objetivos? Promover uma assistência de qualidade não é um de nossos maiores objetivos, senão o maior? Basta o 'fazer' ou devemos 'fazer bem feito' o que nos é confiado?

A boa qualidade da assistência deve ser garantida através de treinamento e desenvolvimento da equipe de enfermagem. Mais uma vez, a preocupação deve ser com o como fazer isso: como treinar e desenvolver profissionais de enfermagem para uma assistência de boa qualidade? O que deve ser contemplado neste treinamento? A nosso ver, esta responsabilidade pode ser atribuída a um serviço estruturado de educação continuada.

Uma das maiores responsabilidades do enfermeiro é desenvolver sua própria liderança, é buscar conhecimento a respeito de seu estilo e orientação para liderar, sobre competências necessárias ao gerenciamento e liderança, sobre trabalho em equipe, para que possa assistir ao paciente de forma adequada e eficaz.

O gerenciar na Enfermagem fazendo "funcionar" as pessoas, sugerido por Santos (1991, p. 77), deixou implícito um estímulo à motivação. Coutinho; Souza e Ferreira (2002, p. 26) defenderam que "à medida que o enfermeiro e os membros de seu time se sintam motivados, vai existir um grau de envolvimento e comprometimento do grupo para que os objetivos, como um todo, possam ser atingidos". 


\subsubsection{Subcategoria Estilos / Modelos de Liderança}

\begin{tabular}{|c|c|}
\hline TÍTULO & $\begin{array}{l}\text { Enfermeiro cirúrgico: seu estilo de liderança com o pessoal auxiliar de } \\
\text { enfermagem. }\end{array}$ \\
\hline AUTOR (ES) & $\begin{array}{l}\text { Cristina Maria Galvão, Maria Auxiliadora Trevizan, Namie Okino Sawada, Isabel } \\
\text { Amélia Costa Mendes. }\end{array}$ \\
\hline PERIÓDICO & evista Gaúcha de Enfermagem. Porto Alegre - RS. \\
\hline LICAÇÃO & 997. \\
\hline OBJETIVOS & $\begin{array}{l}\text { Identificar e analisar a correspondência de opinião entre o enfermeiro e o pessoal } \\
\text { auxiliar de enfermagem sobre o estilo de liderança que o enfermeiro de unidade de } \\
\text { internação cirúrgica deveria adotar em relação ao nível de maturidade de um } \\
\text { elemento do pessoal auxiliar frente às seis categorias de atividades assistenciais } \\
\text { desenvolvidas na unidade (cuidados básicos, administração de medicamentos, } \\
\text { procedimentos invasivos, preparo do paciente cirúrgico no pré - operatório, } \\
\text { assistência ao paciente cirúrgico no encaminhamento para o Centro Cirúrgico, } \\
\text { assistência ao paciente cirúrgico no pós-operatório). }\end{array}$ \\
\hline $\begin{array}{l}\text { POP } \\
E S T L\end{array}$ & $\begin{array}{l}52 \text { profissionais de enfermagem atuantes em unidades de internação cirúrgica de dois } \\
\text { hospitais gerais, um público e um particular, da cidade de Ribeirão Preto - SP. }\end{array}$ \\
\hline AMOSTRA & $\begin{array}{l}52 \text { profissionais de enfermagem. Hospital público }(A): 13 \text { enfermeiros, } 02 \text { técnicos e } \\
11 \text { auxiliares de enfermagem. Hospital particular }(B): 13 \text { enfermeiros, } 04 \text { técnicos e } 09 \\
\text { auxiliares de enfermagem. }\end{array}$ \\
\hline $\begin{array}{l}\text { UMENTO } \\
\text { TA DE DADOS }\end{array}$ & $\begin{array}{l}\text { Questionário, baseado no instrumento Integração de Maturidade e Estilo, dos estudos } \\
\text { de Hersey \& Blanchard (1986). }\end{array}$ \\
\hline $\begin{array}{l}\text { RESULTADOS / } \\
\text { CONCLUSÕES }\end{array}$ & $\begin{array}{l}\text { A correspondência de opinião entre o enfermeiro e o auxiliar foi maior no hospital B } \\
\text { (61 pares) do que no hospital A (54 pares). } \\
\text { No hospital A e no hospital B houve predominância dos estilos de liderança E3 } \\
\text { (compartilhar) e E4 (delegar). } \\
\text { “... na maioria das vezes, os sujeitos apontaram os estilos de liderança compartilhar } \\
\text { (E3) e/ou delegar (E4), que são estilos participativos. Esses achados demonstraram } \\
\text { que o pessoal auxiliar pesquisado apresenta nível de maturidade moderado a alto } \\
\text { (M3) e/ou alto (M4)". } \\
\text { "O enfermeiro deverá utilizar o estilo E3 (compartilhar) com um elemento da equipe } \\
\text { de enfermagem com nível de maturidade moderado a alto (M3), e o estilo de } \\
\text { liderança E4 (delegar) com um elemento da equipe de enfermagem com nível de } \\
\text { maturidade alto (M4)". } \\
\text { "Assim, entendemos que o enfermeiro, além de compreender o processo de liderança } \\
\text { relativo a uma determinada situação, esse profissional precisa também conhecer e } \\
\text { conciliar o nível de maturidade do liderado com o estilo de liderança apropriado". }\end{array}$ \\
\hline $\begin{array}{l}\text { RECOMENDAÇÕES } \\
\text { PARA A } \\
\text { ENFERMAGEM }\end{array}$ & $\begin{array}{l}\text { "A nosso ver, o desenvolvimento da habilidade de liderar pelo enfermeiro consiste em } \\
\text { uma ESTRATÉGIA que este profissional poderá empregar na sua prática diária com o } \\
\text { intuito de promover mudanças, as quais possibilitem a melhoria da QUALIDADE da } \\
\text { assistência de enfermagem prestada ao paciente/cliente". } \\
\text { "Desta forma, acreditamos que a Liderança Situacional poderá ser utilizada como } \\
\text { estrutura teórica no que tange à habilidade de liderar do enfermeiro no contexto } \\
\text { hospitalar, sobretudo voltada para o gerenciamento da assistência e para o } \\
\text { desenvolvimento do potencial do pessoal de enfermagem". }\end{array}$ \\
\hline $\begin{array}{l}\text { REFEREM-SE À } \\
\text { MOTIVAÇÃO? }\end{array}$ & $\begin{array}{l}\text { Maturidade dos liderados (Hersey \& Blanchard, 1986) - dimensão psicológica, } \\
\text { relacionada com a disposição ou MOTIVAÇÃO para realizar alguma coisa. }\end{array}$ \\
\hline $\begin{array}{l}\text { REFEREM-SE À } \\
\text { QUALIDADE? }\end{array}$ & $\begin{array}{l}\text { "...] mudanças que possibilitem a melhoria da QUALIDADE da assistência de } \\
\text { enfermagem prestada ao paciente/cliente". }\end{array}$ \\
\hline
\end{tabular}

Quadro 9. Estudo 6. Fonte: Dados analisados pela autora (2007). 


\begin{tabular}{|c|c|}
\hline TÍTULO & $\begin{array}{l}\text { Liderança e comunicação: estratégias essenciais para o } \\
\text { gerenciamento da assistência de enfermagem no contexto } \\
\text { hospitalar. }\end{array}$ \\
\hline AUTOR (ES) & $\begin{array}{l}\text { Cristina Maria Galvão, Namie Okino Sawada, Adélia Paula de Castro, } \\
\text { Fabiana Corniani. }\end{array}$ \\
\hline PERIÓDICO & Revista Latino Americana de Enfermagem. Ribeirão Preto-SP. \\
\hline ANO PUBLICAÇÃO & 2000. \\
\hline OBJETIVOS & $\begin{array}{l}\text { Relatar a elaboração, implementação e avaliação de um programa de } \\
\text { Educação Continuada sobre liderança e comunicação realizado com } \\
\text { enfermeiros de um hospital privado; } \\
\text { Apresentar a aplicação da Liderança Situacional desenvolvida pelos } \\
\text { participantes do programa de Educação Continuada. }\end{array}$ \\
\hline POPULAÇÃO ESTUDADA & 32 enfermeiros. \\
\hline AMOSTRA & $\begin{array}{l}24 \text { enfermeiros responderam o instrumento sobre a aplicação da } \\
\text { liderança situacional. }\end{array}$ \\
\hline $\begin{array}{l}\text { INSTRUMENTO COLETA DE } \\
\text { DADOS }\end{array}$ & Questionário. \\
\hline RESULTADOS / CONCLUSÕES & $\begin{array}{l}\text { Contribuições do programa: "... melhoria do desempenho em liderança } \\
\text { através da comunicação; reflexões sobre a forma de liderar e } \\
\text { comunicar-se com a equipe de enfermagem; utilização da liderança e } \\
\text { comunicação para promover mudanças com vistas à melhoria da } \\
\text { assistência de enfermagem, do relacionamento com os liderados e } \\
\text { incrementar o potencial pessoal e profissional da equipe de } \\
\text { enfermagem". } \\
\text { Analisados através da Técnica de Incidentes Críticos, agrupados em } \\
\text { categorias: } \\
\text { Situações (09), Comportamentos (12) e Conseqüências (06). } \\
\text { Profissionais empregaram estilos de liderança mais diretivos, ou seja, o } \\
\text { determinar (E1) ou persuadir (E2). } \\
\text { "Frente ao exposto, podemos afirmar que a Liderança Situacional pode } \\
\text { ser utilizada como embasamento teórico para fundamentar a habilidade } \\
\text { de liderar do enfermeiro no contexto hospitalar com vistas à melhoria } \\
\text { da QUALIDADE da assistência prestada ao paciente/cliente e } \\
\text { possibilitar o desenvolvimento do potencial da equipe de enfermagem". } \\
\text { "Assim, entendemos que a liderança e a comunicação são estratégias } \\
\text { que possibilitam ao enfermeiro implementar as mudanças requeridas". }\end{array}$ \\
\hline $\begin{array}{l}\text { RECOMENDAÇÕES PARA A } \\
\text { ENFERMAGEM }\end{array}$ & $\begin{array}{l}\text { "... acreditamos que os programas de Educação Continuada devem } \\
\text { capacitar o indivíduo para enfrentar mudanças levando em } \\
\text { consideração as necessidades dos profissionais que atuam na } \\
\text { enfermagem e os propósitos da organização". } \\
\text { "... investimentos na capacitação para o exercício de liderança são } \\
\text { fundamentais para que o profissional enfermeiro tente viabilizar } \\
\text { mudanças na sua prática diária, de modo compartilhado com o grupo } \\
\text { com o qual trabalha em conjunto, desenvolvendo neste habilidades } \\
\text { para o exercício da liderança situacional e promovendo maior } \\
\text { maturidade nos liderados a fim de compartilharem decisões relativas à } \\
\text { prática profissional". }\end{array}$ \\
\hline REFEREM-SE À MOTIVAÇÃO? & “... o líder terá que enfrentar um problema motivacional...". \\
\hline REFEREM-SE À QUALIDADE? & $\begin{array}{l}\text { "... buscando meios que possibilitem a melhoria da qualidade da } \\
\text { assistência de enfermagem". } \\
\text { "... a comunicação como um recurso para o sucesso da liderança [...] } \\
\text { buscando a melhoria da qualidade da assistência prestada". } \\
\text { "... as transformações com vistas à melhoria da QUALIDADE da } \\
\text { assistência de enfermagem prestada ao paciente/cliente". }\end{array}$ \\
\hline
\end{tabular}

Quadro 10: Estudo 7. Fonte: Dados analisados pela autora (2007). 


\begin{tabular}{|c|c|}
\hline TÍTULO & $\begin{array}{l}\text { Liderança situacional: estrutura de referência para o trabalho do } \\
\text { enfermeiro - líder no contexto hospitalar. }\end{array}$ \\
\hline AUTOR (ES) & $\begin{array}{l}\text { Cristina Maria Galvão, Maria Auxiliadora Trevizan, Namie Okino } \\
\text { Sawada, José Augusto Dela Coleta. }\end{array}$ \\
\hline PERIÓDICO & Revista Latino Americana de Enfermagem. Ribeirão Preto - SP. \\
\hline ANO PUBLICAÇÃO & 1998. \\
\hline OBJETIVOS & $\begin{array}{l}\text { Identificar e analisar os comportamentos dos enfermeiros de unidade } \\
\text { de internação cirúrgica, segundo relato do pessoal auxiliar, com vistas } \\
\text { à possível utilização da Liderança Situacional como estrutura de } \\
\text { referência para o trabalho do enfermeiro - líder no contexto hospitalar. }\end{array}$ \\
\hline POPULAÇÃO ESTUDADA & $\begin{array}{l}\text { Técnicos e auxiliares de enfermagem atuantes nas unidades de } \\
\text { internação cirúrgica de dois hospitais gerais da cidade de Ribeirão } \\
\text { Preto - SP, um governamental e um particular. }\end{array}$ \\
\hline AMOSTRA & 26 técnicos e auxiliares de enfermagem. \\
\hline $\begin{array}{l}\text { INSTRUMENTO COLETA DE } \\
\text { DADOS }\end{array}$ & Formulário. \\
\hline RESULTADOS / CONCLUSÕES & $\begin{array}{l}\text { “... para o pessoal auxiliar de enfermagem a habilidade técnica do } \\
\text { enfermeiro foi fundamental para o desenvolvimento de procedimentos } \\
\text { referentes à assistência de enfermagem ao paciente cirúrgico, em } \\
\text { decorrência da colaboração recebida do enfermeiro ficou evidenciada a } \\
\text { satisfação dos membros da equipe de enfermagem”. } \\
\text { "Em contrapartida, quando o comportamento do enfermeiro não } \\
\text { correspondia às solicitações do pessoal auxiliar houve insatisfação do } \\
\text { mesmo acarretando prejuízos na assistência de enfermagem”. } \\
\text { “... a situação 'falha humana' na execução do procedimento foi } \\
\text { constatada no hospital B. Foram dois comportamentos dos enfermeiros } \\
\text { que apresentaram maior freqüência na situação mencionada: não } \\
\text { fornece informações para a realização do procedimento e comunica-se } \\
\text { de forma inadequada”. } \\
\text { "... acreditamos que a comunicação seja um instrumento básico da } \\
\text { enfermagem, utilizada em todas as atividades desenvolvidas pelo } \\
\text { enfermeiro; recurso fundamental que permite a este profissional o } \\
\text { desempenho de suas ações através de um interrelação com o } \\
\text { paciente/cliente e pessoal de enfermagem, buscando a melhoria da } \\
\text { QUALIDADE da assistência prestada”. } \\
\text { “... Liderança Situacional pode ser utilizada como estrutura teórica para } \\
\text { fundamentar a habilidade de liderar do enfermeiro, com vistas ao } \\
\text { aprimoramento da QUALIDADE da assistência de enfermagem e do } \\
\text { desenvolvimento do potencial do pessoal de enfermagem”. }\end{array}$ \\
\hline $\begin{array}{l}\text { RECOMENDAÇÕES PARA A } \\
\text { ENFERMAGEM }\end{array}$ & $\begin{array}{l}\text { “... devemos buscar estratégias que de alguma forma possibilite } \\
\text { mudanças". } \\
\text { “... cabe ao enfermeiro a busca de estratégias para tentar modificações } \\
\text { na sua prática diária. [...] o investimento para obtenção de } \\
\text { conhecimento e habilidade em liderança seja uma alternativa } \\
\text { essencial". }\end{array}$ \\
\hline REFEREM-SE À MOTIVAÇÃO? & “... estratégias motivacionais”, citando Chase (1994). \\
\hline REFEREM-SE À QUALIDADE? & $\begin{array}{l}\text { “... acreditamos que a comunicação seja um instrumento básico da } \\
\text { enfermagem, utilizada em todas as atividades desenvolvidas pelo } \\
\text { enfermeiro; recurso fundamental que permite a este profissional o } \\
\text { desempenho de suas ações através de um interrelação com o } \\
\text { paciente/cliente e pessoal de enfermagem, buscando a melhoria da } \\
\text { QUALIDADE da assistência prestada". }\end{array}$ \\
\hline
\end{tabular}

Quadro 11. Estudo 8. Fonte: Dados analisados pela autora (2007). 


\begin{tabular}{|c|c|}
\hline TÍTULO & $\begin{array}{l}\text { O estilo de liderança exercido pelo enfermeiro de unidade de } \\
\text { internação cirúrgica sob o enfoque da liderança situacional. }\end{array}$ \\
\hline AUTOR (ES) & $\begin{array}{l}\text { Cristina Maria Galvão, Maria Auxiliadora Trevizan, Namie Okino Sawada, } \\
\text { Neide Fávero. }\end{array}$ \\
\hline PERIÓDICO & Revista Latino Americana de Enfermagem. Ribeirão Preto - SP. \\
\hline ANO PUBLICAÇÃO & 1997. \\
\hline OBJETIVOS & $\begin{array}{l}\text { Identificar e analisar a correspondência de opinião entre o enfermeiro e um } \\
\text { elemento do pessoal auxiliar de enfermagem sobre o estilo de liderança } \\
\text { exercido pelo enfermeiro de unidade de internação cirúrgica, em relação às } \\
\text { seis categorias de atividades assistenciais desenvolvidas na unidade } \\
\text { (cuidados básicos, administração de medicamentos, procedimentos } \\
\text { invasivos, preparo do paciente cirúrgico no pré - operatório, assistência ao } \\
\text { paciente cirúrgico no encaminhamento para o Centro Cirúrgico, assistência } \\
\text { ao paciente cirúrgico no pós - operatório). }\end{array}$ \\
\hline POPULAÇÃO ESTUDADA & $\begin{array}{l}52 \text { profissionais de enfermagem atuantes em unidades de internação } \\
\text { cirúrgica de dois hospitais gerais, um governamental }(A) \text { e um particular }(B) \text {, } \\
\text { da cidade de Ribeirão Preto-SP. }\end{array}$ \\
\hline AMOSTRA & $\begin{array}{l}52 \text { profissionais de enfermagem. } \\
\text { Hospital A: } 13 \text { enfermeiros, } 02 \text { técnicos e } 11 \text { auxiliares de enfermagem. } \\
\text { Hospital B: } 13 \text { enfermeiros, } 04 \text { técnicos e } 09 \text { auxiliares de enfermagem. }\end{array}$ \\
\hline $\begin{array}{l}\text { INSTRUMENTO COLETA DE } \\
\text { DADOS }\end{array}$ & $\begin{array}{l}\text { Questionário, baseado no instrumento Integração de Maturidade e Estilo, } \\
\text { dos estudos de Hersey \& Blanchard (1986). }\end{array}$ \\
\hline RESULTADOS / CONCLUSÕES & $\begin{array}{l}\text { A correspondência de opinião entre o enfermeiro e o auxiliar foi maior no } \\
\text { hospital A (26 pares) do que no hospital B (11 pares). } \\
\text { No hospital A houve predominância dos estilos de liderança determinar (E1) } \\
\text { e persuadir (E2). } \\
\text { No hospital B houve predominância dos estilos de liderança compartilhar } \\
\text { (E3) e determinar (E1). } \\
\text { "Observamos que os enfermeiros têm se dedicado aos estilos de liderança } \\
\text { mais diretivos, orientando, portanto, seu comportamento, sobretudo para a } \\
\text { tarefa, sugerindo - nos que o pessoal auxiliar tem apresentado nível de } \\
\text { maturidade baixo e baixo a moderado, ou então, que os enfermeiros têm } \\
\text { utilizado inadequadamente o estilo gerencial". } \\
\text { "Desta forma, é necessário que o enfermeiro, além de compreender o } \\
\text { processo de liderança relativo a uma determinada situação, precisa } \\
\text { também conhecer e conciliar o nível de maturidade dos liderados, com o } \\
\text { estilo de liderança apropriado". }\end{array}$ \\
\hline $\begin{array}{l}\text { RECOMENDAÇÕES PARA A } \\
\text { ENFERMAGEM }\end{array}$ & $\begin{array}{l}\text { "No contexto hospitalar, cabe ao enfermeiro - líder buscar mecanismos que } \\
\text { proporcionem ao paciente uma assistência individualizada e com } \\
\text { QUALIDADE, e ao pessoal de enfermagem, desenvolvimento do seu } \\
\text { potencial, bem como o atendimento das suas necessidades". } \\
\text { "... acreditamos que a Liderança Situacional poderá ser utilizada como } \\
\text { estrutura teórica no que tange à habilidade de liderar do enfermeiro com } \\
\text { vistas ao aprimoramento da qualidade da assistência de enfermagem } \\
\text { prestada ao paciente / cliente e do desenvolvimento do potencial do } \\
\text { pessoal de enfermagem". }\end{array}$ \\
\hline REFEREM-SE À MOTIVAÇÃO? & $\begin{array}{l}\text { Maturidade dos liderados (Hersey \& Blanchard, 1986) - dimensão } \\
\text { psicológica, relacionada com a disposição ou MOTIVAÇÃO para realizar } \\
\text { alguma coisa. }\end{array}$ \\
\hline REFEREM-SE À QUALIDADE? & $\begin{array}{l}\text { "No contexto hospitalar, cabe ao enfermeiro - líder buscar mecanismos que } \\
\text { proporcionem ao paciente uma assistência individualizada e com } \\
\text { QUALIDADE, e ao pessoal de enfermagem, desenvolvimento do seu } \\
\text { potencial, bem como o atendimento das suas necessidades". }\end{array}$ \\
\hline
\end{tabular}

Quadro 12. Estudo 9. Fonte: Dados analisados pela autora (2007). 


\begin{tabular}{|c|c|}
\hline TÍTULO & Liderança do enfermeiro de centro cirúrgico. \\
\hline AUTOR (ES) & Cristina Maria Galvão. \\
\hline PERIÓDICO & Revista Paulista de Enfermagem. São Paulo - SP. \\
\hline ANO PUBLICAÇÃO & 1991. \\
\hline OBJETIVOS & $\begin{array}{l}\text { Verificar o estilo de liderança idealizado para o enfermeiro de Centro } \\
\text { Cirúrgico, segundo a opinião deste próprio profissional. } \\
\text { Verificar o estilo de liderança exercido pelo enfermeiro de Centro } \\
\text { Cirúrgico, segundo sua própria percepção. }\end{array}$ \\
\hline POPULAÇÃO ESTUDADA & $\begin{array}{l}12 \text { enfermeiros que trabalhavam em centros cirúrgicos em oito } \\
\text { hospitais gerais (um governamental e sete particulares) da cidade de } \\
\text { Ribeirão Preto - SP. }\end{array}$ \\
\hline AMOSTRA & $\begin{array}{l}11 \text { enfermeiros. } 05 \text { responderam sobre o comportamento ideal e } 06 \\
\text { sobre o comportamento real. }\end{array}$ \\
\hline $\begin{array}{l}\text { INSTRUMENTO COLETA DE } \\
\text { DADOS }\end{array}$ & $\begin{array}{l}\text { Questionários baseados nos instrumentos Grid \& Liderança em } \\
\text { Enfermagem (Trevizan, 1989). }\end{array}$ \\
\hline RESULTADOS / CONCLUSÕES & $\begin{array}{l}\text { Comportamento ideal: estilo Grid 9.9: obteve maior número de pontos. } \\
\text { Os enfermeiros pesquisados desejam prioritariamente que os } \\
\text { enfermeiros de Centro Cirúrgico adotem uma liderança fundamentada } \\
\text { no estilo Grid 9,9, seguido pelos estilos } 1,9 \text { e 5,5. } \\
\text { Caracterizado por um estilo de gerência fundamentado no trabalho em } \\
\text { equipe, conciliando objetivos organizacionais e as necessidades do } \\
\text { pessoal. } \\
\text { Comportamento real: estilo Grid } 9.9 \text { apontado como o mais exercido } \\
\text { pelo enfermeiro de centro cirúrgico, auto - atribuído e, portanto, } \\
\text { indicando a existência de uma auto - ilusão, conforme possibilidade } \\
\text { apontada por Blake \& Mouton (1987). Os enfermeiros pesquisados } \\
\text { indicaram ser o estilo Grid 9,9 o mais exercido pelos enfermeiros de } \\
\text { Centro Cirúrgico, seguido pelos estilos 5,5 e 1,9. } \\
\text { Análise estatística dos resultados relativos aos comportamentos ideal e } \\
\text { real apresentados pelos enfermeiros de Centro Cirúrgico não } \\
\text { identificou diferença significante entre estes. }\end{array}$ \\
\hline $\begin{array}{l}\text { RECOMENDAÇÕES PARA A } \\
\text { ENFERMAGEM }\end{array}$ & $\begin{array}{l}\text { “... compete às escolas de enfermagem propiciar o desenvolvimento da } \\
\text { habilidade de liderança na formação dos enfermeiros. É necessário } \\
\text { então que se promovam discussões com o intuito de acrescentarmos } \\
\text { nos currículos atuais conteúdos e estratégias que viabilizem o } \\
\text { aprendizado sobre liderança”. }\end{array}$ \\
\hline REFEREM-SE À MOTIVAÇÃO? & Não. \\
\hline REFEREM-SE À QUALIDADE? & Não. \\
\hline
\end{tabular}

Quadro 13. Estudo 10. Fonte: Dados analisados pela autora (2007). 


\begin{tabular}{|c|c|}
\hline TÍTULO & Os estilos de liderança idealizados pelos enfermeiros. \\
\hline AUTOR (ES) & Elza de Fátima Ribeiro Higa, Maria Auxiliadora Trevizan. \\
\hline PERIÓDICO & Revista Latino-Americana de Enfermagem. Ribeirão Preto - SP. \\
\hline ANO PUBLICAÇÃO & 2005. \\
\hline OBJETIVOS & $\begin{array}{l}\text { Verificar e analisar o estilo de liderança idealizado para o enfermeiro, } \\
\text { sob a ótica do próprio enfermeiro. } \\
\text { Comparar a liderança idealizada pelos enfermeiros de dois hospitais } \\
\text { diferentes }(A \text { e B). }\end{array}$ \\
\hline POPULAÇÃO ESTUDADA & $\begin{array}{l}13 \text { enfermeiros atuantes em dois hospitais do interior do estado de } \\
\text { São Paulo. }\end{array}$ \\
\hline AMOSTRA & $\begin{array}{l}13 \text { enfermeiros - } 07 \text { assistenciais do hospital } A, 06 \text { do hospital } B \text {, } \\
\text { sendo destes } 05 \text { assistenciais e } 01 \text { docente assistencial. }\end{array}$ \\
\hline $\begin{array}{l}\text { INSTRUMENTO COLETA DE } \\
\text { DADOS }\end{array}$ & $\begin{array}{l}\text { Instrumento Grid \& Liderança em Enfermagem: comportamento } \\
\text { ideal, de Trevizan (1993). }\end{array}$ \\
\hline RESULTADOS / CONCLUSÕES & $\begin{array}{l}\text { Comportamento ideal de liderança: } \\
\text { Hospitais A e B - estilo } 9.9 \text { é o mais desejável, o qual corresponde à } \\
\text { proposta de trabalho em equipe, desejável na Enfermagem. } \\
\text { "Podemos dizer que os enfermeiros participantes do estudo indicam } \\
\text { que idealizam os comportamentos dos estilos 9.9, } 5.5 \text { e } 1.9 \text {. } \\
\text { Inferimos que, nessa evidência, transparece a falta de conhecimento } \\
\text { do enfermeiro sobre o próprio estilo de liderança". } \\
\text { Não houve diferença estatisticamente significativa quando } \\
\text { comparamos o desejo de liderança dos enfermeiros nas duas } \\
\text { instituições pesquisadas. }\end{array}$ \\
\hline $\begin{array}{l}\text { RECOMENDAÇÕES PARA A } \\
\text { ENFERMAGEM }\end{array}$ & $\begin{array}{l}\text { “... compreendemos que a liderança é um recurso importante no } \\
\text { processo de cuidar do ser humano e de gerenciar pessoas. Portanto, } \\
\text { precisa ser mais bem desenvolvida pela enfermagem”. } \\
\text { “.. a liderança tem poucas chances ou condições de avançar na } \\
\text { enfermagem, se não for deliberadamente estimulada por meio de } \\
\text { atitudes inovadoras, de projetos e investimentos pessoais e grupais } \\
\text { e pela união de todos os enfermeiros - acreditamos que cada um } \\
\text { pode contribuir para isso". }\end{array}$ \\
\hline REFEREM-SE À MOTIVAÇÃO? & $\begin{array}{l}\text { “... defendemos que a enfermagem precisa de líderes } \\
\text { comprometidos e motivados para direcionar o desenvolvimento dos } \\
\text { processos de trabalho...". } \\
\text { “... precisamos de líderes que estejam motivados...". }\end{array}$ \\
\hline REFEREM-SE À QUALIDADE? & $\begin{array}{l}\text { “... instabilidade política, social, econômica e a revolução tecnológica } \\
\text { que, especialmente no Brasil, colocam os hospitais em crise, com } \\
\text { sérias conseqüências para a qualidade dos serviços prestados...". }\end{array}$ \\
\hline
\end{tabular}

Quadro 14. Estudo 11. Fonte Dados analisados pela autora (2007). 


\begin{tabular}{|c|c|}
\hline TÍTULO & $\begin{array}{l}\text { Liderança Situacional: análise de estilo de enfermeiros - } \\
\text { líderes. }\end{array}$ \\
\hline AUTOR (ES) & Maria Regina Lourenço, Maria Auxiliadora Trevizan. \\
\hline PERIÓDICO & Acta Paulista de Enfermagem. São Paulo - SP. \\
\hline ANO PUBLICAÇÃO & 2002. \\
\hline OBJETIVOS & $\begin{array}{l}\text { Analisar o estilo de liderança principal e secundário de } \\
\text { enfermeiros - líderes. }\end{array}$ \\
\hline POPULAÇÃO ESTUDADA & 25 enfermeiros de um hospital filantrópico. \\
\hline AMOSTRA & 20 enfermeiros. \\
\hline INSTRUMENTO COLETA DE DADOS & $\begin{array}{l}\text { Instrumento LEAD (Descrição da Eficácia e de Adaptabilidade } \\
\text { do Líder), de Hersey \& Blanchard (1986). }\end{array}$ \\
\hline RESULTADOS / CONCLUSÕES & 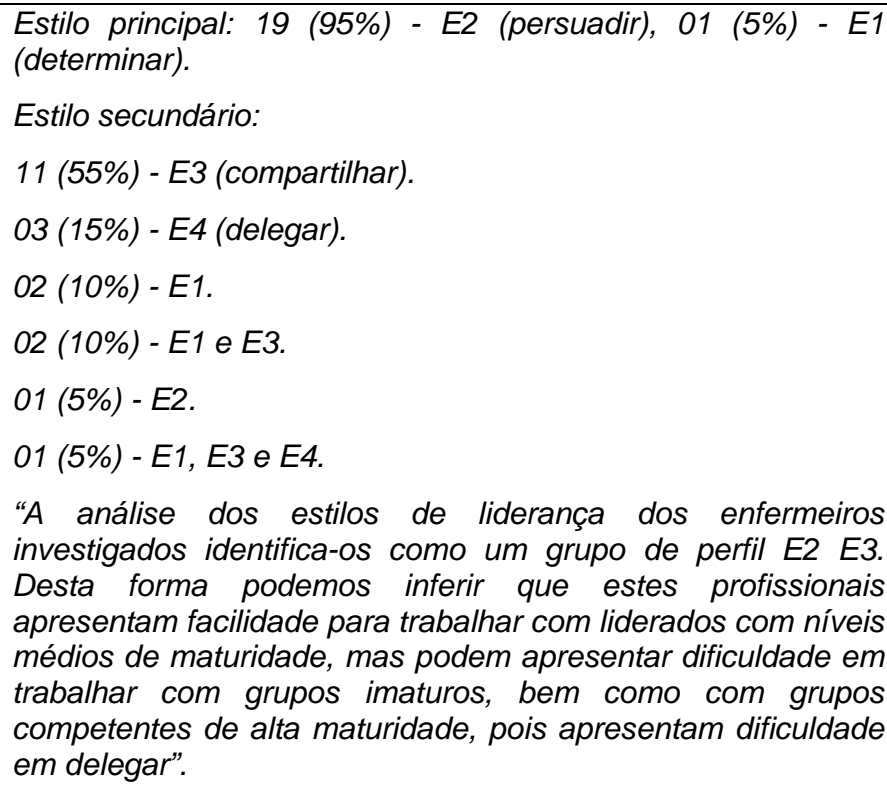 \\
\hline RECOMENDAÇÕES PARA A ENFERMAGEM & $\begin{array}{l}\text { "Para transformar-se em líder eficaz é necessário uma } \\
\text { compreensão do que seja liderança, da autopercepção do seu } \\
\text { estilo e de como poderá desenvolver esta capacidade. } \\
\text { Acreditamos que o enfermeiro deve buscar este } \\
\text { desenvolvimento através de um referencial teórico e, neste } \\
\text { aspecto, a Liderança Situacional poderá contribuir, tornando-o } \\
\text { um líder eficaz e um agente de mudanças organizacionais". }\end{array}$ \\
\hline REFEREM-SE À MOTIVAÇÃO? & $\begin{array}{l}\text { Maturidade psicológica, de Hersey \& Blanchard (1986). } \\
\text { Desmotivação, como problema enfrentado pelo enfermeiro - } \\
\text { líder. }\end{array}$ \\
\hline REFEREM-SE À QUALIDADE? & “... qualidade e competitividade são palavras de ordem". \\
\hline
\end{tabular}

Quadro 15. Estudo 14. Fonte: Dados analisados pela autora (2007). 


\begin{tabular}{|c|c|}
\hline TÍTULO & $\begin{array}{l}\text { Estilos de liderança da enfermeira numa instituição pública de } \\
\text { Fortaleza. }\end{array}$ \\
\hline AUTOR (ES) & $\begin{array}{l}\text { Eucléa Gomes Vale, Francisca Heronildes Patrício Caetano, Marta } \\
\text { Maria Girão Carneiro, Maria Goretti Coelho Sampaio. }\end{array}$ \\
\hline PERIÓDICO & Revista Brasileira de Enfermagem. Brasília - DF. \\
\hline ANO PUBLICAÇÃO & 2000. \\
\hline OBJETIVOS & $\begin{array}{l}\text { Investigar o estilo de liderança exercido pelas enfermeiras, em } \\
\text { cargos de chefia, considerando as opiniões e percepções que as } \\
\text { enfermeiras assistenciais mantêm nas relações de trabalho nas } \\
\text { unidades delimitadas. }\end{array}$ \\
\hline POPULAÇÃO ESTUDADA & $\begin{array}{l}\text { Enfermeiras lotadas nas unidades de emergência, ambulatório, } \\
\text { internação médico - cirúrgica e unidade de terapia intensiva, de um } \\
\text { hospital geral da rede pública de Fortaleza - CE. }\end{array}$ \\
\hline AMOSTRA & 53 enfermeiras. \\
\hline $\begin{array}{l}\text { INSTRUMENTO COLETA DE } \\
\text { DADOS }\end{array}$ & Questionário. \\
\hline RESULTADOS / CONCLUSÕES & $\begin{array}{l}41 \text { (96.3\%) estão satisfeitas com o nível de confiança que o chefe } \\
\text { deposita nelas. } \\
26 \text { (60\%) apontam que a chefe busca sugestões. } \\
23 \text { (53.4\%) afirmaram que a chefe estabelece metas junto com a } \\
\text { equipe, exceto em situações de crise, "o que evidencia a importância } \\
\text { do estabelecimento de metas para eficácia da produtividade no } \\
\text { processo de trabalho da enfermagem”. } \\
\text { “... sobre a imagem que os liderados têm do seu líder, percebeu-se } \\
\text { que no exercício da gerência é importante a imagem que os } \\
\text { liderados têm de seu chefe. [...] demonstraram que as chefias dos } \\
\text { setores apresentam estilos de liderança centradas no serviço e nas } \\
\text { pessoas..... } \\
\text { “... sobre o controle exercido pela chefia, 31.16\% dos enfermeiros } \\
\text { afirmaram que o chefe exerce um controle efetivo sobre as ações } \\
\text { desenvolvidas". } \\
\text { "O estudo revelou que as enfermeiras em cargos de chefia } \\
\text { apresentam estilo de liderança centrado no serviço e nas pessoas”. } \\
\text { "Corroborando a idéia de Blake e Mouton (1995, p. 12), [os } \\
\text { resultados] enfatizam que alguns líderes se destacam por } \\
\text { assegurarem a estima dos subordinados. Outros se preocupam com } \\
\text { a execução das tarefas. Nos dois casos 'a conquista de resultados } \\
\text { com base na confiança e no respeito, na obediência, na simpatia ou } \\
\text { na compreensão e no apoio é manifestação de preocupação com as } \\
\text { pessoas".. } \\
\text { “... vale destacar que o exercício da liderança precisa conjugar a } \\
\text { participação da equipe nas decisões e metas, ao mesmo tempo em } \\
\text { que sejam asseguradas o cumprimento dos objetivos e a missão do } \\
\text { Serviço de Enfermagem”. }\end{array}$ \\
\hline $\begin{array}{l}\text { RECOMENDAÇÕES PARA A } \\
\text { ENFERMAGEM }\end{array}$ & Não. \\
\hline REFEREM-SE À MOTIVAÇÃO? & $\begin{array}{l}\text { “.. a criação de uma co-responsabilidade, que sem dúvida aflora } \\
\text { uma maior motivação para o trabalho". }\end{array}$ \\
\hline REFEREM-SE À QUALIDADE? & $\begin{array}{l}\text { "... pode-se intuir diferentes significados e conseqüências para a } \\
\text { qualidade das ações desenvolvidas pelo grupo". }\end{array}$ \\
\hline
\end{tabular}

Quadro 16. Estudo 29. Fonte: Dados analisados pela autora (2007). 


\begin{tabular}{|c|c|}
\hline TÍTULO & 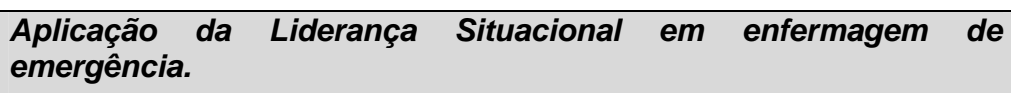 \\
\hline AUTOR (ES) & Grasiela Wehbe, Cristina Maria Galvão. \\
\hline PERIÓDICO & Revista Brasileira de Enfermagem. Brasília - DF. \\
\hline ANO PUBLICAÇÃO & 2005. \\
\hline OBJETIVOS & $\begin{array}{l}\text { Identificar a correspondência de opinião entre o enfermeiro de unidade } \\
\text { de emergência e o pessoal auxiliar de enfermagem em relação ao } \\
\text { estilo de liderança exercido pelo enfermeiro, frente às atividades } \\
\text { assistenciais desenvolvidas no setor. } \\
\text { Identificar a correspondência de opinião entre o enfermeiro de unidade } \\
\text { de emergência e o pessoal auxiliar de enfermagem sobre o estilo de } \\
\text { liderança que o enfermeiro deveria adotar frente ao nível de } \\
\text { maturidade do pessoal auxiliar nas atividades assistenciais } \\
\text { desenvolvidas no setor. }\end{array}$ \\
\hline POPULAÇÃO ESTUDADA & $\begin{array}{l}\text { Enfermeiros e auxiliares de enfermagem atuantes na sala de trauma da } \\
\text { unidade de emergência de um hospital geral de caráter público da } \\
\text { cidade de Ribeirão Preto - SP. }\end{array}$ \\
\hline AMOSTRA & 12 enfermeiros, 02 técnicos e 10 auxiliares de enfermagem. \\
\hline $\begin{array}{l}\text { INSTRUMENTO COLETA DE } \\
\text { DADOS }\end{array}$ & $\begin{array}{l}\text { Instrumento Integração de Maturidade e Estilo, de Hersey, Blanchard e } \\
\text { Keilty. }\end{array}$ \\
\hline RESULTADOS / CONCLUSÕES & $\begin{array}{l}\text { Nove categorias de atividades assistências estudadas (vias aéreas, } \\
\text { respiração e ventilação, circulação e controle de hemorragia, } \\
\text { administração de medicação, avaliação neurológica, exposição do } \\
\text { paciente, procedimentos invasivos, cuidados proporcionados ao } \\
\text { paciente vítima de trauma no encaminhamento a exames } \\
\text { complementares, assistência de enfermagem prestada ao paciente). } \\
30 \text { pares de sujeitos obtiveram correspondência de opinião. Destes, } 24 \\
\text { estavam relacionados com o estilo de liderança E3 (compartilhar), } 3 \\
\text { pares ao estilo E2 (persuadir) e } 3 \text { pares ao E1 (determinar). } \\
73 \text { pares de sujeitos apresentaram correspondência de opinião em } \\
\text { relação ao estilo de liderança que deveria ser adotado pelo enfermeiro } \\
\text { frente ao nível de maturidade do pessoal auxiliar. Destes, } 45 \text { indicaram } \\
\text { o estilo E4 (delegar). } \\
\text { "Os resultados desta investigação, acrescidos dos estudos } \\
\text { apresentados, apontaram que a equipe de enfermagem tem } \\
\text { apresentado nível de maturidade moderado a alto (M3) ou alto (M4) na } \\
\text { execução diferentes atividades assistenciais do contexto hospitalar. } \\
\text { Assim, entendemos que além de compreender o processo de } \\
\text { liderança, o enfermeiro necessita conhecer e conciliar o nível de } \\
\text { maturidade dos liderados, com o estilo de liderança apropriado frente a } \\
\text { uma atividade específica para o exercício eficaz da liderança no } \\
\text { cotidiano da enfermagem". } \\
\text { "A eficácia da prática da liderança vai depender da habilidade do } \\
\text { enfermeiro e adaptar o seu estilo de liderança em relação ao nível de } \\
\text { maturidade do membro da equipe de enfermagem frente a uma } \\
\text { determinada atividade, ou seja, o seu sucesso como líder depende da } \\
\text { articulação entre maturidade do liderado e o seu estilo de liderança } \\
\text { adotado". }\end{array}$ \\
\hline $\begin{array}{l}\text { RECOMENDAÇÕES PARA A } \\
\text { ENFERMAGEM }\end{array}$ & Não. \\
\hline REFEREM-SE À MOTIVAÇÃO? & $\begin{array}{l}\text { Citando Hersey \& Blanchard (1986), definindo maturidade psicológica, } \\
\text { “... disposição ou motivação para realizar alguma coisa”. }\end{array}$ \\
\hline REFEREM-SE À QUALIDADE? & Não. \\
\hline
\end{tabular}

Quadro 17. Estudo 30. Fonte: Dados analisados pela autora (2007). 


\begin{tabular}{|c|c|}
\hline TÍTULO & $\begin{array}{l}\text { Enfermeiro de unidade de emergência: sua liderança com o } \\
\text { pessoal auxiliar de enfermagem. }\end{array}$ \\
\hline AUTOR (ES) & Grasiela Wehbe, Cristina Maria Galvão. \\
\hline PERIÓDICO & Acta Paulista de Enfermagem. São Paulo - SP. \\
\hline ANO PUBLICAÇÃO & 2001. \\
\hline OBJETIVOS & $\begin{array}{l}\text { Identificar a correspondência de opinião entre o enfermeiro de } \\
\text { unidade de emergência e o pessoal auxiliar de enfermagem em } \\
\text { relação ao estilo de liderança exercido pelo enfermeiro, frente às } \\
\text { atividades assistenciais desenvolvidas no setor. } \\
\text { Identificar a correspondência de opinião entre o enfermeiro de } \\
\text { unidade de emergência e o pessoal auxiliar de enfermagem sobre o } \\
\frac{\text { estilo de liderança que o enfermeiro deveria adotar frente ao nível de }}{\text { maturidade do pessoal auxiliar nas atividades assistenciais }} \\
\text { desenvolvidas no setor. }\end{array}$ \\
\hline POPULAÇÃO ESTUDADA & $\begin{array}{l}\text { Enfermeiros e auxiliares de enfermagem atuantes numa unidade de } \\
\text { emergência de um hospital geral de caráter privado da cidade de } \\
\text { Ribeirão Preto - SP. }\end{array}$ \\
\hline AMOSTRA & 06 enfermeiros e 12 auxiliares de enfermagem. \\
\hline $\begin{array}{l}\text { INSTRUMENTO COLETA DE } \\
\text { DADOS }\end{array}$ & $\begin{array}{l}\text { Instrumento Integração de Maturidade e Estilo, de Hersey, Blanchard } \\
\text { e Keilty. }\end{array}$ \\
\hline RESULTADOS / CONCLUSÕES & $\begin{array}{l}\text { Oito categorias de atividades assistências estudadas (atendimento } \\
\text { ao politraumatizado, cuidados básicos, procedimentos invasivos, } \\
\text { administração de medicamentos, procedimentos de sutura, } \\
\text { procedimento de punção de vias centrais, cuidados proporcionados } \\
\text { ao paciente politraumatizado no encaminhamento a exames } \\
\text { complementares, assistência de enfermagem prestada ao paciente } \\
\text { politraumatizado em observação). } \\
\text { Conjunto de opiniões frente ao estilo de liderança exercido: } \\
\text { apontaram estilos E3 (compartilhar) ou E4 (delegar) como os mais } \\
\text { adotados pelos enfermeiros. } \\
\text { Conjunto de opiniões sobre o estilo de liderança que o enfermeiro } \\
\text { deveria adotar: apontaram estilos E3 (compartilhar) e/ou E4 } \\
\text { (delegar). } \\
\text { “... podemos afirmar que a liderança exercida pelo enfermeiro de } \\
\text { unidade de emergência do hospital investigado está de acordo com a } \\
\text { liderança que este profissional deveria adotar, em relação ao nível } \\
\text { de maturidade do pessoal auxiliar de enfermagem, nas categorias de } \\
\text { atividades assistenciais estudadas”. }\end{array}$ \\
\hline $\begin{array}{l}\text { RECOMENDAÇÕES PARA A } \\
\text { ENFERMAGEM }\end{array}$ & Não. \\
\hline REFEREM-SE À MOTIVAÇÃO? & $\begin{array}{l}\text { Citando Hersey \& Blanchard (1986), definindo maturidade } \\
\text { psicológica, "... disposição ou motivação para realizar alguma coisa". }\end{array}$ \\
\hline REFEREM-SE À QUALIDADE? & $\begin{array}{l}\text { Citando Trevizan (1993), “... cada membro deve ser estimulado a } \\
\text { desenvolver o seu potencial, com vistas à melhoria da qualidade da } \\
\text { assistência de enfermagem”. }\end{array}$ \\
\hline
\end{tabular}

Quadro 18. Estudo 31. Fonte: Dados analisados pela autora (2007). 
Nesta categoria foram reunidos os artigos que apresentaram estudos que, por sua vez, visaram identificar estilos ou modelos de liderança utilizados ou idealizados por um grupo de enfermeiros.

Para facilitar o processo de análise, esta categoria foi subdividida quanto ao modelo ou estilo de liderança utilizado como referencial teórico. Os artigos de número 10, 11 e 29 basearam - se no modelo Grid Gerencial de Blake e Mouton (1987), e os estudos $6,7,8,9,14,30,31$ no modelo Liderança Situacional de Hersey e Blanchard (1986).

Galvão (1991), no estudo 10, entendeu liderança como recurso fundamental a ser utilizado na administração da assistência ao paciente no período perioperatório. Ao comparar os estilos de liderança idealizado e exercido, identificou o mesmo que Blake e Mouton chamaram de condição de auto - ilusão, ou seja, gerentes que querem transmitir uma imagem de estilo (por exemplo: 9,9), mas, na realidade, não é esse o estilo que de fato exercem. Observou que não há um único estilo apropriado para todas as situações defrontadas no dia a dia de trabalho do enfermeiro gerente. Sugere o desenvolvimento da habilidade de liderança e a promoção de discussões para que sejam acrescentados aos currículos conteúdos e estratégias que viabilizem o aprendizado sobre liderança. A promoção de discussões pode ser uma estratégia bastante válida e com potencial real de construção de um novo paradigma.

O estilo de liderança idealizado pelo próprio enfermeiro foi o objeto estudado por Higa e Trevizan (2005) no estudo 11. O estilo 9,9 foi o mais idealizado, o que permitiu inferir sobre a necessidade de maior conhecimento do enfermeiro acerca de sua própria atuação profissional. As autoras recomendam desenvolver a liderança no processo de cuidar do ser humano e de gerenciar pessoas, estimulando - a "por 
meio de atitudes inovadoras, de projetos e investimentos pessoais e grupais, e pela união de todos os enfermeiros". Mas, quais seriam essas atitudes? O que inovariam? Para Maximiano (2000, p. 132), inovação significa a "capacidade de apresentar novos produtos e serviços". Como poderíamos inovar o cuidar do ser humano?

No estudo 29, enfermeiras em cargos de chefia foram investigadas por Vale et al. (2000) quanto ao estilo de liderança exercido. A partir da análise de opiniões e percepções, foi possível identificar um estilo de liderança centrado no serviço e nas pessoas. Destacaram que "o exercício de liderança precisa conjugar a participação da equipe nas decisões e metas ao mesmo tempo em que sejam assegurados o cumprimento dos objetivos e a missão do serviço de enfermagem", o que pode ser entendido como possíveis meios de se promover a assistência.

Foi com a aplicação de um programa de ensino sobre liderança através de um serviço de educação continuada hospitalar, que Galvão et al. (2000) no estudo 7 discutiram os estilos de liderança mais aplicados na instituição local da pesquisa. Os enfermeiros sujeitos do estudo, atuantes em unidades diversas do hospital, mostraram a adoção de estilos mais diretivos, correspondentes ao E1 - determinar e ao E2 - persuadir. Concluíram que o modelo de Hersey e Blanchard pode ser utilizado "como embasamento teórico para fundamentar a habilidade de liderar do enfermeiro com vistas à melhoria da qualidade da assistência" e que uma gerência inovadora se faz necessária, "orientada para as transformações com vistas à melhoria da qualidade da assistência de enfermagem [...]". Recomendam investimento na capacitação para o exercício de liderança, além de iniciativas que desenvolvam habilidades para o exercício da Liderança Situacional para promover 
maior maturidade nos liderados. Como capacitar para liderança? Como promover maior maturidade dos liderados?

De maneira semelhante, os estudos 6,8 e 9 também recomendam a aplicação do modelo de liderança de Hersey e Blanchard para o alcance da qualidade da assistência. Galvão et al. $(1997,1998)$ desenvolveram suas pesquisas em unidades de internação cirúrgica de instituições hospitalares diferentes.

No estudo 6, afirmam que "o desenvolvimento da habilidade de liderar pelo enfermeiro consiste em uma estratégia [...] com o intuito de promover mudanças, as quais possibilitem a melhoria da qualidade da assistência de enfermagem prestada ao paciente / cliente". Entendem que para o enfermeiro exercer uma liderança eficaz é fundamental que este profissional compreenda o processo de liderança, desenvolva as qualidades necessárias, bem como deve formular e viabilizar estratégias, empregando-as na prática.

Da mesma forma, no estudo 8, Galvão et al. (1998) apontaram a liderança situacional como ferramenta para a qualidade da assistência, e sugerem que estratégias que possibilitem mudanças também devem ser buscadas, recomendando que "o investimento para obtenção de conhecimento e habilidade em liderança seja uma alternativa essencial".

Já no estudo 9, Galvão et al. (1997) identificaram a adoção de estilos mais diretivos, com comportamentos voltados à tarefa, sugerindo que o pessoal auxiliar investigado apresentava nível de maturidade baixo, conforme o que preconiza o modelo de Hersey \& Blanchard. Apontam que "cabe ao enfermeiro líder buscar mecanismos que proporcionem ao paciente uma assistência individualizada e com qualidade", assim como desenvolver o potencial do pessoal de enfermagem e atender suas necessidades. O 'buscar mecanismos' remete às estratégias, ao como 
realizar tal atividade atingindo seus objetivos, o que deve ser iniciativa do enfermeiro.

Com a participação de enfermeiros componentes do serviço de enfermagem de uma instituição hospitalar, Lourenço e Trevizan (2002) no estudo 14 investigaram o estilo primário - o que o líder utiliza com mais freqüência - e o estilo secundário, utilizado em determinadas ocasiões. Identificaram um grupo de perfil E2 (persuadir) e E3 (compartilhar), com facilidade para trabalhar com liderados com níveis médios de maturidade. Segundo as autoras, para que o enfermeiro transforme - se em um líder eficaz, é necessária uma compreensão do que seja liderança e do como poderá desenvolver esta capacidade, além de uma autopercepção do seu estilo. Como pode o enfermeiro transformar-se em um líder, e em um líder eficaz? A partir desta constatação, como podemos alcançar tal objetivo?

Wehbe e Galvão (2001, 2005) desenvolveram os estudos 30 e 31 em unidades de emergência de instituições hospitalares. No estudo 30, desenvolvido na sala de trauma da unidade estudada, as autoras concluem que a eficácia da liderança vai depender da habilidade do enfermeiro em adaptar o seu estilo de liderar em relação ao nível de maturidade do membro da equipe de enfermagem frente a uma determinada atividade. O estudo 31 apontou correspondência de opinião entre o enfermeiro e pessoal auxiliar de enfermagem sobre o estilo de liderança exercido pelo enfermeiro. Em ambos os estudos, os estilos E3 (compartilhar) e E4 (delegar) foram os que se destacaram entre aqueles exercidos pelos enfermeiros e entre os que deveriam ser adotados diante do nível de maturidade de seus liderados.

Conhecer o liderado pode ser apontado como uma ação estratégica adequada à aplicação do modelo de Hersey e Blanchard. Entretanto, resta ao 
enfermeiro descobrir como pode conhecer seu estilo de liderança e o nível de maturidade do liderado, para somente a partir daí adaptar um ao outro, o que, por sua vez, também exige a utilização de alguma estratégia.

É preciso que o enfermeiro invista em autoconhecimento, que conheça o seu estilo de liderança e os fatores que o orientam para a adoção deste. O autoconhecimento e a auto-avaliação são, potencialmente, estratégias válidas e eficazes. Para tanto, deve reconhecer que este olhar para si mesmo é imprescindível ao exercício de liderança, interferindo diretamente na sua atuação diária com vistas à qualidade da assistência. É preciso que o enfermeiro reflita sobre suas reais motivações, sobre como vem atuando, analisando seu comportamento diante dos desafios diários que a assistência impõe e promova mudanças. É imprescindível que esteja comprometido com o que faz, fazendo aquilo que realmente acredita que de fato deve fazer, e preocupando-se em fazer bem, da melhor forma que for capaz.

Os conjuntos de estudos das subcategorias Grid Gerencial e Liderança Situacional apontam que enfermeiros demonstram falta de conhecimento sobre estilo de liderança que exercem.

Em relação à subcategoria Grid Gerencial, os estudos demonstram um autoexame equivocado por parte dos enfermeiros, já que desejam ser "9,9", mas não o são. Desta forma, devem ser estimulados a refletir sobre o estilo de liderança que adotam e a reconhecer a importância em traçar diretrizes que determinam o seu trabalho na instituição, assim como traçar estratégias para que estas sejam cumpridas.

Autores sugerem inovar a gerência orientando-a para transformações com vistas à melhoria da qualidade da assistência de enfermagem. Diante da 
responsabilidade do enfermeiro em buscar mecanismos que proporcionem ao paciente assistência individualizada e de qualidade, como seria essa gerência? Quais transformações são necessárias? Como transformar a gerência?

Se o objetivo é promover mudanças que possibilitem a melhoria da qualidade da assistência de enfermagem prestada ao paciente/cliente, a estratégia apontada 'desenvolver a habilidade de liderar do enfermeiro' não explicita o que de fato deve ser feito. Como desenvolver tal habilidade? Quais seriam as habilidades necessárias ao enfermeiro para o desenvolvimento de uma liderança eficaz?

Sob o ponto de vista da Liderança Situacional, autores entendem que o enfermeiro deve conhecer seus liderados, desenvolvendo a habilidade de adaptar seu estilo de liderança em relação ao nível de maturidade destes profissionais. Sendo assim, o enfermeiro deve investir na obtenção de conhecimento para desenvolver habilidade de liderança, para saber como poderão desenvolver esta capacidade e perceber qual é o estilo que deve ser adotado na interação com sua equipe. O enfermeiro deve, portanto, antes de qualquer outra ação, querer desenvolver-se. Deve desejar seu aperfeiçoamento e querer dedicar-se a promover qualidade da assistência, o que poderá resultar em satisfação profissional e pessoal, sua e de sua equipe.

Ser enfermeiro é ser gerente da assistência de enfermagem. O enfermeiro, ao gerenciar a assistência ao paciente através da sistematização de suas ações, está desta forma, assistindo ao paciente e atendendo às suas necessidades. 0 'assistir' em enfermagem não deve ser entendido somente como o cuidado direto, com o enfermeiro à cabeceira do paciente. O gerenciamento em Enfermagem deve ser entendido como assistência. 
Para Trevizan (1988), o reconhecimento da função administrativa centrada na assistência ao paciente é a essência do trabalho do enfermeiro no contexto hospitalar.

Entende-se que gerenciar em enfermagem é sinônimo de assistir. O que não pode acontecer é o enfermeiro assumir uma posição passiva - de submissão à burocracia imposta pela instituição, escondido atrás de suas escalas de pessoal e requisições de materiais - diante das inúmeras atividades a serem realizadas em prol e na presença do paciente. Para bem gerenciar, gerenciar atribuindo qualidade à assistência, é preciso liderar. Para ser líder, o enfermeiro inevitavelmente deverá adotar um estilo compatível com a relação entre ele e seus liderados. Daí a importância do 'conhecer-se' e conhecer os membros de sua equipe. É necessário que o enfermeiro se disponha a conhecer seu liderado, seu 'parceiro', para saber do que ele é capaz e o que ele quer enquanto profissional e pessoa, além de também dirigir essa mesma atenção a si próprio.

Segundo Cunha ${ }^{4}$ (2004 apud CUNHA, 2005, p. 42), "na Enfermagem, a liderança deve, em primeiro lugar, ser associada à responsabilidade. Enfermeiros assumem a responsabilidade pelos comportamentos por eles influenciados".

[...] o processo de trabalho da Enfermagem é desenvolvido em equipe e espera-se que o enfermeiro tenha as competências requeridas para o exercício da liderança, a habilidade de influenciar para que trabalhe entusiasticamente em prol de objetivos identificados como sendo para o bem comum. [...] O enfermeiro deve inspirar confiança servindo sua equipe para que ela seja eficaz e eficiente e almeje os objetivos traçados (p. 43).

\footnotetext{
${ }^{4}$ CUNHA, K. C. (Coord.) Gestão de pessoas na enfermagem: módulo 5 do curso de Especialização em Gerenciamento de Unidades e Serviços de Enfermagem. Programa de Pós-Graduação Lato Sensu. São Paulo: Faculdade Santa Marcelina, 2004.
} 


\subsubsection{Subcategoria Significados e Percepções de Liderança}

\begin{tabular}{|c|c|}
\hline TÍTULO & $\begin{array}{l}\text { O uso da técnica do incidente crítico na investigação da } \\
\text { assistência de enfermagem ao doente mental internado. }\end{array}$ \\
\hline AUTOR (ES) & $\begin{array}{l}\text { Sueli Aparecida Frari Galera, César Aléxis Galera, Marina Borges } \\
\text { Teixeira. }\end{array}$ \\
\hline PERIÓDICO & Revista Paulista de Enfermagem. São Paulo - SP. \\
\hline ANO PUBLICAÇÃO & 1997. \\
\hline OBJETIVOS & $\begin{array}{l}\text { Identificar alguns significados do tema qualidade da assistência de } \\
\text { enfermagem prestada ao doente mental no hospital psiquiátrico, a } \\
\text { partir da opinião de enfermeiros que prestam este tipo de } \\
\text { assistência. }\end{array}$ \\
\hline POPULAÇÃO ESTUDADA & $\begin{array}{l}13 \text { enfermeiros que trabalhavam em um hospital psiquiátrico da } \\
\text { rede privada, de } 500 \text { leitos, no interior do estado de São Paulo. }\end{array}$ \\
\hline AMOSTRA & 11 enfermeiros. \\
\hline $\begin{array}{l}\text { INSTRUMENTO COLETA DE } \\
\text { DADOS }\end{array}$ & Entrevistas, gravadas, posteriormente transcritas. \\
\hline RESULTADOS / CONCLUSÕES & $\begin{array}{l}\text { Temas: } \\
\text { - Interações entre o pessoal de enfermagem e o paciente: } \\
\text { indicadores valorizam aspectos tais como demonstrar interesse, } \\
\text { respeito e compreensão; } \\
\text { - O enfermeiro com líder: da equipe de enfermagem, no projeto de } \\
\text { assistência do paciente. “... liderança do enfermeiro foi } \\
\text { considerada crítica para a qualidade da assistência"; } \\
\text { - Sistematização de procedimentos; } \\
\text { - Envolvimento com a assistência. } \\
\text { “... a assistência de enfermagem nos hospitais brasileiros ainda é } \\
\text { custodial. Os resultados desta pesquisa indicam que apesar dessa } \\
\text { tendência, os enfermeiros quando solicitados a refletir sobre a } \\
\text { assistência de enfermagem de qualidade, pensam na assistência } \\
\text { direta". }\end{array}$ \\
\hline $\begin{array}{l}\text { RECOMENDAÇÕES PARA A } \\
\text { ENFERMAGEM }\end{array}$ & $\begin{array}{l}\text { "... um dos principais problemas da enfermagem, [...] é a } \\
\text { operacionalização do conhecimento teórico sobre o quê constitui } \\
\text { uma boa prática, em uma prática de melhor qualidade". }\end{array}$ \\
\hline REFEREM-SE À MOTIVAÇÃO? & Não. \\
\hline REFEREM-SE À QUALIDADE? & $\begin{array}{l}\text { “... a liderança do enfermeiro foi considerada crítica para a } \\
\text { qualidade da assistência”. } \\
\text { "... capacidade das pessoas que compõem a equipe de } \\
\text { enfermagem para prestar uma assistência de boa qualidade...". } \\
\text { "... interação entre pessoal de enfermagem e paciente como um } \\
\text { elemento importante com relação à assistência de boa qualidade”. } \\
\text { "... entrevistados não falaram nada sobre a necessidade de } \\
\text { introduzir ou rever tais procedimentos que possam melhorar a } \\
\text { qualidade da assistência de enfermagem". } \\
\text { "... os enfermeiros quando solicitados a refletir sobre a assistência } \\
\text { de enfermagem de qualidade, pensam na assistência direta". }\end{array}$ \\
\hline
\end{tabular}

Quadro 19. Estudo 5. Fonte: Dados analisados pela autora (2007). 


\begin{tabular}{|c|c|}
\hline TÍTULO & $\begin{array}{l}\text { A liderança na administração do pessoal de enfermagem } \\
\text { segundo a percepção de enfermeiras, auxiliares e atendentes de } \\
\text { enfermagem. }\end{array}$ \\
\hline AUTOR (ES) & $\begin{array}{l}\text { Paulina Kurcgant, Heloisa Helena Ciqueto Peres, Maria Helena } \\
\text { Trench Ciampone. }\end{array}$ \\
\hline PERIÓDICO & Revista da Escola de Enfermagem da USP. São Paulo - SP. \\
\hline ANO PUBLICAÇÃO & 1996. \\
\hline OBJETIVOS & $\begin{array}{l}\text { Conhecer como um grupo de enfermeiras, auxiliares e atendentes de } \\
\text { enfermagem percebe a liderança na enfermagem. } \\
\text { Subsidiar, com esse saber, o ensino da liderança na enfermagem. } \\
\text { "Reconhecer a liderança como é, a partir da atribuição do significado } \\
\text { dos líderes e dos liderados, sem levar em conta sua gênese } \\
\text { administrativa ou explicações causais dos cientistas da } \\
\text { administração, é o que pretendemos". }\end{array}$ \\
\hline POPULAÇÃO ESTUDADA & Grupo de enfermeiras, auxiliares e atendentes de enfermagem. \\
\hline AMOSTRA & $\begin{array}{l}08 \text { enfermeiras, de duas instituições de saúde, que vivenciavam o } \\
\text { papel de chefes dos serviços de enfermagem. } \\
08 \text { auxiliares e } 01 \text { atendente de enfermagem. }\end{array}$ \\
\hline $\begin{array}{l}\text { INSTRUMENTO COLETA DE } \\
\text { DADOS }\end{array}$ & Entrevistas, gravadas e transcritas posteriormente. \\
\hline RESULTADOS / CONCLUSÕES & $\begin{array}{l}\text { Enfermeiros - temas: concebendo a liderança; caracterizando o líder; } \\
\text { o poder na liderança; as diferentes formas de liderar; as condições } \\
\text { para a liderança. } \\
\text { Auxiliares e atendentes de enfermagem - temas: o poder do líder; o } \\
\text { significado da liderança; as características do líder; os sentimentos } \\
\text { do ser liderado. }\end{array}$ \\
\hline $\begin{array}{l}\text { RECOMENDAÇÕES PARA A } \\
\text { ENFERMAGEM }\end{array}$ & Não. \\
\hline REFEREM-SE À MOTIVAÇÃO? & $\begin{array}{l}\text { "... o comportamento organizacional resultava do comportamento dos } \\
\text { indivíduos, e este, por sua vez, era influenciado, em grande parte, } \\
\text { pela motivação humana". } \\
\text { "... sociólogos e psicólogos que também influenciaram o ensino da } \\
\text { liderança abordavam a influência da motivação no desempenho } \\
\text { humano em situações de trabalho". }\end{array}$ \\
\hline REFEREM-SE À QUALIDADE? & Não. \\
\hline
\end{tabular}

Quadro 20. Estudo 12. Fonte: Dados analisados pela autora (2007). 


\begin{tabular}{|c|c|}
\hline TÍTULO & $\begin{array}{l}\text { Líderes da enfermagem brasileira - sua visão sobre a temática e } \\
\text { sua percepção a respeito da relação liderança \& enfermagem. }\end{array}$ \\
\hline AUTOR (ES) & Maria Regina Lourenço, Maria Auxiliadora Trevizan. \\
\hline PERIÓDICO & Revista Latino Americana de Enfermagem. Ribeirão Preto - SP. \\
\hline ANO PUBLICAÇÃO & 2001. \\
\hline OBJETIVOS & $\begin{array}{l}\text { Conhecer a visão de enfermeiros - líderes sobre a temática da } \\
\text { liderança e suas percepções acerca da relação entre liderança e } \\
\text { enfermagem. }\end{array}$ \\
\hline POPULAÇÃO ESTUDADA & $\begin{array}{l}\text { Enfermeiros que se destacam em liderança no cenário brasileiro, os } \\
\text { quais foram indicados por docentes da área de Administração Aplicada } \\
\text { à Enfermagem e membros da diretoria da SOBRAGEN. }\end{array}$ \\
\hline AMOSTRA & $\begin{array}{l}14 \text { enfermeiros. } 01 \text { do Rio de Janeiro, } 01 \text { do Distrito Federal, } 01 \text { de } \\
\text { Goiás, } 01 \text { de Minas Gerais e } 10 \text { de São Paulo. } \\
\text { Áreas de atuação: 01, assistência. 02, gerência de serviços de } \\
\text { enfermagem. 02, consultoria de enfermagem. 09, docência e pesquisa. }\end{array}$ \\
\hline $\begin{array}{l}\text { INSTRUMENTO COLETA DE } \\
\text { DADOS }\end{array}$ & Entrevistas, gravadas e posteriormente transcritas. \\
\hline RESULTADOS / CONCLUSÕES & $\begin{array}{l}\text { Definição de liderança: ação de influenciar pessoas e comportamentos, } \\
\text { ligada a um processo de grupo e/ou de equipe onde se tem um objetivo } \\
\text { a ser atingido. } \\
\text { Funções do líder: influenciador, agente de mudanças, conselheiro, } \\
\text { energizador, visionário, pensador crítico, condutor e comunicador. } \\
\text { Relações entre liderança e enfermagem: } \\
\text { o enfermeiro é o profissional que ocupa a função central na instituição } \\
\text { por ser um agregador na equipe multiprofissional; } \\
\text { Necessidade de mudança do estilo de liderança autoritário do } \\
\text { enfermeiro para um estilo participativo; } \\
\text { Ser um líder é quase que natural na profissão de enfermagem e que a } \\
\text { própria forma como está estruturado o trabalho e a formação favorece } \\
\text { o exercício da liderança. } \\
\text { "Que se faz necessário o desenvolvimento de líderes e da liderança no } \\
\text { contexto da enfermagem, sendo necessária uma mudança de estilo de } \\
\text { liderança na enfermagem: de um estilo autoritário para um estilo } \\
\text { participativo. O líder deve apresentar características de personalidade } \\
\text { que facilitem o exercício de tal estilo, pois enfocam a flexibilidade, o } \\
\text { saber ouvir, o apoiar o grupo, o facilitador do processo". } \\
\text { Acreditam "em um potencial inicial e que, se desenvolvido, poderá } \\
\text { fazer com que um indivíduo se capacite para a liderança". }\end{array}$ \\
\hline $\begin{array}{l}\text { RECOMENDAÇÕES PARA A } \\
\text { ENFERMAGEM }\end{array}$ & $\begin{array}{l}\text { “... uma mudança de estilo de liderança na enfermagem: de um estilo } \\
\text { autoritário para um estilo participativo". } \\
\text { Estimular o aluno de graduação a ser líder, expondo-o a oportunidades } \\
\text { suscetíveis de desenvolver o potencial de liderança existente em todos } \\
\text { os indivíduos, revendo o processo de ensino - aprendizagem. }\end{array}$ \\
\hline REFEREM-SE À MOTIVAÇÃO? & $\begin{array}{l}\text { "O discurso atual consiste em delegação de poderes, alianças, } \\
\text { equipes, envolvimento, parcerias, negociações, e exploração da } \\
\text { motivação humana". }\end{array}$ \\
\hline REFEREM-SE À QUALIDADE? & Não. \\
\hline
\end{tabular}

Quadro 21. Estudo 15. Fonte: Dados analisados pela autora (2007). 


\begin{tabular}{|c|c|}
\hline TÍTULO & $\begin{array}{l}\text { A enfermagem e o conhecimento dos conceitos de liderança, } \\
\text { motivação, comunicação e mudança. }\end{array}$ \\
\hline AUTOR (ES) & Margarita Villar Luiz. \\
\hline PERIÓDICO & Acta Paulista de Enfermagem. São Paulo - SP. \\
\hline ANO PUBLICAÇÃO & 1989. \\
\hline OBJETIVOS & $\begin{array}{l}\text { Apresentar percepções que enfermeiras assistenciais têm sobre os } \\
\text { conceitos liderança, motivação comunicação e mudança, e reflexões da } \\
\text { autora a respeito do assunto. }\end{array}$ \\
\hline POPULAÇÃO ESTUDADA & "Enfermeiros de um hospital - escola do interior". \\
\hline AMOSTRA & 10 enfermeiros. \\
\hline $\begin{array}{l}\text { INSTRUMENTO COLETA DE } \\
\text { DADOS }\end{array}$ & Entrevista. \\
\hline RESULTADOS / CONCLUSÕES & 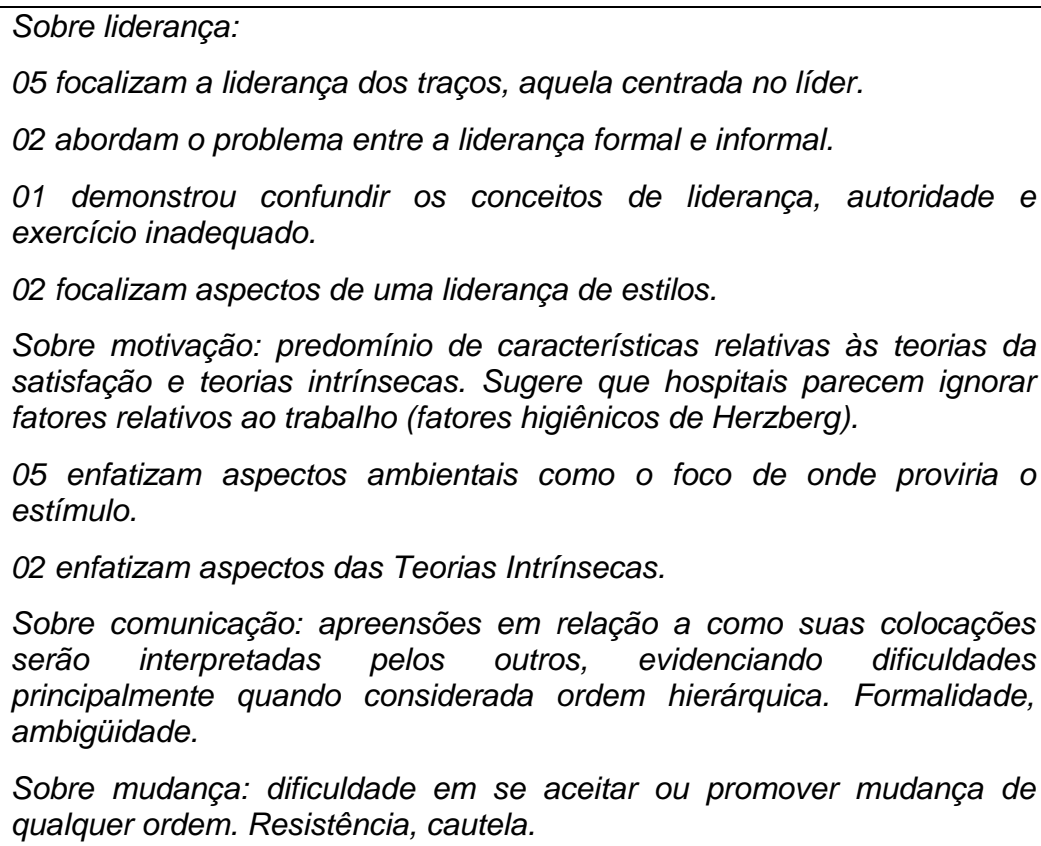 \\
\hline $\begin{array}{l}\text { RECOMENDAÇÕES PARA A } \\
\text { ENFERMAGEM }\end{array}$ & $\begin{array}{l}\text { "A enfermagem tem que se libertar desse modelo que a sufoca, tem que } \\
\text { buscar novas alternativas que permitam a expressão de suas múltiplas } \\
\text { potencialidades, que a tornam atrativa para os jovens, eficaz no } \\
\text { atendimento à população e eficiente para as instituições". }\end{array}$ \\
\hline REFEREM-SE À MOTIVAÇÃO? & Um dos conceitos discutidos. Apresenta síntese teórica do conceito. \\
\hline REFEREM-SE À QUALIDADE? & Não. \\
\hline
\end{tabular}

Quadro 22. Estudo 16-LID. Fonte: Dados analisados pela autora (2007). 


\begin{tabular}{|c|c|}
\hline TÍTULO & Liderança do enfermeiro: desafios da prática. \\
\hline AUTOR (ES) & Sérgio Ribeiro dos Santos, Rocilda Cabral Moreira. \\
\hline PERIÓDICO & Online Brazilian Journal of Nursing (Online). \\
\hline ANO PUBLICAÇÃO & 2004. \\
\hline OBJETIVOS & $\begin{array}{l}\text { Conhecer o significado de liderança atribuído pelos enfermeiros. } \\
\text { Identificar as dificuldades enfrentadas pelos enfermeiros no } \\
\text { exercício da liderança. }\end{array}$ \\
\hline POPULAÇÃO ESTUDADA & $\begin{array}{l}\text { Enfermeiros que ocupavam posições de liderança na equipe de } \\
\text { enfermagem, em hospitais públicos da rede estadual da cidade de } \\
\text { João Pessoa - PB. }\end{array}$ \\
\hline AMOSTRA & 08 enfermeiros. \\
\hline $\begin{array}{l}\text { INSTRUMENTO COLETA DE } \\
\text { DADOS }\end{array}$ & Entrevistas, gravadas. \\
\hline RESULTADOS / CONCLUSÕES & $\begin{array}{l}\text { Quanto ao significado: } \\
\text { Liderança está presente na filosofia de trabalho da enfermagem; } \\
\text { enfermeiros gostam da experiência de liderar, do bom } \\
\text { relacionamento com as pessoas e de conduzir a equipe para } \\
\text { alcançar objetivo. Julgam complexo "trabalhar com os seres } \\
\text { humanos e sem o menor incentivo psicológico ou financeiro"; } \\
\text { direção do hospital os escolhe aleatoriamente, para ocuparem os } \\
\text { cargos de liderança. } \\
\text { Quanto às dificuldades: } \\
\text { Instituição dispõe de pouco recurso financeiro; material sucateado; } \\
\text { falta de compreensão da direção; insatisfação; falta de apoio da } \\
\text { direção. } \\
\text { "Enfermeiros necessitam de uma direção participativa que } \\
\text { reconheça sua capacidade para realizar seus objetivos e prestar } \\
\text { uma assistência de QUALIDADE aos pacientes". }\end{array}$ \\
\hline $\begin{array}{l}\text { RECOMENDAÇÕES PARA A } \\
\text { ENFERMAGEM }\end{array}$ & $\begin{array}{l}\text { Cursos de capacitação e especialização para os líderes de } \\
\text { enfermagem. } \\
\text { Negociação em busca de uma direção participativa. } \\
\text { Melhorar relacionamento interpessoal. } \\
\text { Enfatizar a importância da liderança pelos docentes de } \\
\text { Administração Aplicada à Enfermagem. }\end{array}$ \\
\hline REFEREM-SE À MOTIVAÇÃO? & $\begin{array}{l}\text { “... o enfermeiro - líder precisa de motivação”. } \\
\text { “... o líder deve valorizar e reconhecer a capacidade de cada } \\
\text { membro da equipe, motivando-os a agir". } \\
\text { “... às vezes, um simples elogio motiva o líder e a equipe”. } \\
\text { “... chefe autoritário amortece a motivação...”. }\end{array}$ \\
\hline REFEREM-SE À QUALIDADE? & $\begin{array}{l}\text { "No contexto hospitalar a liderança de enfermagem deve estar à } \\
\text { frente da supervisão e da coordenação, visando melhorar a } \\
\text { qualidade do trabalho e da assistência prestada ao paciente". } \\
\text { "O principal objetivo de todo enfermeiro / líder consiste em ver sua } \\
\text { equipe trabalhando com prazer e não por obrigação, prestando } \\
\text { uma assistência de qualidade e promovendo o bem estar do } \\
\text { paciente...". }\end{array}$ \\
\hline
\end{tabular}

Quadro 23. Estudo 24. Fonte: Dados analisados pela autora (2007). 


\begin{tabular}{|c|c|}
\hline TÍTULO & Enfermagem: fatores de satisfação. \\
\hline AUTOR (ES) & Sérgio Ribeiro dos Santos, José Rodrigues Filho. \\
\hline PERIÓDICO & Revista Brasileira de Enfermagem. Brasília - DF. \\
\hline ANO PUBLICAÇÃO & 1995. \\
\hline OBJETIVOS & $\begin{array}{l}\text { Identificar os principais fatores geradores de satisfação e insatisfação } \\
\text { no trabalho dos enfermeiros; } \\
\text { Apresentar sugestões para um melhor ajustamento das necessidades } \\
\text { individuais e organizacionais, na prestação de assistência ao paciente. }\end{array}$ \\
\hline POPULAÇÃO ESTUDADA & $\begin{array}{l}\text { Enfermeiros que trabalhavam nas instituições hospitalares (públicas e } \\
\text { privadas) e nas unidades de serviços de saúde da cidade de João } \\
\text { Pessoa - PB. }\end{array}$ \\
\hline AMOSTRA & Não especificada. 20 enfermeiros realizaram um teste piloto. \\
\hline $\begin{array}{l}\text { INSTRUMENTO COLETA DE } \\
\text { DADOS }\end{array}$ & Questionário. \\
\hline RESULTADOS / CONCLUSÕES & $\begin{array}{l}\text { "Os componentes que mais contribuíram, em ordem fatorial, para que } \\
\text { os enfermeiros avaliassem diretamente seus sentimentos em relação a } \\
\text { vários aspectos concretos do trabalho foram os seguintes: } \\
\text { Fator } 1 \text { - Autonomia com interação social. } \\
\text { Fator } 2 \text { - Reconhecimento da importância do trabalho. } \\
\text { Fator } 3 \text { - Pagamento. } \\
\text { Fator } 4 \text { - Política organizacional. } \\
\text { Fator } 5 \text { - Relação administração - enfermagem. } \\
\text { Fator } 6 \text { - Trabalho em si". } \\
\text { "Portanto, tornou-se imperativa a necessidade de se reestruturar o } \\
\text { ambiente de trabalho dos enfermeiros". } \\
\text { “... os resultados aqui apresentados sugerem que a motivação não } \\
\text { deve ser descartada". }\end{array}$ \\
\hline $\begin{array}{l}\text { RECOMENDAÇÕES PARA A } \\
\text { ENFERMAGEM }\end{array}$ & $\begin{array}{l}\text { Recomendações aos administradores hospitalares, para que } \\
\text { gerenciem os fatores identificados neste estudo, "... promovendo uma } \\
\text { atmosfera mais intelectual, através de programas de educação em } \\
\text { serviço, organização racional do trabalho (sistematização da } \\
\text { assistência), valorização do trabalho por meio de um salário compatível } \\
\text { com a responsabilidade e capacidade do enfermeiro, interação } \\
\text { multiprofissional, condições materiais e tecnológicas para assistir ao } \\
\text { paciente, oportunidades aos enfermeiros para participar do processo } \\
\text { decisório entre outras medidas relacionadas às necessidades } \\
\text { comportamentais do indivíduo". }\end{array}$ \\
\hline REFEREM-SE À MOTIVAÇÃO? & $\begin{array}{l}\text { “... a motivação no trabalho pode ser mais facilmente discutida em } \\
\text { termos das dimensões de autonomia no trabalho, pagamento...". } \\
\text { Condutas e fatores motivacionais. }\end{array}$ \\
\hline REFEREM-SE À QUALIDADE? & $\begin{array}{l}\text { Por todo o texto. Qualidade do trabalho, qualidade de vida no trabalho } \\
\text { do enfermeiro, da assistência de enfermagem. }\end{array}$ \\
\hline
\end{tabular}

Quadro 24. Estudo 25-LID. Fonte: Dados analisados pela autora (2007). 


\begin{tabular}{|c|c|}
\hline TÍTULO & $\begin{array}{l}\text { Aprendizagem da liderança: opinião de enfermeiros sobre a } \\
\text { formação acadêmica. }\end{array}$ \\
\hline AUTOR (ES) & Ana Lúcia de Assis Simões, Neide Fávero. \\
\hline PERIÓDICO & Revista Latino Americana de Enfermagem. Ribeirão Preto - SP. \\
\hline ANO PUBLICAÇÃO & 2000. \\
\hline OBJETIVOS & $\begin{array}{l}\text { Verificar a opinião do enfermeiro sobre o preparo durante o curso de } \\
\text { graduação, para o desempenho da função de liderar a equipe de } \\
\text { enfermagem. }\end{array}$ \\
\hline POPULAÇÃO ESTUDADA & Enfermeiros de unidade de internação. \\
\hline AMOSTRA & 17 enfermeiros. \\
\hline $\begin{array}{l}\text { INSTRUMENTO COLETA DE } \\
\text { DADOS }\end{array}$ & Entrevista. \\
\hline RESULTADOS / CONCLUSÕES & $\begin{array}{l}97 \text { unidades de registro destacadas dos discursos: } \\
34 \text { (35\%) - mostram que alguns se sentem adequadamente preparados } \\
\text { para assumir a liderança na enfermagem. } \\
63 \text { (65\%) - revelam descontentamento em relação ao processo ensino - } \\
\text { aprendizagem, declarando despreparo para o desempenho da função } \\
\text { de líder. } \\
\text { Identificaram: } \\
\text { - Insatisfação por parte da maioria dos profissionais entrevistados. } \\
\text { - Falhas no processo ensino - aprendizagem. } \\
\text { - Falta de modelos de liderança e de oportunidades para vivenciar } \\
\text { situações práticas. }\end{array}$ \\
\hline $\begin{array}{l}\text { RECOMENDAÇÕES PARA A } \\
\text { ENFERMAGEM }\end{array}$ & $\begin{array}{l}\text { “... formação de líderes é um desafio a ser perseguido, não apenas } \\
\text { pelos órgãos de ensino, como também por todos os profissionais } \\
\text { enfermeiros, pois se trata de uma condição essencial para a } \\
\text { visualização de um futuro com novas alternativas e propostas de } \\
\text { atuação, podendo-se, assim, vislumbrar maior prestígio e valorização } \\
\text { profissional". } \\
\text { Visar a "... formação de enfermeiros com maior satisfação profissional } \\
\text { e com mais habilidade em liderança; empregadores mais satisfeitos } \\
\text { com o desempenho deste profissional e, acima de tudo, clientes } \\
\text { assistidos com um padrão de atendimento com a qualidade e o } \\
\text { respeito a que têm direito". }\end{array}$ \\
\hline REFEREM-SE À MOTIVAÇÃO? & $\begin{array}{l}\text { Citando Manfredi (1988), “... mudança estrutural que Ihe permitisse } \\
\text { utilizar habilidades, capacidades e motivações". }\end{array}$ \\
\hline REFEREM-SE À QUALIDADE? & $\begin{array}{l}\text { “... sociedade aspira por maior qualidade na assistência à sua saúde”. } \\
\text { “... clientes assistidos com um padrão de atendimento com a qualidade } \\
\text { e o respeito a que têm direito". }\end{array}$ \\
\hline
\end{tabular}

Quadro 25. Estudo 27. Fonte: Dados analisados pela autora (2007). 


\begin{tabular}{|c|c|}
\hline TÍTULO & O desafio da liderança para o enfermeiro. \\
\hline AUTOR (ES) & Ana Lúcia de Assis Simões, Neide Fávero. \\
\hline PERIÓDICO & Revista Latino Americana de Enfermagem. Ribeirão Preto - SP. \\
\hline ANO PUBLICAÇÃO & 2003. \\
\hline OBJETIVOS & $\begin{array}{l}\text { Conhecer a opinião do enfermeiro sobre a possibilidade de tornar-se } \\
\text { um líder. } \\
\text { Identificar, segundo a opinião dos enfermeiros, as principais } \\
\text { características e habilidades de um líder. } \\
\text { Apresentar, de acordo com a auto - avaliação dos enfermeiros, } \\
\text { pontos fortes e fracos relacionados ao desempenho da liderança. }\end{array}$ \\
\hline POPULAÇÃO ESTUDADA & $\begin{array}{l}\text { Enfermeiros responsáveis pela organização do serviço e } \\
\text { coordenação das equipes de enfermagem, de um hospital público } \\
\text { federal, localizado na microrregião do Triângulo Mineiro, no estado } \\
\text { de Minas Gerais. }\end{array}$ \\
\hline AMOSTRA & 36 enfermeiros. \\
\hline $\begin{array}{l}\text { INSTRUMENTO COLETA DE } \\
\text { DADOS }\end{array}$ & Questionário. \\
\hline RESULTADOS / CONCLUSÕES & $\begin{array}{l}28 \text { enfermeiros (77.7\%) responderam afirmativamente sobre a } \\
\text { possibilidade de tornarem-se líderes. } \\
\text { Possuir habilidade de comunicação foi o aspecto mais lembrado em } \\
\text { um líder. Destacaram-se características como honestidade, } \\
\text { integridade, determinação e responsabilidade. Poder de exercer } \\
\text { influência nas pessoas e o estilo participativo de liderança. } \\
\text { Pontos fortes: comportamentos geradores de bom relacionamento. } \\
\text { Estar envolvido com o trabalho. Comunicação transparente e clara. } \\
\text { Capacidade de iniciativa. } \\
\text { Pontos fracos: postura de insegurança, gerada pela falta de } \\
\text { conhecimentos e de experiências no trabalho. Dificuldade na } \\
\text { resolução de conflitos. } \\
\text { “... reconhecemos que, para o enfermeiro, desempenhar a função de } \\
\text { líder da equipe de enfermagem é uma experiência que, muitas } \\
\text { vezes, encontra-se permeada por dificuldades decorrentes da } \\
\text { inabilidade em lidar com situações grupais, da falta de } \\
\text { conhecimentos profissionais e da incapacidade de manter uma } \\
\text { comunicação eficaz". }\end{array}$ \\
\hline $\begin{array}{l}\text { RECOMENDAÇÕES PARA A } \\
\text { ENFERMAGEM }\end{array}$ & $\begin{array}{l}\text { "As experiências profissionais desses enfermeiros revelaram que } \\
\text { estabelecer um bom relacionamento com os funcionários, estar } \\
\text { envolvido com as questões do trabalho, demonstrar segurança na } \\
\text { condução da equipe e manter uma comunicação eficaz são } \\
\text { condições importantes para o sucesso na liderança do enfermeiro". } \\
\text { "Sendo assim, almejar melhor desempenho do enfermeiro, como } \\
\text { líder da equipe de enfermagem, pressupõe a ocorrência de } \\
\text { mudanças de comportamentos, de busca constante de novos } \\
\text { conhecimentos e do desenvolvimento de habilidades essenciais para } \\
\text { a liderança, as quais envolvem qualidades pessoais, habilidades } \\
\text { interpessoais e o domínio do contexto organizacional". }\end{array}$ \\
\hline REFEREM-SE À MOTIVAÇÃO? & $\begin{array}{l}\text { "[...] Ressalta-se, ainda, que os novos líderes não dão ordens, } \\
\text { apenas motivam as pessoas a agirem". }\end{array}$ \\
\hline REFEREM-SE À QUALIDADE? & $\begin{array}{l}\text { "Um dos desafios atuais encontrados pela enfermagem é conseguir } \\
\text { oferecer um atendimento de melhor qualidade ao cliente...". }\end{array}$ \\
\hline
\end{tabular}

Quadro 26. Estudo 28. Fonte: Dados analisados pela autora (2007). 
Os artigos que apresentaram estudos cujo objeto estava relacionado ao como os profissionais pesquisados entendem, percebem ou visualizam a liderança foram reunidos nesta subcategoria. São os de número 5, 12, 15, 16-LID, 24, 25-LID, 27 e 28. Estes trabalhos expressam uma ação de reflexão ou auto-avaliação destes enfermeiros. Diante de questionamentos tais como 'o que significa liderança para você?', 'como você vê a liderança?', eles manifestaram seus pensamentos e sentimentos sobre liderança e o trabalho da enfermagem.

O significado de qualidade da assistência de enfermagem foi pesquisado por Galera et al. (1997) no estudo 5. Em um hospital psiquiátrico, os enfermeiros foram questionados sobre sua atuação como líderes da equipe de enfermagem e no projeto de assistência ao paciente. Apontaram a liderança como sendo crítica para a qualidade da assistência, no que tange à organização do trabalho da equipe de enfermagem e ao projeto de assistência ao paciente. Sugerem a operacionalização do conhecimento teórico a respeito do que promove qualidade à prática.

Kurcgant et al. (1996), estudo 12, propuseram - se a desvelar o papel dos líderes e dos liderados sob o enfoque fenomenológico. Sugerem o repensar do ensino de graduação em Enfermagem e concluem o artigo afirmando que:

[...] a explicitação de sentimentos desvela o fenômeno liderança no seu sentido relacional. É na presença do outro e é a presença do outro que permite ao ser-no-mundo a consciência de sua própria existência. É na troca de sentimentos e na repercussão dessa troca que está captado o significado da liderança.

No estudo 15, Lourenço e Trevizan (2001) dedicaram-se a ouvir enfermeiros que se destacaram na liderança da enfermagem brasileira. Observaram que os líderes pesquisados tinham uma visão clara da temática e percebiam uma relação estreita entre enfermagem e liderança. Recomendaram expor o aluno a oportunidades suscetíveis de desenvolver o potencial de liderança existente em 
todos os indivíduos, revendo o processo de ensino-aprendizagem, para estimulá-lo a ser líder.

Luiz (1989) - estudo 16-LID - identificou e analisou as percepções de um grupo de enfermeiras sobre os conceitos de liderança, motivação, comunicação e mudança. Evidenciou que o tradicionalismo das teorias mais antigas da administração é o que predomina na prática da assistência de enfermagem da amostra estudada que, segundo ela, adota um modelo "sufocante". Sobre liderança, constatou que o grupo estudado entende-a como centrada na pessoa do líder, a quem são atribuídas características que acentuam a onipotência e o uso da autoridade no exercício de suas atribuições.

Santos e Moreira (2004) desenvolveram seu estudo (24) com o objetivo de conhecer o que significava liderança para enfermeiros atuantes em instituições de saúde da cidade de João Pessoa (PB). A complexidade em trabalhar com seres humanos, "sem incentivo psicológico ou financeiro", surgiu como uma das questões levantadas pelo grupo. Sugeriram cursos de capacitação e especialização para os líderes de enfermagem.

No estudo 25-LID, Santos e Rodrigues Filho (1995) apresentaram uma investigação dos fatores de satisfação e insatisfação no trabalho dos enfermeiros. Acerca dos ambientes e profissionais pesquisados, os autores apontaram que a falta de estímulos e condições satisfatórias por parte das "organizações burocráticas" é a principal causa da insatisfação, que interfere no desempenho do trabalho com qualidade. Observaram ainda que a interação dos enfermeiros com o pessoal de enfermagem é marcada por dificuldades de relacionamento e que "[...] aos enfermeiros é exigida uma postura de líder da equipe de enfermagem". Acreditam que "dessa maneira, o enfermeiro assume o papel de gerente do serviço de 
enfermagem, e os outros elementos desenvolvem suas funções junto ao paciente, ocupando, assim, o espaço que é da competência do enfermeiro".

Com o objetivo de verificar o preparo do enfermeiro, realizado durante a graduação para liderar a equipe de enfermagem, Simões e Fávero (2000), no estudo 27, também identificaram insatisfação, uma vez que a maioria do grupo investigado declarou despreparo e insegurança quanto ao desempenho de liderança, apresentando descontentamento em relação ao processo ensino-aprendizagem. Defendem que a "formação de líderes é um desafio a ser perseguido, não apenas pelos órgãos de ensino, como também por todos os profissionais enfermeiros".

Já no estudo 28, Simões e Fávero (2003) apresentaram as opiniões do grupo de enfermeiros investigados sobre a possibilidade de tornarem-se líderes, sobre as principais características e habilidades de um líder e os pontos fortes ou fracos relacionados ao desempenho da liderança. Dentre as dificuldades por eles apontadas estão a inabilidade em lidar com situações grupais, a falta de conhecimentos profissionais e a incapacidade em se manter uma comunicação eficaz.

Os autores dos estudos desta categoria preocuparam-se em expressar as percepções, visões e significados de liderança pelos grupos de profissionais de enfermagem investigados. Mesmo que de modo particular a cada instituição local dos estudos, todos contribuíram para a identificação de fatores que interferem na formação do enfermeiro e na estrutura e organização da instituição hospitalar, além de apontarem ações essenciais à qualidade da assistência, entre estas, o exercício pleno da liderança pelo enfermeiro.

Ao identificarem a liderança como crítica para a qualidade da assistência, enfermeiros demonstram reconhecer a importância de promover o relacionamento 
entre eles e seus liderados, além de oferecer ao paciente a assistência de boa qualidade. Vivenciar a liderança deve ser oportunidade dada a todos integrantes da equipe de enfermagem, para que compreendam a importância de seu papel diante da dinâmica de trabalho voltada à qualidade.

O conhecimento sobre a complexidade do ser humano, sobre relacionamento interpessoal e trabalho de equipe é imprescindível ao bom desempenho de liderança. Além disso, a revisão do processo ensino-aprendizagem mostra-se essencial. Expor o aluno de graduação a situações que permitam o desenvolver do potencial de liderança pode se constituir estratégia viável ao seu pleno exercício profissional.

Como afirmou Mezomo (2001, p. 90):

Ninguém nasce sabendo. As pessoas não sabem como agir para garantir excelência no trato com os outros: os "clientes" da organização. Garantir excelência significa ir além do "não ofender" e do "ser bom". É preciso atender com competência, com delicadeza, com rapidez e com respeito. É preciso "encantar" o cliente, oferecendo-lhe mais do que o esperado. [...] Pelo treinamento as pessoas se fortalecem, ganham confiança, melhoram sua auto-imagem, tornam-se mais produtivas, têm orgulho do que fazem, garantem melhor imagem para a organização, colaboram com o ambiente de trabalho, tornando-o local de eleição para todos e sentem-se realizadas.

Foi identificado como problema o fato de o enfermeiro líder da equipe permanecer somente na administração da unidade, afastando - se do cuidado direto, por ele delegado aos auxiliares e técnicos de enfermagem, sugerindo assim uma visão equivocada da assistência e do trabalho em equipe. Considerando os determinantes históricos da profissão, assim como a conquista de seu espaço social, não se pode mais dissociar o cuidado de sua administração pelo enfermeiro. A assistência de enfermagem e seu gerenciamento devem ser entendidos como um conjunto de ações integradas - planejadas, realizadas e avaliadas - por uma equipe, sendo o enfermeiro o líder responsável pela sua execução e tudo que a determina. 
Quais estratégias devem ser adotadas pelos órgãos formadores e instituições de saúde diante de enfermeiros que declaram insatisfação, despreparo, insegurança quanto ao desempenho de liderança, inabilidade em lidar com situações grupais, falta de conhecimento e incapacidade em se manter comunicação eficaz? Talvez seja necessário - e urgente - um esforço conjunto entre instituições e profissionais para promoverem discussões visando avaliar a sua formação e atuação e, conseqüentemente, repensar fatores que interferem na qualidade da assistência de enfermagem prestada por estes profissionais. O "operacionalizar conhecimento teórico" deve ser sustentado por ações concretas, possibilitando que a profissão se renove, permitindo um repensar de suas bases fundamentais.

Propôr estratégias não constitui tarefa simples. São vários os fatores que devem ser considerados para que mudanças sejam realizadas. Entretanto, antes de qualquer outra atitude, é preciso manifestar vontade em transformar a realidade, em ultrapassar as barreiras por nós mesmos, profissionais de Enfermagem, já instaladas. É preciso direcionar o olhar para fora de nosso 'individual', enxergando no 'coletivo' o objetivo de nossas ações. Trabalhamos para alguém, em prol de alguém. Nossas ações são sempre em direção à conquista de objetivos, e não são somente os nossos, como também os daqueles que de nosso trabalho necessitam. É essencial que desejemos transformar, mudar o status quo das coisas e, mais do que tudo, que compreendamos o ser humano e suas especificidades como a razão de existir da Enfermagem. 


\subsubsection{Categoria temática motivação}

\subsubsection{Subcategoria Satisfação e Motivação}

\begin{tabular}{|c|c|}
\hline TÍTULO & Satisfação e motivação no trabalho do enfermeiro. \\
\hline AUTOR (ES) & Arthur Velloso Antunes, Lígia Rodrigues Sant Anna. \\
\hline PERIÓDICO & Revista Brasileira de Enfermagem. Brasília - DF. \\
\hline ANO PUBLICAÇÃO & 1996. \\
\hline OBJETIVOS & $\begin{array}{l}\text { Verificar se o enfermeiro se sente satisfeito no trabalho. } \\
\text { Verificar se o enfermeiro se sente motivado em seu trabalho. } \\
\text { Verificar se existe relação das condições de trabalho (fatores } \\
\text { higiênicos) com a satisfação e das características do trabalho (fatores } \\
\text { motivacionais) com a motivação. }\end{array}$ \\
\hline POPULAÇÃO ESTUDADA & 52 enfermeiros, de um hospital de clínicas de Minas Gerais, 420 leitos. \\
\hline AMOSTRA & 37 (71.15\%). \\
\hline $\begin{array}{l}\text { INSTRUMENTO COLETA DE } \\
\text { DADOS }\end{array}$ & Questionário. \\
\hline RESULTADOS / CONCLUSÕES & $\begin{array}{l}\text { Enfermeiros que se sentem satisfeitos no trabalho: } 20 \text { (56\%). } \\
\text { Insatisfeitos: } 16 \text { (44\%). } \\
\text { Enfermeiros que se sentem motivados no trabalho: } 15 \text { (42\%). } \\
\text { Desmotivados: } 21 \text { (58\%). } \\
\text { Enfermeiros que se sentem satisfeitos e motivados no trabalho: } 13 \\
\text { (36\%). Insatisfeitos e desmotivados: } 14 \text { (39\%). } \\
\text { "Uma pequena parte dos enfermeiros se sente satisfeita e motivada, } \\
\text { pronta para o bom desempenho, enquanto a grande maioria precisa ter } \\
\text { seu trabalho enriquecido por se sentir insatisfeita e/ou desmotivada”. } \\
\text { Relações fator higiênico - satisfação e fator motivacional - motivação } \\
\text { existentes e válidas. }\end{array}$ \\
\hline $\begin{array}{l}\text { RECOMENDAÇÕES PARA A } \\
\text { ENFERMAGEM }\end{array}$ & $\begin{array}{l}\text { "A análise dos fatores que levam à satisfação e motivação do } \\
\text { enfermeiro constitui, portanto, um componente significativo no estudo } \\
\text { do serviço de enfermagem e da organização hospitalar". }\end{array}$ \\
\hline REFEREM-SE À LIDERANÇA? & $\begin{array}{l}\text { Aos chefes e gerentes, como 'lideranças democráticas', necessárias } \\
\text { como um apelo, para fazer com que as pessoas trabalhassem mais. }\end{array}$ \\
\hline REFEREM-SE À QUALIDADE? & ão. \\
\hline
\end{tabular}

Quadro 27. Estudo 2. Fonte: Dados analisados pela autora (2007). 


\begin{tabular}{|c|c|}
\hline TÍTULO & A motivação do trabalho do gerente de enfermagem. \\
\hline AUTOR (ES) & Norma Lúcia de Matos. \\
\hline PERIÓDICO & Mundo saúde. \\
\hline ANO PUBLICAÇÃO & 1985. \\
\hline OBJETIVOS & $\begin{array}{l}\text { Testar as seguintes hipóteses (resumidas): } \\
\text { - Gerentes de enfermagem devem participar do planejamento global da } \\
\text { organização; } \\
\text { - Motivados, eles aumentam a eficiência profissional da equipe, os riscos da } \\
\text { empresa são menores, e o resultado final é uma atenção de enfermagem melhor } \\
\text { ao paciente e à comunidade; } \\
\text { - Trabalho em si traz satisfação, mas, para assumir a gerência, o salário não é } \\
\text { compensador. }\end{array}$ \\
\hline $\begin{array}{l}\text { POPULAÇÃO } \\
\text { ESTUDADA }\end{array}$ & $\begin{array}{l}\text { Gerentes e supervisores de enfermagem, de duas organizações, uma particular e } \\
\text { uma pública. }\end{array}$ \\
\hline AMOSTRA & $\begin{array}{l}23 \text { enfermeiros: } 08 \text { (36\%) com funções de gerência, da organização particular. } 15 \\
(14 \%) \text { enfermeiros encarregados de serviço, setor ou turno, da organização } \\
\text { pública. }\end{array}$ \\
\hline $\begin{array}{l}\text { INSTRUMENTO } \\
\text { COLETA DE DADOS }\end{array}$ & Questionário. \\
\hline $\begin{array}{l}\text { RESULTADOS / } \\
\text { CONCLUSÕES }\end{array}$ & $\begin{array}{l}\text { 97\% satisfeitos com o trabalho em si. } \\
91.4 \% \text { valorizam sua profissão, vêem nela pleno sentido e se identificam com ela. } \\
87 \% \text { sentem que seus esforços levarão à valorização profissional e aumento da } \\
\text { eficácia e eficiência. } \\
78 \% \text { não supõem que perdem tempo na execução do trabalho, pela má } \\
\text { organização da empresa ou do próprio trabalho, e reconhecem suas aptidões e o } \\
\text { alto grau de habilidade que elas exigem. } \\
73.9 \% \text { têm algum 'feedback' do seu desempenho procurando melhorá-lo sempre. } \\
82.6 \% \text { insatisfeitos quanto ao salário, para o nível de supervisão e gerência. } \\
\text { "Dados confirmam as hipóteses ou: } \\
\text { - Há falta liberdade do gerente de enfermagem participar no planejamento global, } \\
\text { do serviço de enfermagem e do seu trabalho, o que promove insatisfação e não } \\
\text { aproveitamento de suas capacidades e habilidades, dificultando o alcance dos } \\
\text { objetivos da organização, do serviço, e do próprio profissional. } \\
\text { - o trabalho em si, ou partes do mesmo, são motivantes para o gerente de } \\
\text { enfermagem, levando-os a executar seu trabalho com vontade, sem perda de } \\
\text { tempo, valorizando-o e procurando maior eficiência e desenvolvimento no } \\
\text { desempenho de suas funções, não desejando mudança de área ou de emprego, } \\
\text { mas altamente insatisfeitos com o baixo nível salarial". }\end{array}$ \\
\hline $\begin{array}{l}\text { RECOMENDAÇÕES } \\
\text { PARA A ENFERMAGEM }\end{array}$ & $\begin{array}{l}\text { Recomendações para as organizações particulares e públicas: } \\
\text { - Adoção de política salarial mais condizente para os gerentes; } \\
\text { - Política de desenvolvimento de recursos humanos; } \\
\text { - Administração mais participativa; } \\
\text { - Feedback aos gerentes quanto ao seu desempenho; } \\
\text { - Política de promoção dos enfermeiros na empresa. } \\
\text { "Consequentemente, teremos gerentes mais motivados com desempenho muito } \\
\text { mais eficiente e eficaz, trazendo mais satisfação aos pacientes em relação ao } \\
\text { atendimento recebido, mais satisfação aos funcionários pela orientação e } \\
\text { gerenciamento consciente e motivado, diminuindo os riscos das organizaços, } \\
\text { aumentando seus lucros e melhorando sua imagem perante o paciente, família e } \\
\text { comunidade". }\end{array}$ \\
\hline $\begin{array}{l}\text { REFEREM-SE À } \\
\text { LIDERANÇA? }\end{array}$ & $\begin{array}{l}\text { Citam Kast et al (1976) “... tornam a enfermeira importante força de influência e } \\
\text { LIDERANÇA, não formal na organização...”. }\end{array}$ \\
\hline $\begin{array}{l}\text { REFEREM-SE À } \\
\text { QUALIDADE? }\end{array}$ & Gerente motivado: atenção melhor ao paciente. \\
\hline
\end{tabular}

Quadro 28. Estudo 18. Fonte: Dados analisados pela autora (2007). 


\begin{tabular}{|c|c|}
\hline TÍTULO & Enfermagem: fatores de satisfação. \\
\hline $\operatorname{AUTOR}(E S)$ & Sérgio Ribeiro dos Santos, José Rodrigues Filho. \\
\hline PERIÓDICO & Revista Brasileira de Enfermagem. Brasília - DF. \\
\hline ANO PUBLICAÇÃO & 1995. \\
\hline OBJETIVOS & $\begin{array}{l}\text { Identificar os principais fatores geradores de satisfação e insatisfação no } \\
\text { trabalho dos enfermeiros; } \\
\text { Apresentar sugestões para um melhor ajustamento das necessidades } \\
\text { individuais e organizacionais, na prestação de assistência ao paciente. }\end{array}$ \\
\hline POPULAÇÃO ESTUDADA & $\begin{array}{l}\text { Enfermeiros que trabalhavam nas instituições hospitalares (públicas e } \\
\text { privadas) e nas unidades de serviços de saúde da cidade de João } \\
\text { Pessoa - PB. }\end{array}$ \\
\hline AMOSTRA & Não especificada. 20 enfermeiros realizaram um teste piloto. \\
\hline $\begin{array}{l}\text { INSTRUMENTO COLETA DE } \\
\text { DADOS }\end{array}$ & Questionário. \\
\hline RESULTADOS / CONCLUSÕES & $\begin{array}{l}\text { "Os componentes que mais contribuíram, em ordem fatorial, para que os } \\
\text { enfermeiros avaliassem diretamente seus sentimentos em relação a } \\
\text { vários aspectos concretos do trabalho foram os seguintes: } \\
\text { Fator } 1 \text { - Autonomia com interação social. } \\
\text { Fator } 2 \text { - Reconhecimento da importância do trabalho. } \\
\text { Fator } 3 \text { - Pagamento. } \\
\text { Fator } 4 \text { - Política organizacional. } \\
\text { Fator } 5 \text { - Relação administração - enfermagem. } \\
\text { Fator } 6 \text { - Trabalho em si". } \\
\text { "Portanto, tornou-se imperativa a necessidade de se reestruturar o } \\
\text { ambiente de trabalho dos enfermeiros". } \\
\text { “... os resultados aqui apresentados sugerem que a motivação não deve } \\
\text { ser descartada". }\end{array}$ \\
\hline $\begin{array}{l}\text { RECOMENDAÇÕES PARA A } \\
\text { ENFERMAGEM }\end{array}$ & $\begin{array}{l}\text { Recomendações aos administradores hospitalares, para que gerenciem } \\
\text { os fatores identificados neste estudo, "... promovendo uma atmosfera } \\
\text { mais intelectual, através de programas de educação em serviço, } \\
\text { organização racional do trabalho (sistematização da assistência), } \\
\text { valorização do trabalho por meio de um salário compatível com a } \\
\text { responsabilidade e capacidade do enfermeiro, interação multiprofissional, } \\
\text { condições materiais e tecnológicas para assistir ao paciente, } \\
\text { oportunidades aos enfermeiros para participar do processo decisório } \\
\text { entre outras medidas relacionadas às necessidades comportamentais do } \\
\text { indivíduo". }\end{array}$ \\
\hline REFEREM-SE À LIDERANÇA? & $\begin{array}{l}\text { “.. Nota-se ainda que aos enfermeiros é exigida uma postura de LÍDER } \\
\text { da equipe de enfermagem". }\end{array}$ \\
\hline REFEREM-SE À QUALIDADE? & $\begin{array}{l}\text { Por todo o texto. Qualidade do trabalho, qualidade de vida no trabalho do } \\
\text { enfermeiro, da assistência de enfermagem. }\end{array}$ \\
\hline
\end{tabular}

Quadro 29. Estudo 25-MOT. Fonte: Dados analisados pela autora (2007).

Reunidos aqui os estudos 2, 18 e 25-MOT, os quais tiveram a satisfação no trabalho como objeto de pesquisa, relacionando-a aos fatores de motivação.

No estudo 2, Antunes e Sant'Anna (1996) entenderam que o grau de satisfação/motivação das pessoas que trabalham em um hospital é importante para 
o seu equilíbrio interno enquanto organização. Embasados na Teoria dos dois Fatores de Herzberg (1959) e na interpretação de Maximiano (1989) sobre a mesma, os autores determinaram fatores que levam à satisfação e à motivação da população estudada. Sugerem que a análise destes fatores pode se constituir componente significativo no estudo do serviço de enfermagem e da organização hospitalar, podendo ser assim entendida como uma estratégia potencialmente eficaz.

Matos (1985) desenvolveu sua pesquisa (estudo 18) analisando a atuação do enfermeiro gerente na organização. Entre os aspectos da satisfação no trabalho apresentou a valorização profissional, a participação no planejamento da organização e a insatisfação salarial para o nível de supervisão e gerência. O baixo nível salarial foi apontado como fator de alta insatisfação entre a população estudada. A autora sugeriu algumas recomendações às organizações particulares e públicas e seus dirigentes, entre estas a adoção de uma política de desenvolvimento de recursos humanos e de promoção dos enfermeiros na empresa. Defendeu que a satisfação dos pacientes em relação ao atendimento recebido e a satisfação dos funcionários pela orientação e gerenciamento consciente e motivado podem aumentar os lucros da organização e melhorar sua imagem perante o paciente, família e comunidade.

O estudo 25-MOT referiu-se aos fatores geradores de satisfação e insatisfação no trabalho do enfermeiro. Santos e Rodrigues Filho (1995) apontaram que há ausência de satisfação no trabalho em virtude da burocracia que o enfermeiro é obrigado a lidar, por ele entendida como sinônimo de tramitação de papéis e cumprimento de rotinas e normas. Além disso, apontam que há presença de insatisfação por causa do excesso de atividades desenvolvidas pelo enfermeiro, 
inviabilizando o bom desempenho no trabalho. Os autores afirmaram que torna - se imperativa a necessidade de se reestruturar o ambiente de trabalho dos enfermeiros, sugerindo que "a motivação não deve ser descartada". Sugeriram aos administradores hospitalares o gerenciamento destes fatores de satisfação e motivação.

\subsubsection{Subcategoria Significados e Percepções de Motivação}

\begin{tabular}{|c|c|}
\hline TÍTULO & $\begin{array}{l}\text { A enfermagem e o conhecimento dos conceitos de liderança, } \\
\text { motivação, comunicação e mudança. }\end{array}$ \\
\hline$\overline{A U T O R}(E S)$ & Margarita Villar Luiz. \\
\hline PERIÓDICO & Acta Paulista de Enfermagem. São Paulo - SP. \\
\hline ANO PUBLICAÇÃO & 1989. \\
\hline OBJETIVOS & $\begin{array}{l}\text { Apresentar percepções que enfermeiras assistenciais têm desses } \\
\text { conceitos, e reflexões da autora a respeito do assunto. }\end{array}$ \\
\hline POPULAÇÃO ESTUDADA & "Enfermeiros da área hospitalar". \\
\hline AMOSTRA & 10 enfermeiros. \\
\hline $\begin{array}{l}\text { INSTRUMENTO COLETA DE } \\
\text { DADOS }\end{array}$ & Questionário / entrevista (?). \\
\hline RESULTADOS / CONCLUSÕES & $\begin{array}{l}\text { Sobre liderança: centrada no líder, sendo-lhe atribuídas características } \\
\text { que acentuam a onipotência e o uso da autoridade no exercício de } \\
\text { suas atribuições. Liderado é visto como um subalterno a quem é } \\
\text { necessário dirigir. } \\
\text { Sobre motivação: predomínio de características relativas às teorias da } \\
\text { satisfação e teorias intrínsecas. Sugere que hospitais parecem ignorar } \\
\text { fatores relativos ao trabalho (fatores higiênicos de Herzberg). } \\
\text { Sobre comunicação: apreensões em relação a como suas colocações } \\
\text { serão interpretadas pelos outros, evidenciando dificuldades } \\
\text { principalmente quando considerada ordem hierárquica. Formalidade, } \\
\text { ambigüidade. } \\
\text { Sobre mudança: dificuldade em se aceitar ou promover mudança de } \\
\text { qualquer ordem. Resistência, cautela. }\end{array}$ \\
\hline $\begin{array}{l}\text { RECOMENDAÇÕES PARA A } \\
\text { ENFERMAGEM }\end{array}$ & $\begin{array}{l}\text { Enfermagem tem que se libertar desse modelo que a sufoca, tem que } \\
\text { buscar novas alternativas que permitam a expressão de suas múltiplas } \\
\text { potencialidades, que a tornam atrativa para os jovens, eficaz no } \\
\text { atendimento à população e eficiente para as instituições. }\end{array}$ \\
\hline REFEREM-SE À LIDERANÇA? & Um dos conceitos discutidos. Apresenta síntese teórica do conceito. \\
\hline REFEREM-SE À QUALIDADE? & Não. \\
\hline
\end{tabular}

Quadro 30. Estudo 16-MOT. Fonte: Dados analisados pela autora (2007). 


\begin{tabular}{|c|c|}
\hline TÍTULO & A motivação no trabalho da equipe de enfermagem. \\
\hline $\operatorname{AUTOR}(E S)$ & Marta Cristiane Alves Pereira, Neide Fávero. \\
\hline PERIÓDICO & Revista Latino Americana de Enfermagem. Ribeirão Preto - SP. \\
\hline ANO PUBLICAÇÃO & 2001. \\
\hline OBJETIVOS & $\begin{array}{l}\text { Conhecer a opinião do pessoal de enfermagem sobre a motivação } \\
\text { no trabalho. } \\
\text { Identificar aspectos motivacionais que contribuem para a motivação } \\
\text { e para a desmotivação no trabalho. }\end{array}$ \\
\hline POPULAÇÃO ESTUDADA & $\begin{array}{l}18 \text { profissionais de enfermagem de um hospital universitário, em } \\
\text { Ribeirão Preto - SP. }\end{array}$ \\
\hline AMOSTRA & 06 enfermeiros e 12 técnicos e auxiliares de enfermagem. \\
\hline INSTRUMENTO COLETA DE DADOS & Entrevista semi - estruturada e gravada. \\
\hline RESULTADOS / CONCLUSÕES & $\begin{array}{l}10 \text { categorias de resposta entre os fatores motivacionais e higiênicos } \\
\text { de Herzberg. } \\
122 \text { unidades de resposta dos fatores higiênicos x } 63 \text { unidades de } \\
\text { resposta dos fatores motivacionais. } \\
\text { Trabalho em si - categoria mais motivadora; } \\
\text { Organização do trabalho - desmotivadora. } \\
\text { "A análise da questão 'trabalho em si' como principal motivador no } \\
\text { trabalho, permite inferir que o cuidado ao paciente pode ser } \\
\text { considerado o alicerce da prática de enfermagem, enquanto a } \\
\text { 'organização do trabalho', como maior desmotivadora, alerta-nos } \\
\text { para a importância da 'saúde' das organizações”. } \\
\text { “... o estudo da motivação, em decorrência da sua complexidade e } \\
\text { dificuldade, parece não ser esgotável, necessitando assim, de maior } \\
\text { aprofundamento e atenção das organizações e instituições } \\
\text { formadoras. Além disso, há a dificuldade da abordagem do tema } \\
\text { 'motivação' entre os elementos da equipe de enfermagem, dentro do } \\
\text { atual contexto dos serviços públicos de saúde no Brasil”. }\end{array}$ \\
\hline $\begin{array}{l}\text { RECOMENDAÇÕES PARA A } \\
\text { ENFERMAGEM }\end{array}$ & $\begin{array}{l}\text { “... 'relacionamento interpessoal' e 'organização do trabalho'... } \\
\text { aspectos do trabalho que podem ser transformados através de } \\
\text { investimentos na área de recursos humanos e de mudanças na } \\
\text { política organizacional. O desejo dos profissionais quanto às } \\
\text { mudanças em relação a esses aspectos do trabalho merece } \\
\text { atenção, pois, apesar de extrínsecos, a garantia desses aspectos } \\
\text { proporciona oportunidade para que a motivação do profissional seja } \\
\text { refletida no alcance dos objetivos da organização". }\end{array}$ \\
\hline REFEREM-SE À LIDERANÇA? & $\begin{array}{l}\text { "Enfocando mais especificamente a administração, a LIDERANÇA e } \\
\text { suas relações com a motivação...". }\end{array}$ \\
\hline REFEREM-SE À QUALIDADE? & $\begin{array}{l}\text { "... a motivação surge como aspecto fundamental na busca de maior } \\
\text { eficiência e, consequentemente, de maior QUALIDADE na } \\
\text { assistência de enfermagem prestada, aliada à satisfação dos } \\
\text { trabalhadores". }\end{array}$ \\
\hline
\end{tabular}

Quadro 31. Estudo 22. Fonte: Dados analisados pela autora (2007).

Os estudos 16-MOT e 22 abordaram a motivação e o trabalho da enfermagem sob as percepções e opiniões de enfermeiras e técnicos de enfermagem. Tais estudos evidenciaram que os profissionais pesquisados 
estabelecem relações entre a satisfação no trabalho e a motivação. Apontaram ainda a necessidade de mudanças no ambiente da organização, no que tange à sua estrutura e funcionamento.

Luiz (1989) - estudo 16-MOT - reuniu e analisou o conhecimento de um grupo de enfermeiros acerca dos conceitos de liderança, motivação, comunicação e mudança. Identificou que o tradicionalismo das teorias mais antigas da administração é o que predomina na prática da assistência de enfermagem da amostra estudada que, segundo ela, adota um modelo "sufocante". Sobre motivação, percebeu o predomínio de características relativas às teorias da satisfação e teorias intrínsecas. Sugere um novo olhar para a realidade e a busca de novas alternativas de trabalho.

No estudo 22, Pereira e Fávero (2001), por sua vez, visaram apreender aspectos que intervêm na motivação humana e suas implicações no resultado do trabalho da equipe de enfermagem estudada. A categoria trabalho em si foi considerada a principal motivadora no trabalho, o que permitiu aos autores inferir que o cuidado ao paciente pode ser considerado o alicerce da prática de enfermagem. A organização do trabalho, categoria mais desmotivadora, alertou para a importância da "saúde" das organizações ou, melhor dizendo, como as mesmas se estruturam e lidam com seus funcionários. 


\subsubsection{Subcategoria Fatores e Perfis Motivacionais}

\begin{tabular}{|c|c|}
\hline TÍTULO & $\begin{array}{l}\text { A realização, a afiliação e o poder: em qual destes três fatores está } \\
\text { calcada a motivação dos enfermeiros em um hospital de ensino? }\end{array}$ \\
\hline AUTOR (ES) & Agnes Olschowsky, Enaura Helena Brandão Chaves. \\
\hline PERIÓDICO & Revista Gaúcha de Enfermagem. Porto Alegre - RS. \\
\hline ANO PUBLICAÇÃO & 1997. \\
\hline OBJETIVOS & $\begin{array}{l}\text { Identificar qual destes três aspectos (realização, afiliação e poder) é o } \\
\text { fator motivacional mais freqüente entre os enfermeiros que trabalham em } \\
\text { unidades de internação de Enfermagem Clínica para adultos em um } \\
\text { hospital de ensino. }\end{array}$ \\
\hline POPULAÇÃO ESTUDADA & $\begin{array}{l}71 \text { enfermeiros que trabalham em unidades de internação de } \\
\text { enfermagem médica para adultos de um hospital universitário, em Porto } \\
\text { Alegre-RS. }\end{array}$ \\
\hline AMOSTRA & $55(77 \%)$ enfermeiros. \\
\hline $\begin{array}{l}\text { INSTRUMENTO COLETA DE } \\
\text { DADOS }\end{array}$ & Questionários. \\
\hline RESULTADOS / CONCLUSÕES & $\begin{array}{l}\text { Fator motivacional predominante: Realização - } 44 \text { enfermeiros (80\%). } \\
\text { Afiliação e Poder - } 7 \% \text {. } \\
\text { Dos } 44,37 \text { eram enfermeiros de unidade. } 07 \text { possuíam cargo de } \\
\text { enfermeiro chefe de unidade. } \\
\text { Dos } 44,16 \text { (36\%) possuíam experiência anterior em chefia. Os demais } \\
\text { nunca tinham exercido qualquer chefia. } \\
\text { o9 participaram de algum curso sobre chefia. Destes, } 05 \text { eram aqueles } \\
\text { que respondiam pelas chefias de unidade. Dos } 04 \text { restantes, apenas } 1 \\
\text { relatou não ter tido experiência anterior em chefia, o que nos indica a } \\
\text { constante atuação deste profissional em cargos de gerência. } \\
21 \text { não responderam sobre a participação em cursos. } 14 \text { não participaram } \\
\text { de nenhum curso. } \\
\text { “... conhecer os fatores motivacionais dos enfermeiros contribui para } \\
\text { estabelecermos atitudes estratégicas na QUALIDADE das relações entre } \\
\text { os profissionais e, consequentemente, no gerenciamento da assistência } \\
\text { de enfermagem”. }\end{array}$ \\
\hline $\begin{array}{l}\text { RECOMENDAÇÕES PARA A } \\
\text { ENFERMAGEM }\end{array}$ & $\begin{array}{l}\text { "Como ascensão profissional o enfermeiro possui somente a área administrativa } \\
\text { através de cargos de chefia de unidade, chefia de serviço e coordenação de } \\
\text { serviços e, para tal o enfermeiro muitas vezes pensa estar afastando-se da razão } \\
\text { de ser do seu trabalho: a assistência de enfermagem, desconhecendo que a } \\
\text { adequada administração desta assistência prestada pela equipe de enfermagem é } \\
\text { que garantirá a QUALIDADE da mesma e o conseqüente bem - estar da equipe } \\
\text { (realização)". }\end{array}$ \\
\hline REFEREM-SE À LIDERANÇA? & $\begin{array}{l}\text { "... os enfermeiros de unidade [...] exercendo importante papel na coordenação e } \\
\text { liderança do grupo". } \\
\text { "... a preocupação dos mesmos com aspectos relativos a liderança e } \\
\text { administração de pessoal torna-se evidente à medida que assumem cargos } \\
\text { diretivos". } \\
\text { "... preparo de nossos estudantes, desenvolvendo com os mesmos noções } \\
\text { atualizadas sobre liderança". }\end{array}$ \\
\hline REFEREM-SE À QUALIDADE? & $\begin{array}{l}\text { “... conhecer os fatores motivacionais dos enfermeiros contribui para } \\
\text { estabelecermos atitudes estratégicas na QUALIDADE das relações entre } \\
\text { os profissionais e, consequentemente, no gerenciamento da assistência } \\
\text { de enfermagem". } \\
\text { "[...] a adequada administração desta assistência prestada pela equipe de } \\
\text { enfermagem é que garantirá a QUALIDADE da mesma e o conseqüente } \\
\text { bem - estar da equipe (realização)". }\end{array}$ \\
\hline
\end{tabular}

Quadro 32. Estudo 20. Fonte: Dados analisados pela autora (2007). 


\begin{tabular}{|c|c|}
\hline TÍTULO & $\begin{array}{l}\text { Perfil motivacional do enfermeiro atuante em um hospital geral do } \\
\text { interior paulista. }\end{array}$ \\
\hline$\overline{A U T O R}(E S)$ & Maria José Pasti, Elucir Gir, José Augusto Dela Coleta. \\
\hline PERIÓDICO & Revista Latino Americana de Enfermagem. Ribeirão Preto - SP. \\
\hline ANO PUBLICAÇÃO & 1999. \\
\hline OBJETIVOS & $\begin{array}{l}\text { Geral: } \\
\text { Identificar o perfil motivacional dos enfermeiros de uma instituição de } \\
\text { saúde do interior do estado de São Paulo. } \\
\text { Buscar compreender o comportamento dos enfermeiros em situação de } \\
\text { trabalho. } \\
\text { Específicos: } \\
\text { Mapear as motivações que conduzem o grupo de enfermeiros no } \\
\text { trabalho. } \\
\text { Correlacionar as atitudes e crenças verificadas em relação ao trabalho e } \\
\text { suas motivações. }\end{array}$ \\
\hline POPULAÇÃO ESTUDADA & $\begin{array}{l}\text { Média de } 238 \text { enfermeiros de um hospital geral universitário de } 600 \text { leitos, } \\
\text { no interior do estado de São Paulo. }\end{array}$ \\
\hline AMOSTRA & 184 (77.31\%) enfermeiros. \\
\hline $\begin{array}{l}\text { INSTRUMENTO COLETA DE } \\
\text { DADOS }\end{array}$ & Duas escalas tipo Likert (Inventário MOSE e ACTRA), e um questionário. \\
\hline RESULTADOS / CONCLUSÕES & $\begin{array}{l}\text { Dentre as três motivações básicas a motivação de Realização apareceu como a } \\
\text { mais importante dentro do perfil motivacional do enfermeiro, "no que se refere ao } \\
\text { desenvolvimento pessoal e estratégias de ação para alcançar essas metas". } \\
\text { “... estão correlacionadas positivamente as medidas de motivação de realização } \\
\text { (metas e instrumentação), de internalidade, de esperança ativa e otimismo". } \\
\text { Constatação: “... a maioria dos enfermeiros estudados caminha para a superação } \\
\text { do subdesenvolvimento, demonstrando altos níveis de motivação de realização e } \\
\text { menores com relação à motivação de afiliação e poder". }\end{array}$ \\
\hline $\begin{array}{l}\text { RECOMENDAÇÕES PARA A } \\
\text { ENFERMAGEM }\end{array}$ & $\begin{array}{l}\text { “... é preciso enfatizar a necessidade de se valorizar os aspectos } \\
\text { motivacionais no trabalho, considerando-se as variáveis psicológicas, } \\
\text { sobretudo no sentido de reforçar ou aumentar os níveis das variáveis } \\
\text { desejáveis e diminuir os níveis das indesejáveis". }\end{array}$ \\
\hline REFEREM-SE À LIDERANÇA? & Não. \\
\hline REFEREM-SE À QUALIDADE? & Não. \\
\hline
\end{tabular}

Quadro 33: Estudo 21. Fonte: Dados analisados pela autora (2007).

Os estudos 20 e 21 trataram dos fatores e perfis motivacionais, utilizando em comum a abordagem sobre as Necessidades Sociais de Realização, Poder e Afiliação de David McClelland (1965). Ambos identificaram a necessidade de Realização como sendo o fator motivacional mais importante. Além disso, apontaram como importantes aspectos relativos à organização do trabalho e ao desenvolvimento / treinamento dos profissionais através, por exemplo, dos serviços de Educação Continuada. 
No estudo 20, Olschowsky e Chaves (1997) confirmaram que "a maioria dos enfermeiros busca através de seu trabalho chegar a Realização, e esta só é possível através não só de seu próprio esforço, mas do apoio organizacional". Apontaram para a necessidade de se "oferecer cada vez mais subsídios na formação e orientação de enfermeiros, instrumentalizando - os para o gerenciamento na área de enfermagem". Salientaram ainda que o incentivo e reconhecimento por parte da empresa são imprescindíveis, e sugeriram o conhecimento dos fatores motivacionais e de técnicas para o exercício do poder.

Pasti; Gir e Dela Coleta (1999), no estudo 21, também identificaram a motivação de Realização como a mais importante dentro do perfil motivacional do enfermeiro integrante daquela amostra. Afirmaram que "ainda que os enfermeiros busquem estabelecer metas cada vez mais difíceis, porém alcançáveis, há uma grande necessidade de superar - se a si mesmo e aos outros". Recomendaram ênfase na valorização dos aspectos motivacionais no trabalho do enfermeiro.

Mezomo (2001, p. 240) corroborou nosso entendimento acerca da necessidade em formularmos estratégias quando questiona: "Como potencializar as pessoas?", "Como motivá-las para a responsabilidade?", "Como modificar suas atitudes e comportamentos?". Aponta o esforço corporativo, educação e treinamento das pessoas, as quais devem ser convidadas a participarem da missão da instituição, a viverem seus valores e a se identificarem com seus objetivos. "A qualidade só ocorre quando as pessoas são capazes de melhorar os processos, e só o serão através da educação e treinamento continuado". 


\subsubsection{Categoria temática qualidade}

\subsubsection{Subcategoria Gerenciamento da Qualidade}

\begin{tabular}{|c|c|}
\hline TÍTULO & Liderança para a Qualidade na Enfermagem. \\
\hline AUTOR (ES) & Arthur Velloso Antunes \\
\hline PERIÓDICO & Nursing. São Paulo. \\
\hline ANO PUBLICAÇÃO & 1999. \\
\hline OBJETIVOS & $\begin{array}{l}\text { Analisar o gerenciamento da qualidade em um serviço de enfermagem } \\
\text { de uma instituição hospitalar. }\end{array}$ \\
\hline POPULAÇÃO ESTUDADA & $\begin{array}{l}70 \text { enfermeiros - } 01 \text { gerente de divisão, } 05 \text { chefes de setores, } 22 \\
\text { supervisores, e } 42 \text { assistenciais. } \\
\text { Serviço de Enfermagem de uma instituição localizada em um município } \\
\text { no litoral do estado de São Paulo. }\end{array}$ \\
\hline AMOSTRA & 57 enfermeiros (81\%). \\
\hline $\begin{array}{l}\text { INSTRUMENTO COLETA DE } \\
\text { DADOS }\end{array}$ & Questionário. \\
\hline RESULTADOS/CONCLUSÕES & $\begin{array}{l}\text { Analisado gerenciamento sob a aplicação do Princípio } 7 \text { de Deming } \\
\text { (1990) - adotar e instituir liderança - este não é utilizado } \\
\text { adequadamente; supervisão ainda é importante; funcionários } \\
\text { expressam medo; há clima de cooperação e participação; com certa } \\
\text { freqüência chefes são apoiadores e facilitadores; há a adoção do } \\
\text { trabalho em equipe. } \\
\text { Liderança é fundamental ao bom gerenciamento do serviço de } \\
\text { enfermagem e, consequentemente, à qualidade da assistência } \\
\text { prestada ao paciente. }\end{array}$ \\
\hline $\begin{array}{l}\text { RECOMENDAÇÕES PARA A } \\
\text { ENFERMAGEM }\end{array}$ & $\begin{array}{l}\text { "[...] é indispensável que o enfermeiro que atua como líder no } \\
\text { desempenho de suas atividades esteja capacitado para atuar como um } \\
\text { 'líder competente' nas diferentes situações profissionais”. } \\
\text { Para o desenvolvimento e melhoria da qualidade da assistência que } \\
\text { presta ao paciente, Liderança deve ser tema presente nos cursos de } \\
\text { graduação e pós - graduação em Enfermagem, bem como nos } \\
\text { programas de capacitação das instituições de saúde. }\end{array}$ \\
\hline REFEREM-SE À LIDERANÇA? & $\begin{array}{l}\text { Fundamento para o gerenciamento da qualidade na Enfermagem. Que } \\
\text { o enfermeiro seja líder da qualidade da assistência de enfermagem. }\end{array}$ \\
\hline REFEREM-SE À MOTIVAÇÃO? & $\begin{array}{l}\text { Não explicitamente. Citam estímulo ao envolvimento, ao } \\
\text { comprometimento. "[...] estimular as pessoas em busca dos objetivos". }\end{array}$ \\
\hline
\end{tabular}

Quadro 34. Estudo 1-QUA. Fonte: Dados analisados pela autora (2007). 


\begin{tabular}{|c|c|}
\hline TÍTULO & Gerenciamento da qualidade: utilização no serviço de enfermagem. \\
\hline AUTOR (ES) & Arthur Velloso Antunes, Maria Auxiliadora Trevizan. \\
\hline PERIÓDICO & Rev. latino-am. enfermagem. Ribeirão Preto - SP. \\
\hline $\begin{array}{l}\text { ANO PUBLICAÇÃO / ANO } \\
\text { ESTUDO (coleta de dados) }\end{array}$ & $2000 / 1996$. \\
\hline OBJETIVOS & $\begin{array}{l}\text { Estudar a forma de implantação da Qualidade adotada no serviço de } \\
\text { enfermagem de uma instituição hospitalar; } \\
\text { Verificar se os enfermeiros desta instituição sabem o que é Qualidade } \\
\text { Total e seus fundamentos, se acreditam em bons resultados com sua } \\
\text { implantação, se estão empenhados no processo, e se perceberam } \\
\text { melhoria na satisfação do pessoal e do paciente; } \\
\text { Verificar se os princípios da qualidade, como propostos por Deming, e as } \\
\text { recomendações neles contidas estão sendo empregados na } \\
\text { administração desse serviço de Enfermagem. }\end{array}$ \\
\hline POPULAÇÃO ESTUDADA & $\begin{array}{l}70 \text { enfermeiros - } 01 \text { gerente de divisão, } 05 \text { chefes de setores, } 22 \\
\text { supervisores, e } 42 \text { assistenciais. } \\
\text { Hospital geral, privado, } 236 \text { leitos, em um município no litoral do estado } \\
\text { de São Paulo. }\end{array}$ \\
\hline AMOSTRA & $\begin{array}{l}57 \text { enfermeiros (81\%). } 38 \text { assistenciais (66.6\%) e } 19 \text { enfermeiros com } \\
\text { cargo de chefia (33.3\%). }\end{array}$ \\
\hline $\begin{array}{l}\text { INSTRUMENTO COLETA DE } \\
\text { DADOS }\end{array}$ & Questionário. \\
\hline RESULTADOS/CONCLUSÕES & $\begin{array}{l}\text { Implantação do gerenciamento da qualidade: contratação de duas } \\
\text { empresas de consultoria, que ministraram cursos sobre Qualidade; } \\
\text { chefias aderiram aos cursos. Não houve difusão dos princípios da } \\
\text { liderança para a qualidade (Deming). } \\
\text { Opinião e envolvimento do enfermeiro: Com o gerenciamento da } \\
\text { qualidade } 79 \% \text { dos enfermeiros observaram melhoria na satisfação do } \\
\text { pessoal e 89,5\% na satisfação do paciente. } \\
\text { Utilização dos princípios de Deming: Princípio } 6 \text { (institua treinamento) foi } \\
\text { o melhor aplicado. Princípio } 7 \text { (adote e institua liderança) obteve a menor } \\
\text { nota. } \\
\text { "Os enfermeiros estão envolvidos no Gerenciamento da Qualidade e } \\
\text { quase todos sabem o que é, acreditam em bons resultados e estão } \\
\text { empenhados no processo". } \\
\text { "[...] o serviço de enfermagem em estudo tem experimentado um } \\
\text { desenvolvimento significativo [...]. Entre as mudanças importantes, [...] } \\
\text { estão a criação de um Centro de Educação Continuada e a melhoria na } \\
\text { qualidade dos recursos humanos [...]". }\end{array}$ \\
\hline $\begin{array}{l}\text { RECOMENDAÇÕES PARA A } \\
\text { ENFERMAGEM }\end{array}$ & $\begin{array}{l}\text { "[...] o gerenciamento da qualidade, se bem implantado pode ser útil à } \\
\text { enfermagem, ajudando - a na realização das mudanças necessárias ao } \\
\text { seu desenvolvimento, na implementação de novas metodologias e no } \\
\text { alcance da satisfação do paciente e do seu pessoal". }\end{array}$ \\
\hline REFEREM-SE À LIDERANÇA? & Somente com um dos princípios de Deming (1990). \\
\hline REFEREM-SE À MOTIVAÇÃO? & Não. \\
\hline
\end{tabular}

Quadro 35. Estudo 3. Fonte: Dados analisados pela autora (2007).

O gerenciamento da qualidade foi o objeto comum aos estudos 1-QUA e 3. Ambos identificaram a importância da liderança para a qualidade da assistência de 
enfermagem prestada ao paciente, sob o enfoque da aplicação dos princípios de Deming (1990).

Antunes (1999) desenvolveu seu estudo (1-QUA) apontando o gerenciamento da qualidade como uma forma de gestão que ajudará a enfermagem a implementar as transformações exigidas pelos novos tempos. Abordou a liderança exercida pelo enfermeiro no desempenho de suas funções como um dos fatores considerados fundamentais ao sucesso dessa forma de gerenciamento. Citando Deming (1990), Antunes enfatizou somente o princípio 7 - adote e institua liderança estabelecendo uma relação direta entre liderança e qualidade, defendendo que o enfermeiro deve ser líder da qualidade da assistência. Ao fundamentar seu estudo, apontou ações que devem ser executadas pelo líder da qualidade em qualquer contexto organizacional, mencionando estratégias de liderança para a qualidade. Em relação à enfermagem, apontou sugestões sobre como o enfermeiro líder da qualidade deve agir perante seus liderados.

No estudo 3, Antunes e Trevizan (2000) visaram verificar a utilização dos 14 princípios de Deming (1990). Identificaram que o princípio 7 - adote e institua liderança - foi o que obteve a menor nota, ou foi o menos aplicado. O princípio 6 institua treinamento - foi o melhor aplicado, já que o serviço de enfermagem da instituição se preocupa com educação continuada. Os autores apontaram que "[...] o gerenciamento da qualidade, se bem implantado, pode ser útil à Enfermagem, ajudando - a na realização de mudanças necessárias ao seu desenvolvimento [...]". Defenderam ainda que tal gerenciamento "através do desenvolvimento das pessoas e do trabalho em equipe" deve procurar o comprometimento e o envolvimento de todos para atender às expectativas dos trabalhadores e pacientes. 
O que é o gerenciamento da qualidade "bem" implantado? Como a enfermagem poderia implantar bem o gerenciamento da qualidade?

Segundo os autores, o comprometimento e o envolvimento de todos no processo de melhoria contínua dos processos devem ser "procurados" ao se gerenciar qualidade. Isto permite subentender a identificação e estímulo de tais fatores, através da utilização de estratégias específicas para tal objetivo. Desta forma, são dois passos a serem seguidos: identificar o que gera comprometimento e envolvimento; agir estrategicamente para estimulá-los.

No contexto apontado pelos autores, o atendimento das expectativas dos trabalhadores de enfermagem e dos pacientes se torna conseqüência deste gerenciamento da qualidade. Não se discutiu, entretanto, como proceder este atendimento, como gerenciar qualidade para este objetivo. Tomar ciência destas expectativas é ação prioritária. Posteriormente, se faz necessário determinar se a organização - no que diz respeito às expectativas dos trabalhadores - e se a equipe de enfermagem - em relação aos pacientes - possuem condições e apresentam-se disponíveis para atendê-las. 


\subsubsection{Subcategoria Satisfação no Trabalho}

\begin{tabular}{|c|c|}
\hline TÍTULO & $\begin{array}{l}\text { Gestão de equipe de enfermagem de uma UTI: a satisfação } \\
\text { profissional em foco. }\end{array}$ \\
\hline AUTOR (ES) & Laura Misue Matsuda, Yolanda Dora Martinez Évora. \\
\hline PERIÓDICO & Ciência, Cuidado e Saúde. Maringá - PR. \\
\hline ANO PUBLICAÇÃO & 2003. \\
\hline OBJETIVOS & $\begin{array}{l}\text { Desenvolver um estudo voltado à satisfação profissional de uma } \\
\text { equipe de enfermagem de uma UTI - adulto, alicerçado no sistema de } \\
\text { Gestão da Qualidade (GQ). } \\
\text { Conhecer os componentes de satisfação no trabalho pelos quais a } \\
\text { equipe se encontra menos satisfeita. }\end{array}$ \\
\hline POPULAÇÃO ESTUDADA & $\begin{array}{l}\text { Equipe de enfermagem - UTI adulto (04 leitos), de um hospital - } \\
\text { escola, em Maringá - PR. }\end{array}$ \\
\hline AMOSTRA & 08 enfermeiras e 09 auxiliares de enfermagem. \\
\hline $\begin{array}{l}\text { INSTRUMENTO COLETA DE } \\
\text { DADOS }\end{array}$ & Entrevista e aplicação de questionário. \\
\hline RESULTADOS / CONCLUSÕES & $\begin{array}{l}\text { Enfermeiros apontaram maior insatisfação aos aspectos relacionados à } \\
\text { organização do trabalho. Suas necessidades eram mais voltadas à } \\
\text { organização e gestão do serviço. } \\
\text { Os auxiliares de enfermagem demonstraram carecer de mais } \\
\text { reconhecimento e abertura no trabalho. Estes se mostraram ainda } \\
\text { menos satisfeitos no trabalho do que as enfermeiras. Problemas no } \\
\text { serviço e na profissão afetam a satisfação das duas categorias. } \\
\text { Identificaram deficiências estruturais e de organização, as quais } \\
\text { dificultam as ações dos profissionais e resultam em insatisfação dos } \\
\text { mesmos. } \\
\text { Pesquisadores ofereceram sugestões de instrumentos administrativos } \\
\text { e de trabalho. Tais medidas foram adotadas para os componentes com } \\
\text { os quais as equipes se encontravam menos satisfeitas e serviram de } \\
\text { base para discussões referentes ao planejamento e organização do } \\
\text { serviço. } \\
\text { "Percebemos que, ao darmos vez e voz aos trabalhadores, estes } \\
\text { demonstraram interesse em promover mudanças, passaram a se sentir } \\
\text { desejosos e até motivados". }\end{array}$ \\
\hline $\begin{array}{l}\text { RECOMENDAÇÕES PARA A } \\
\text { ENFERMAGEM }\end{array}$ & $\begin{array}{l}\text { Sugerem que os estudos que enfocam a melhoria da satisfação no } \\
\text { trabalho da enfermagem necessitam de maior incremento, visto que a } \\
\text { demanda e a complexidade dos serviços têm aumentado e isso induz } \\
\text { os profissionais à otimização dos serviços e à qualidade profissional. }\end{array}$ \\
\hline REFEREM-SE À LIDERANÇA? & No plural - lideranças - referindo-se a chefias, gerentes. \\
\hline REFEREM-SE À MOTIVAÇÃO? & $\begin{array}{l}\text { Diferenciando-o do conceito de satisfação, citando Marquis e Huston } \\
\text { (1999) - “... motivação é de cunho interno...". }\end{array}$ \\
\hline
\end{tabular}

Quadro 36. Estudo 19. Fonte: Dados analisados pela autora (2007). 
No estudo 19, Matsuda e Évora (2003) trataram da satisfação no trabalho, identificando os componentes de satisfação no trabalho da equipe de enfermagem em questão. Nesta pesquisa, a participação dos auxiliares de enfermagem em atividades de planejamento e organização do serviço na unidade mostrou - se fundamental para a satisfação destes profissionais. Eles demonstraram motivação e interesse em promover mudanças quando Ihes foram dadas "vez e voz", ou seja, quando suas opiniões e sugestões foram acatadas.

Ao longo de sua experiência profissional, Matsuda e Évora (2003) constataram que, na maioria das vezes, as causas do baixo impacto na atuação do enfermeiro no serviço e na sociedade são resultados do conformismo, da resistência às inovações e da falta de comprometimento com o seu papel. Observaram ainda que muitos enfermeiros resistem às inovações e poucos são os que tomam a iniciativa de adotar uma abordagem gerencial inovadora alicerçada em princípios e indicadores e padrões de qualidade voltados às necessidades pessoais e profissionais dos trabalhadores.

As autoras acreditaram que com criatividade, persistência e determinação, a satisfação do profissional de enfermagem e o seu trabalho poderão ser melhorados. Defenderam que a incorporação de uma nova filosofia na organização também deve ser feita ao nível individual, "pois é a partir da internalização de conceitos e princípios semelhantes que a mudança se inicia". Recomendaram maior incremento nos estudos que enfocam a melhoria da satisfação no trabalho da enfermagem.

É preciso atenção à importância de se ouvir os trabalhadores, identificando suas expectativas e como podem colaborar no processo de melhorias. Os autores sugeriram que a mudança se inicie a partir da atitude individual. Isto não sugere que devemos pesquisar as causas do baixo impacto na atuação do enfermeiro no 
serviço? Quais são as razões para tanta resistência às mudanças? O que e como seria a atuação de enfermagem de alto impacto?

Como melhorar a satisfação no trabalho da enfermagem? Deve-se compreender, primeiramente, toda a dimensão do trabalho de enfermagem (o que é, quem deve fazê - lo, para quem...), e somente depois o que promove satisfação ao realizá - lo. Entender como satisfazer quem o realiza e quem o "recebe". Uma vez identificados, tais fatores deverão ser aprimorados em quantidade e qualidade. 


\subsubsection{Subcategoria Qualidade sob a Ótica dos Pacientes}

\begin{tabular}{|c|c|}
\hline TÍTULO & $\begin{array}{l}\text { A ótica do cliente hospitalizado sobre a qualidade da assistência de } \\
\text { enfermagem. }\end{array}$ \\
\hline AUTOR (ES) & Camila Santejo Silveira, Neide Fávero, Marta Cristiane Alves - Pereira. \\
\hline PERIÓDICO & Revista de Enfermagem da UERJ. Rio de Janeiro - RJ. \\
\hline ANO PUBLICAÇÃO & 2003. \\
\hline OBJETIVOS & $\begin{array}{l}\text { Conhecer as necessidades e expectativas manifestadas pelos pacientes internados } \\
\text { na clínica cirúrgica de um hospital - escola sobre a assistência de enfermagem } \\
\text { prestada a eles, durante o período de internação; } \\
\text { Verificar e analisar se essas expectativas e necessidades foram atendidas. }\end{array}$ \\
\hline $\begin{array}{l}\text { POPULAÇÃO } \\
\text { ESTUDADA }\end{array}$ & $\begin{array}{l}36 \text { pacientes internados na clínica cirúrgica de um hospital - escola, na cidade de } \\
\text { Ribeirão Preto - SP. }\end{array}$ \\
\hline AMOSTRA & 33 pacientes. \\
\hline $\begin{array}{l}\text { INSTRUMENTO } \\
\text { COLETA DE DADOS }\end{array}$ & Entrevista semi - estruturada. \\
\hline $\begin{array}{l}\text { RESULTADOS / } \\
\text { CONCLUSÕES }\end{array}$ & $\begin{array}{l}\text { Quanto às expectativas: } \\
10 \text { (30.3\%) - não referiram nenhuma expectativa em relação à equipe de enfermagem. } \\
08 \text { (24.2\%) - expectativa predominante: ser bem atendido pela equipe. } \\
07(21.2 \%) \text { - referiram mais de uma expectativa. } \\
\text { Destacadas as expectativas negativas: 'não esperavam que fossem prestativos, não } \\
\text { esperavam ter atenção, medo de não ter remédio para dor'. } \\
\text { Confirmado, assim, o desconhecimento da equipe de enfermagem por parte dos clientes. } \\
\text { Aspectos mais valorizados pelos clientes - } 07 \text { (28\% das expectativas expressas): apoio, } \\
\text { compreensão, carinho, consolo, atenção, disposição. } \\
\text { Quanto ao atendimento das expectativas e necessidades: } \\
30 \text { (90.9\%) - afirmaram que todas as necessidades e expectativas foram atendidas. } \\
02 \text { (6.1\%) - afirmaram que isso ocorreu ocasionalmente. } \\
01 \text { (3.0\%) - afirmou que nunca foi atendido adequadamente. } \\
\text { "A maioria das respostas positiva indica o atendimento das expectativas, valorizando os } \\
\text { serviços prestados, o que corresponde ao alcance da finalidade da assistência de } \\
\text { enfermagem". }\end{array}$ \\
\hline $\begin{array}{l}\text { RECOMENDAÇÕES } \\
\text { PARA A } \\
\text { ENFERMAGEM }\end{array}$ & $\begin{array}{l}\text { "Talvez o aprimoramento de uma sistemática de trabalho possa melhorar a qualidade da } \\
\text { assistência de enfermagem. Isso é possível porque a enfermagem possui um conjunto de } \\
\text { conhecimentos técnicos e teóricos próprios que devem ser utilizados para nortear sua prática } \\
\text { de trabalho". } \\
\text { "O conhecimento das necessidades e expectativas do cliente em relação à equipe de } \\
\text { enfermagem se constitui no primeiro passo dado por esses profissionais na busca da } \\
\text { qualidade". "[...] além de estarmos atendendo às suas necessidades, está sendo garantida } \\
\text { também a satisfação profissional do enfermeiro". }\end{array}$ \\
\hline $\begin{array}{l}\text { REFEREM-SE À } \\
\text { LIDERANÇA? }\end{array}$ & $\begin{array}{l}\text { No plural - lideranças - referindo-se a chefias, gerentes. Sugerem o exercício de uma liderança } \\
\text { efetiva pelo enfermeiro para desenvolver uma assistência de enfermagem de qualidade. } \\
\text { "O líder, além de ajudar na elaboração do plano de assistência, conduz a equipe a trabalhar } \\
\text { harmonicamente em busca de objetivos comuns que sejam comuns a todos os integrantes } \\
\text { desse processo". }\end{array}$ \\
\hline $\begin{array}{l}\text { REFEREM-SE À } \\
\text { MOTIVAÇÃO? }\end{array}$ & Não. \\
\hline
\end{tabular}

Quadro 37. Estudo 26. Fonte: Dados analisados pela autora (2007). 
Silveira, Fávero e Alves Pereira (2003) abordaram a qualidade da assistência sob a ótica dos pacientes no estudo 26. Apresentaram-nos como os principais "agentes qualificadores" da assistência de enfermagem. Segundo os autores, as necessidades e expectativas dos pacientes somente serão atendidas se a equipe de enfermagem se propuser a conhecê-las, prestando real atenção ao paciente. Entenderam que o alcance da finalidade da assistência de enfermagem corresponde ao atendimento das expectativas dos pacientes, tendo como conseqüência a valorização dos serviços prestados.

Sugeriram que a sistemática ou a prática de trabalho da enfermagem devem ser aprimoradas, e que as necessidades e expectativas do cliente em relação à equipe devem ser conhecidas e consideradas base de toda a assistência a ser desenvolvida.

Como aprimorar a sistemática de trabalho? Conhecer as necessidades e expectativas dos clientes foi a estratégia apontada para a busca da qualidade da assistência de enfermagem.

Atender às necessidades e expectativas dos clientes e garantir a satisfação profissional da equipe são ações que têm o potencial de atribuir qualidade à assistência de enfermagem. Identificar como conhecer e atender a tais necessidades para então garantir satisfação pode se constituir o primeiro passo rumo à qualidade. Esses passos contêm o potencial de nos conduzir ao chamado "gerenciamento da qualidade". 


\section{APRESENTAÇÃO DA REVISÃO INTEGRATIVA}

No presente estudo, realizamos uma revisão integrativa da produção do conhecimento em enfermagem com o objetivo de avaliar as contribuições das pesquisas produzidas pela enfermagem brasileira acerca das temáticas liderança, motivação e qualidade na assistência de enfermagem em instituições hospitalares. Pretendeu-se também focalizar as estratégias relativas à liderança, motivação e qualidade que podem ser utilizadas pelo enfermeiro, visando à realização, pela equipe, de ações comprometidas com a assistência de enfermagem. Para tanto, foi formulada a questão: a enfermagem brasileira destacou estratégias de liderança e motivação visando a promoção da qualidade da assistência pela equipe?

Compuseram a amostra 31 artigos, indexados nas bases de dados LILACS e BDENF, através do acesso à Biblioteca Virtual de Saúde (BVS). Foram fisicamente localizados e organizados em categorias temáticas - liderança (LID), motivação (MOT) e qualidade (QUA) - de acordo com busca nas bases de dados e utilização destas expressões como descritores, acrescidas das expressões 'enfermagem' e/ou 'assistência de enfermagem'. Posteriormente, foram divididos em subcategorias em função da análise dos objetos e objetivos dos estudos apresentados.

A coleta de dados foi realizada através de um instrumento específico, elaborado pelas autoras e submetido a um pré-teste. Foram analisados a partir da identificação do periódico em que foram publicados (título, cidade, ano de publicação, bases em que foram encontrados), dos dados dos pesquisadores identificados como primeiro autor (profissão, titulação, local de atuação, local da pósgraduação, todos à época do estudo) e dos estudos apresentados (local de 
desenvolvimento do estudo, natureza/tipo do estudo, instrumento utilizado na coleta de dados, população/amostra) Os objetos/objetivos estudados e resultados das pesquisas compuseram o que chamamos de contribuições dos estudos, analisadas através da composição de quadros e divisões em subcategorias.

Para responder à pergunta norteadora da revisão, partimos do entendimento de que estratégia é um conjunto de ações que se adota para que se possa alcançar um determinado objetivo, concordando com os pontos de vista de Maximiano (2000) e Chiavenato (2004) sobre o conceito.

Encontramos três estudos que apontam ações que se aproximam deste conceito no conjunto de artigos da categoria temática Liderança:

- Galvão 10: "[...] promoção de discussões para que sejam acrescentados aos currículos conteúdos e estratégias que viabilizem o aprendizado sobre liderança".

- Vale et al. 29: "[...] conjugar a participação [do enfermeiro] da equipe nas decisões e metas [...]".

- Lourenço e Trevizan 15: "[...] expor o aluno a oportunidades suscetíveis de desenvolver o potencial de liderança existente em todos os indivíduos, revendo o processo de ensino-aprendizagem [...]".

No conjunto de artigos da categoria temática Motivação, foram encontrados três estudos que versaram sobre possíveis estratégias:

- Antunes e Sant'anna 2: "[...] a análise destes fatores [de satisfação e motivação] pode se constituir componente significativo no estudo do serviço de enfermagem e da organização hospitalar".

- Olchowsky e Chaves 20: "[...] conhecimento dos fatores motivacionais e de técnicas para o exercício do poder". 
- Pasti; Gir e Dela Coleta 21: Valorização dos aspectos motivacionais no trabalho do enfermeiro.

Já no conjunto de artigos da categoria temática Qualidade, encontramos um artigo:

- Matsuda e Évora 19: "[...] incorporação de uma nova filosofia na organização"; "[...] internalização de conceitos e princípios semelhantes que a mudança se inicia". "[...] maior incremento nos estudos que enfocam a melhoria da satisfação no trabalho da enfermagem".

Desta forma, dentre os artigos analisados, encontramos sete estudos (cerca de $20 \%$ da amostra) que, no nosso entendimento, apontaram estratégias que contêm potencial de promover a assistência de enfermagem. Estas (estratégias), por sua vez, requerem ação e empenho por parte da Enfermagem para que este potencial seja ativado e, assim, provocarmos as mudanças necessárias à promoção da assistência e, conseqüentemente, à qualidade de todas as ações que caracterizam o exercício da profissão. 


\section{REFERÊNCIAS}

ADAMI, N. P. A melhoria da qualidade nos serviços de enfermagem. Acta Paul. Enferm., São Paulo, n. 13, p. 190-196, 2000.

AZEVEDO, C. da S. Liderança e processos intersubjetivos em organizações públicas de saúde. Ciência \& Saúde Coletiva, Brasília, v. 7, n. 2, p. 349-361, 2002.

BERGAMINI, C. W. Liderança: administração do sentido. São Paulo: Atlas, 1994. $234 \mathrm{p}$.

Motivação nas organizações. 4. ed. São Paulo: Atlas, 1997. 214 p.

.O líder eficaz. São Paulo: Atlas, 2006a.185 p.

. Psicologia aplicada à administração de empresas: psicologia do comportamento organizacional. 4. ed. São Paulo: Atlas, 2006b. 197 p.

BIREME. Centro Latino-Americano e do Caribe de Informação em Ciências da Saúde. Biblioteca Virtual em Saúde: áreas especializadas. São Paulo: BIREME: OPAS: OMS, [2007]. Disponível em:< http://www.bireme.br/php/level.php?lang=pt\&component=107\&item=108>. Acesso em: 19 mar. 2007.

. Biblioteca Virtual em Saúde: ciências da saúde em geral. São Paulo: BIREME: OPAS: OMS, [2007]. Disponível em:< http://www.bireme.br/php/level.php?lang=pt\&component=107\&item=107>. Acesso em: 19 mar. 2007.

Biblioteca Virtual em Saúde. São Paulo: BIREME: OPAS: OMS, [2007].

Disponível em:< http://www.bireme.br/php/level.php?lang=pt\&component=107\&item=108>. Acesso em: 19 mar. 2007.

Modelo da Biblioteca Virtual em Saúde. São Paulo: BIREME: OPAS: OMS, [2007]. Disponível em: < http://bvsmodelo.bvsalud.org/php/index.php>. Acesso em: 19 mar. 2007. 
BITENCOURT, C. et al. (Colab.). Gestão contemporânea de pessoas: novas práticas, conceitos tradicionais. Porto Alegre: Bookman, 2004. 528 p.

BOOG, G. G. O desafio da competência. São Paulo: Círculo do Livro, 1991. 333 p.

CADAH, L. Avaliação da qualidade da assistência de enfermagem sob a ótica da satisfação dos pacientes. 2000. 104 f. Dissertação (Mestrado em Enfermagem Fundamental) - Escola de Enfermagem, Universidade de São Paulo, São Paulo, 2000.

CARAVANTES, G. R.; PANNO, C. C.; KLOECKNER, M. C. Administração: teorias e processos. São Paulo: Pearson Prentice Hall, 2005. 572 p.

CARNEIRO, A. Interrelação dos papéis de chefe, educador e líder, desempenhados pelo enfermeiro. Rev. Baiana Enfermagem; v. 2, n. 2, p. 58-73, dez. 1986.

CHIAVENATO, I. Comportamento organizacional: a dinâmica do sucesso das organizações. 2. ed. Rio de Janeiro: Elsevier, 2005. 539 p.

Gestão de pessoas: o novo papel dos recursos humanos nas organizações. Rio de Janeiro: Campus, 1999. 457p.

. Introdução à teoria geral da administração. 3. ed. rev. atual. Rio de Janeiro: Campus, 2004a. 494 p.

Recursos humanos: o capital humano das organizações. 8. ed. São Paulo: Atlas, 2004b. 515 p.

COOPER, H. M. Scientific guidelines for conducting integrative research reviews. Review of Educational Research, v. 52, p. 291-302, 1982.

COUTINHO, R. M. C.; SOUZA, N. B.; FERREIRA, H. M. A necessidade da liderança na formação do enfermeiro do século XXI. Rev. SOBECC, São Paulo, v. 7, n. 4, p. 25-30, out./dez. 2002.

COVEY, S. $08^{\circ}$ hábito: da eficácia à grandeza. São Paulo: Campus, 2005. 413 p. 
CUNHA, K. C. (Coord.). Gerenciamento na enfermagem: novas práticas e competências. São Paulo: Martinari, 2005. 118 p.

DANIEL, L. F. Enfermagem: modelos e processos de trabalho. São Paulo: EPU, 1987. 117p.

DESSLER, G. Administração de Recursos Humanos. 2. ed. Tradução Cecília Leão Oderich. São Paulo: Prentice Hall, 2003. 331p.

DONNER, G. J.; WHEELER, M. M. New strategies for developing leadership Leadership perspective. Canadian Journal of Nursing Leadership, v. 17, n. 2, 2004. Disponível em: <http://nursingleadership.net/NL172/NL172Donner.html.> Acesso em: 25 jul. 2004.

DRAKE, R. I.; SMITH, P. J. Ciência e comportamento na indústria. São Paulo: Mc Graw-Hill, 1983. 168 p.

DRUCKER, P. F. O melhor de Peter Drucker: a administração. São Paulo: Nobel, 2001. 220 p.

DUBRIN, A. J. Fundamentos do comportamento organizacional. Tradução James Sunderland; Martha Malvezzi Leal. São Paulo: Pioneira Thomson Learning, 2003. $471 \mathrm{p}$.

DUTRA, J. S. Competências: conceitos e instrumentos para a gestão de pessoas na empresa moderna. São Paulo: Atlas, 2004. 206 p.

ETZIONI, A. Organizações modernas. Tradução Miriam L. Moreira Leite. 7. ed. São Paulo: Pioneira, 1984. 163 p.

FISCHER, A. L.; ALBUQUERQUE, L. G. de. Relatório de pesquisa: tendências de mudanças na gestão de pessoas das empresas brasileiras: DELPHI RH-2010. [São Paulo]: MBA, USP, 2001. 18 p. Disponível em:<

http://www.scielo.br/pdf/ci/v32n2/17036.pdf, acesso em 24.05.2007. . . Acesso em: 15 mar. 2007.

GANONG, L. H. Integrative reviews of nursing research. Research in Nursing \& Health, v. 10, p. 1-11, 1987. 
GOLEMAN, D. O que faz um líder? In: LIDERANÇA: os melhores artigos da Harvard Business Review. Rio de Janeiro: Elsevier, 2006. 230 p.

HERSEY, P.; BLANCHARD, K. H. Psicologia para administradores: a teoria e as técnicas da liderança situacional. Tradução e revisão técnica Equipe do CPB Edwino A. Royer. São Paulo: EPU, 1986. 428 p.

JACKSON, G. B. Methods for integrative reviews. Review of Education Research, v. 50, n. 3 , p. $438-460,1980$.

KATZ, D. \& KAHN, R. L. Psicologia social das organizações. Tradução Auriphebo B. Simões. 2. ed. São Paulo: Atlas, 1974. 551 p.

KATZENBACH, J. R. Desempenho máximo. Tradução Roberto Galman. São Paulo: Negócio, 2002. 292 p.

KOTTER, J. P. Afinal, o que fazem os líderes? : a nova face do poder e da estratégia. Tradução Follow-Up. 4. ed. Rio de Janeiro: Campus, 2000. 163 p.

. Liderando mudança. Rio de Janeiro: Campus, 1999. 188 p.

KOUZES, J. M; POSNER, B. Z. O desafio da liderança. Tradução Ana Beatriz Rodrigues. 3. ed. Rio de Janeiro: Campus, 2003. 450 p.

KURCGANT, P. et al. Gerenciamento em enfermagem. Rio de Janeiro: Guanabara Koogan, 2005. 198 p.

MARQUIS, B.L.; HUSTON, C.J. Administração e liderança em enfermagem: teoria e aplicação. 2. ed. Porto Alegre: Artmed, 2002. 557 p.

MARX, L. C; MORITA, L. C. Manual de gerenciamento de enfermagem. 2. ed. rev. atual. São Paulo: EPUB, 2003. 124 p.

MAXIMIANO, A. C. A. A teoria geral da administração: da revolução urbana à digital. 5. ed. São Paulo: Atlas, 2005. 503 p. 
$546 \mathrm{p}$.

. Introdução à administração. 5. ed. rev. ampl. São Paulo: Atlas, 2000.

MAXWELL, J. C. As 21 irrefutáveis leis da liderança: siga-as e as pessoas o seguirão. Tradução Eduardo Pereira e Ferreira. São Paulo: Mundo Cristão, 1999. $243 \mathrm{p}$.

MEZOMO, J. C. Gestão da qualidade na saúde: princípios básicos. São Paulo: Manole, 2001. $301 \mathrm{p}$.

MINICUCCI, A. Relações humanas: psicologia das relações interpessoais. 3. ed. São Paulo: Atlas, 1982. 112 p.

NANNUS, B. Liderança visionária: como planejar o futuro da sua empresa. Tradução Luiz Euclides Trindade Frazão Filho. Rio de Janeiro: Campus, 2000. 235 p.

ORGANIZAÇÃO PAN-AMERICANA DE SAÚDE. A transformação da gestão de hospitais na América Latina e Caribe. Brasília: OPAS/OMS, 2004. 398 p.

PROCHNOW, A. G. et al. Liderança em enfermagem: um repensar necessário à prática gerencial hospitalar. Rev. Enferm. Esc. Anna Nery, Rio de Janeiro, v. 7, n. 3, p. 318-324, dez. 2003.

ROBBINS, S. P. Comportamento organizacional. 9. ed. São Paulo: Prentice Hall, 2002. $637 \mathrm{p}$.

ROZENDO, C. A. Liderança no cotidiano da enfermagem hospitalar: entre luzes e sombras. 2000. 228 f. Tese. (Doutorado em Enfermagem Fundamental) - Escola de Enfermagem de Ribeirão Preto, Universidade de São Paulo, Ribeirão Preto, 2000.

SANTOS, I.; FIGUEIREDO, N. M. A. A enfermagem como instituição hospitalar. In: . et al. Enfermagem assistencial no ambiente hospitalar: realidade, questões, soluções. São Paulo: Atheneu, 2004. cap 6. p. 93-104.

TANNENBAUM, R.; WESCHLER, I. R.; MASSARIK, F. Liderança e organização: uma abordagem à ciência do comportamento. Tradução Auriphebo B. Simões. 2. ed. São Paulo: Atlas, 1972. 516 p. 
TEIXEIRA, J. D. R. et al. A elaboração de indicadores de qualidade da assistência de enfermagem nos períodos puerperal e neonatal. Rev. Enferm. UERJ, Rio de Janeiro, v. 14, n.2, p. 271-278, abr./jun. 2006.

TREVIZAN, M. A. Enfermagem hospitalar: administração e burocracia. Brasília: UNB, 1988. $142 \mathrm{p}$.

Liderança do enfermeiro: o ideal e o real no contexto hospitalar. São Paulo: Sarvier, 1993. 94 p.

UNIVERSIDADE DE SÃO PAULO. Sistema Integrado de Bibliotecas: SIBI. Diretrizes para apresentação de dissertações e teses da USP: documento eletrônico e impresso. São Paulo: USP, 2004. 110 p.

VERGARA, S. C. Gestão de pessoas. 2. ed. São Paulo: Atlas, 2000. 213 p.

WALDOW, V. R. Cuidado humano: o resgate necessário. 3. ed. Porto Alegre: Sagra Luzzatto, 2001. 202 p. 


\section{APÊNDICES}

\section{APÊNDICE A - ARTIGOS COMPONENTES DA AMOSTRA}

\begin{tabular}{|c|c|}
\hline N ESTUDO & ARTIGO \\
\hline $\begin{array}{l}\text { 1-LID } \\
1-Q U A\end{array}$ & $\begin{array}{l}\text { ANTUNES, A. V. Liderança para a qualidade na enfermagem. Nursing, Säo Paulo, v. } \\
2, \text { n. } 15, \text { p. 22-26, ago. } 1999 .\end{array}$ \\
\hline 2 & $\begin{array}{l}\text { ANTUNES, A. V.; SANT'ANNA, L. R. Satisfaçäo e motivaçäo no trabalho do } \\
\text { enfermeiro. Rev. Bras. Enfermagem, v. 49, n. 3, p. 425-34, jul./set. } 1996 \text {. }\end{array}$ \\
\hline 3 & $\begin{array}{l}\text { ANTUNES, A. V.; TREVIZAN, M. A. Gerenciamento da qualidade: utilização no } \\
\text { serviço de enfermagem. Rev. Latinoam. Enfermagem, v. 8, n. 1, p. 35-44, jan. } 2000 \text {. }\end{array}$ \\
\hline 4 & $\begin{array}{l}\text { CALDAS, N. P.; SANTOS, I. Atuação dos enfermeiros nos diferentes níveis } \\
\text { gerenciais. Rev. Enfermagem UERJ, Rio de Janeiro, v. 1, n. 1, p. 77-89, jun. } 1993 .\end{array}$ \\
\hline 5 & $\begin{array}{l}\text { GALERA, S. A. F.; GALERA, C. A.; TEIXEIRA, M. B. O uso da técnica do incidente } \\
\text { crítico na investigação da assistência de enfermagem ao doente mental internado. } \\
\text { Rev. Paul. Enfermagem, v. 16, n. 1/3, p. 12-19, jan./dez. } 1997 \text {. }\end{array}$ \\
\hline 6 & $\begin{array}{l}\text { GALVÃO, C. M. et al. Enfermeiro cirúrgico: seu estilo de liderança com o pessoal } \\
\text { auxiliar de enfermagem. Rev. Gaúcha Enfermagem, v. 18, n. 1, p. 31-42, jan. } 1997 \text {. }\end{array}$ \\
\hline 7 & $\begin{array}{l}\text { GALVÃO, C. M. et al. Liderança e comunicação: estratégias essenciais para o } \\
\text { gerenciamento da assistência de enfermagem no contexto hospitalar. Rev. Latinoam. } \\
\text { Enfermagem, v. } 8 \text {, n. } 5 \text {, p. } 34-43 \text {, out. } 2000 \text {. }\end{array}$ \\
\hline 8 & $\begin{array}{l}\text { GALVÃO, C. M. et al. Liderança situacional: estrutura de referência para o trabalho do } \\
\text { enfermeiro-líder no contexto hospitalar. Rev. Latinoam. Enfermagem, v. } 6, \text { n. 1, p. } \\
\text { 81-90, jan. 1998. }\end{array}$ \\
\hline 9 & $\begin{array}{l}\text { GALVÃO, C. M. et al. O estilo de liderança exercido pelo enfermeiro de unidade de } \\
\text { internação cirúrgica sob o enfoque da liderança situacional. Rev. Latinoam. } \\
\text { Enfermagem, v. } 5 \text {, n. 2, p. } 39-47 \text {, abr. } 1997 \text {. }\end{array}$ \\
\hline 10 & $\begin{array}{l}\text { GALVÃO, C. M. Liderança do enfermeiro de centro cirúrgico. Rev. Paul. } \\
\text { Enfermagem, n. esp., p. 57-60, jul. } 1991 .\end{array}$ \\
\hline 11 & $\begin{array}{l}\text { HIGA, E. F. R.; TREVIZAN, M. A. Os estilos de liderança idealizados pelos } \\
\text { enfermeiros. Rev. Latinoam. Enfermagem, v. 13, n. 1, p. 59-64, jan./fev. } 2005 \text {. }\end{array}$ \\
\hline 12 & $\begin{array}{l}\text { KURCGANT, P.; PERES, H. H. C.; CIAMPONE, M. H. T. A liderança na } \\
\text { administração de pessoal de enfermagem segundo a percepção de enfermeiras, } \\
\text { auxiliares e atendentes de enfermagem. Rev. Esc. Enfermagem USP, v. 30, n. 3, p. 416- } \\
\text { 38, dez. 1996. }\end{array}$ \\
\hline 13 & $\begin{array}{l}\text { LEITÃO, I. M. T. A.; ARRUDA, R. B. Clima organizacional: novos rumos no perfil do } \\
\text { enfermeiro e desafios a assistência de enfermagem. Mundo Saúde, v. 287, n. 2, p. } \\
\text { 151-159, abr./jun. } 2004 \text {. }\end{array}$ \\
\hline 14 & $\begin{array}{l}\text { LOURENÇO, M. R.; TREVIZAN, M. A. Lide } \\
\text { enfermeiros-líderes. Acta Paul. Enfermagem }\end{array}$ \\
\hline
\end{tabular}




\begin{tabular}{|c|c|}
\hline 15 & $\begin{array}{l}\text { LOURENÇO, M. R.; TREVIZAN, M. A. Líderes da enfermagem brasileira: sua visão } \\
\text { sobre a temática da liderança e sua percepção a respeito da relação liderança e } \\
\text { enfermagem. Rev. Latinoam. Enfermagem, v. } 9 \text {, n. 3, p. 14-19, maio. } 2001 \text {. }\end{array}$ \\
\hline $\begin{array}{l}\text { 16-LID } \\
\text { 16-MOT }\end{array}$ & $\begin{array}{l}\text { LUIZ, M. V. A enfermagem e o conhecimento dos conceitos de liderança, motivação, } \\
\text { comunicação e mudança. Acta Paul. Enfermagem, v. 2, n. 4, p. 111-22, dez. } 1989 .\end{array}$ \\
\hline 17 & $\begin{array}{l}\text { MATHEUS, M. C. C. O trabalho em equipe: um instrumento básico e um desafio para } \\
\text { a enfermagem. Rev. Esc. Enfermagem USP, v. 29, n. 1, p. 13-25, abr. } 1995 .\end{array}$ \\
\hline 18 & $\begin{array}{l}\text { MATOS, N. L. A motivação do trabalho do gerente de enfermagem. Mundo Saúde, v. } \\
9, \text { n. } 35, \text { p. 185-94, jul./set. } 1985 \text {. }\end{array}$ \\
\hline 19 & $\begin{array}{l}\text { MATSUDA, L. M.; ÉVORA, Y. D. M. Gestão da equipe de enfermagem de uma UTI: a } \\
\text { satisfação profissional em foco. Ciênc. Cuid. Saúde, v. 2, n. 1, p. 11-18, jan./jun. } \\
2003 .\end{array}$ \\
\hline 20 & $\begin{array}{l}\text { OLSCHOWSKY, A.; CHAVES, E. H. B. A realização, a afiliação e o poder: em qual } \\
\text { destes três fatores está calcada a motivação dos enfermeiros em um hospital de } \\
\text { ensino? Rev. Gaúcha Enfermagem, v. 18, n. 1, p. 9-16, jan. } 1997 \text {. }\end{array}$ \\
\hline 21 & $\begin{array}{l}\text { PASTI, M. J.; GIR, E.; DELA COLETA, J. A. Perfil motivacional do enfermeiro atuante } \\
\text { em um hospital geral do interior paulista. Rev. Latinoam. Enfermagem, v. 7, n. 5, p. } \\
\text { 33-41, dez. } 1999 \text {. }\end{array}$ \\
\hline 22 & $\begin{array}{l}\text { PEREIRA, M. C. A.; FÁVERO, N. A motivação no trabalho da equipe de enfermagem. } \\
\text { Rev. Latinoam. Enfermagem, v. 9, n. 4, p. 7-12, jul. } 2001 .\end{array}$ \\
\hline 23 & $\begin{array}{l}\text { SANTOS, I. Estilos gerenciais dos enfermeiros na área de recuperação da saúde. } \\
\text { Rev. Bras. Enfermagem, v. 44, n. 2/3, p. 76-88, abr./set. } 1991 .\end{array}$ \\
\hline 24 & $\begin{array}{l}\text { SANTOS, S. R.; MOREIRA, R. C. Liderança do enfermeiro: desafios da prática. } \\
\text { Online Braz. J. Nurs.; v. 3, n. 3, dez. } 2004 \text {. }\end{array}$ \\
\hline $\begin{array}{l}\text { 25-LID } \\
\text { 25-MOT }\end{array}$ & $\begin{array}{l}\text { SANTOS, S. R.; RODRIGUES FILHO, J. Enfermagem: fatores de satisfação. Rev. } \\
\text { Bras. Enfermagem, v. 48, n. 3, p. 242-50, jul./set. } 1995 .\end{array}$ \\
\hline 26 & $\begin{array}{l}\text { SILVEIRA, C. S.; FÁVERO, N.; A.; PEREIRA, M. C. A ótica do cliente hospitalizado } \\
\text { sobre a qualidade da assistência de enfermagem. Rev. Enfermagem UERJ, v. 11, n. } \\
\text { 1, p. } 76-79,2003 .\end{array}$ \\
\hline 27 & $\begin{array}{l}\text { SIMÕES, A. L. A.; FÁVERO, N. Aprendizagem da liderança: opinião de enfermeiros } \\
\text { sobre a formação acadêmica. Rev. Latinoam. Enfermagem, v. 8, n. 3, p. 91-96, jul. } \\
2000 .\end{array}$ \\
\hline 28 & $\begin{array}{l}\text { SIMÕES, A. L. A.; FÁVERO, N. O desafio da liderança para o enfermeiro. Rev. } \\
\text { Latinoam. Enfermagem, v. } 11 \text {, n. 5, p. 567-573, set./out. } 2003 .\end{array}$ \\
\hline 29 & $\begin{array}{l}\text { VALE, E. G. et al. Estilos de liderança da enfermeira numa instituição pública de } \\
\text { Fortaleza. Rev. Bras. Enfermagem, v. 53, n. 4, p. 533-6, out./dez. } 2000 \text {. }\end{array}$ \\
\hline 30 & $\begin{array}{l}\text { WEHBE, G.; GALVÃO, C. M. Aplicação da liderança situacional em enfermagem de } \\
\text { emergência. Rev. Bras. Enfermagem, v. 58, n. 1, p. 33-38, jan./fev. } 2005 .\end{array}$ \\
\hline 31 & $\begin{array}{l}\text { WEHBE, G.; GALVÃO, C. M. Enfermeiro de unidade de emergência: sua liderança } \\
\text { com o pessoal auxiliar de enfermagem. Acta Paul. Enfermagem, v. 14, n. 3, p. 60- } \\
\text { 70, set./ dez.2001. }\end{array}$ \\
\hline
\end{tabular}


APÊNDICE B - INSTRUMENTO DE COLETA DE DADOS

1 IDENTIFICAÇÃO DO ARTIGO

1.1 Título artigo:

1.2 Ano de realização do estudo:

1.3 Periódico:

1.4 Ano de publicação:

Volume:

No:

Páginas:

1.5 Localizado na base de dados:

( ) LILACS ( ) BDENF ( ) AMBAS

\section{IDENTIFICAÇÃO DO(S) AUTOR(ES)}

$1^{\circ}$ Autor

Nome:

Profissão:

Titulação:

Local de atuação:

\section{$2^{\circ}$ Autor}

Nome:

Profissão:

Titulação:

Local de atuação:

\section{$3^{\circ}$ Autor}

Nome:

Profissão:

Titulação:

Local de atuação:

\section{$4^{\circ}$ Autor}

Nome:

Profissão:

Titulação:

Local de atuação:

$\mathbf{5}^{\circ}$ Autor
Nome:
Profissão:
Titulação:
Local de atuação:




\section{OBJETIVOS}

3.1 ( ) Geral

$3.2($ ) Específicos

4 DELINEAMENTO DO ESTUDO:

( ) Não especificado

( ) Especificado:

5 POPULAÇÃO DO ESTUDO:

6 AMOSTRA:

7 RESULTADOS ENCONTRADOS

8 CONCLUSÕES / RECOMENDAÇÕES PARA A ENFERMAGEM 


\section{Há referência à LIDERANÇA?}

( ) NÃO ( ) SIM:

9.1 Conclusões:

9.2 Sugerem estratégias ou recomendações para a prática de enfermagem?

( ) NÃO ( ) SIM:

\section{Há referência à MOTIVAÇÃO?}

( ) NÃO ( ) SIM:

10.1 Conclusões:

10.2 Sugerem estratégias ou recomendações para a prática de enfermagem?

( ) NÃO ( ) SIM:

\section{Há referência à QUALIDADE?}

( ) NÃO ( ) SIM:

11.1 Conclusões:

11.2 Sugerem estratégias ou recomendações para a prática de enfermagem?

( ) NÃO ( ) SIM: 